\title{
MAINTAINING CONTACT: DESIGN AND USE OF ACOUSTIC SIGNALS IN KILLER WHALES, ORCINUS ORCA
}

by

Patrick James O’Malley Miller

B.S.F.S., Georgetown University, 1988

B.S., University of Washington, 1994

Submitted in partial fulfillment of the requirements for the degree of

Doctor of Philosophy

at the

MASSACHUSETTS INSTITUTE OF TECHNOLOGY

and the

WOODS HOLE OCEANOGRAPHIC INSTITUTION

September 2000

(c) 2000 Patrick J. O. Miller. All rights reserved.

The author hereby grants to MIT and WHOI permission to reproduce paper and electronic copies of this thesis in whole or in part and to distribute them publicly

Signature of Author

Joint Program in Biological Oceanography Massachusetts Institute of Technology

Certified by

Woods Hole Oceanographic Institution

Accepted by

Peter Lloyd Tyack

Thesis Supervisor

Mark Hahn, Chairman

Joint Committee on Biological Oceanography

Massachusetts Institute of Technology

Woods Hole Oceanographic Institution 
To Ms. Jane Crosby, a gifted facilitator of learning. 


\title{
MAINTAINING CONTACT: DESIGN AND USE OF ACOUSTIC SIGNALS IN KILLER WHALES, ORCINUS ORCA
}

by

\author{
Patrick James O'Malley Miller
}

Submitted in partial fulfillment of the requirements for the degree of Doctor of Philosophy at the Massachusetts Institute of Technology and the Woods Hole Oceanographic Institution.

\begin{abstract}
This thesis presents data on the structure and use of acoustic signals produced by free-ranging resident killer whales. The analysis focuses on signal features that might be useful for animals to maintain contact and coordinate activities with preferred associates, including: distinctiveness by group or individual, call amplitude, and directionality cues that might cue the direction-of-movement of the signaler. Research was conducted in Haro and Johnstone Straits off Vancouver Island, British Columbia, where killer whales have been the focus of a long-term photo-identification effort. Extensive previous research on this population has demonstrated stable kin-based matrilineal social groups and pod-specific calling behavior.
\end{abstract}

Individually-distinctive markings and pigmentation patterns were used to identify groups or individuals from which sounds were recorded. Recordings from each of the three matrilineal groups composing pod A1 were made when each subgroup was isolated from the two other subgroups. Analysis of call use and structure revealed subgroupspecificity that was qualitatively similar to previously observed differences between pods, although more subtle. This finding suggests that pod-specific calling arises primarily as a consequence of accumulated drift or divergence of calls between highly cohesive matrilineal subgroups as they gradually separate into different pods. A new towed array beamforming system was developed to identify vocalizing killer whales concurrent with focal behavioral observations. Carefully positioning the array relative to the animals and linking visual observations of whale position with the angle-of-arrival of sounds on the towed array allows reliable identification of signalers in many circumstances. Using this new system, a sample of 140 calls was recorded from identified individuals within W-pod to compare the call-type repertoires of individuals within a matrilineal subgroup. The three individuals composing W-pod shared at least four different call types and call-type 
frequency did not differ by individual, suggesting each matrilineal group member uses the same call types in a similar fashion.

To measure signal source levels, the range from the array to a signaler was calculated by triangulating the angles-of-arrival of the sound on two beamforming arrays towed in series. Source levels of 819 calls and 24 whistles were combined with a model of sound propagation and perception to estimate the maximum range at which another killer whale could detect each sound in quiet conditions. The estimated maximum range of detectability of all sounds ranged from 4.5 to $26.2 \mathrm{~km}$, suggesting killer whales can maintain acoustic contact with each other over long ranges. Whistles and variable calls have a smaller active space than stereotyped calls which appear to consist of two groups: long- and short-range call types with a mean estimated active space of 14.5 and $8.8 \mathrm{~km}$, respectively. Directionality features of calls were described by recording sounds in front of, and behind, groups of animals as they passed the towed-array system. The frequency structure of the sample of 263 calls recorded in these conditions was clearly dependent on the orientation of the signaler to the receiver, with high-frequency components strongly attenuated when the whales were oriented away from the array. This directionality pattern appears to provide a simple and reliable cue of the direction-of-movement of signalers, and may be an important structural feature of calls helping killer whales regulate their spacing relative to each other. 


\section{ACKNOWLEDGEMENTS}

I owe an enormous debt to very many people who aided me throughout graduate school. I'd like to start with my advisor, Peter Tyack, who supported my goals with boundless optimism and insightful advice. I cannot thank Peter enough for the many opportunities he's given me, and the kind and respectful approach he has toward his students. Many thanks to the other members of my thesis committee: David Bain mentored me before I came to Woods Hole and continues to be a well-spring of genius and insight; Darlene Ketten clearly demonstrated to me the importance of the perception side of communication (I'm still chewing that hat!!); Stephanie Seneff of MTT brought a strong insight from the human communication perspective; and Peter Slater brought a vast expertise in behavioral science and animal communication.

Mark Johnson, Lee Freitag, Matt Grund, Keith von der Heydt and other members of the Acoustic Systems Group in AOP\&E helped tranform me from a biologist to an engineer, and then back to a biologist again. Mark Johnson in particular provided me with critical advice on multiple occasions and a strong friendship both inside and outside the lab. Bill Watkins, Kurt Fristrup, John Ford and Amy Samuels all played important mentor roles for me at various stages of this thesis. Other members of the Tyack lab, past and present, have helpfully criticized and reviewed my work - including Amy Samuels (again), Debbie Fripp, Doug Nowacek (cyclop-topus finally flies!), Rebecca Thomas, Stephanie Watwood, Susan Parks, and Sarah Marsh.

Loving thanks to Nicoletta Biassoni who has cared for me through this tough effort and stayed into the wee hours reviewing my manuscripts. Both as a colleague and a dear friend, Nicoletta has helped me in ways too numerous to list - it's been great fun and I'm sure we'll look back on this as just one of many academic achievements for us both. Grazie mille Nicoletta!! Hugs and thanks to Robert Hamersley and Rebecca Green for constructive criticism and great discussions on the use of Occam's razor. Thanks to all of the other JP students and friends here at WHOI - it's been a great six years.

Vincent Janik deserves special mention as a colleague/mentor both at St. Andrews and here in Woods Hole (thanks a million Vincent). I'd like to thank Andy Solow for statistical advice on multiple occassions and Mary Ann Daher for remembering me. Robin Baird, Volker Deecke, Aaron Thode, Sal Cerchio, are a few among many outside colleagues who aided this effort. Others at Woods Hole or MIT who've aided me through the years include James Partan, John Buck, Karlen Wannop, Joe Bondaryk, \& Henrik Schmidt. I'd like to particularly thank the great support team within WHOI for helping with field work logistics, including Judy Kleindinst, Mary Jane Tucci, Delores Chausse, Barbara Martineau, Debra Snurkowski, Lynn Ladetto, Marie Basile, Susan Vaughn, Judy Fenwick, Lisa Taylor, and others. 
The field work I carried out would not have been possible without the help of many people. Richard Osborne, Bill \& Donna MacKay, Dave Tyre, Paul Spong and Helena Symonds, Jim Borrowman, and David Bain for expert electronic debugging advice. Field assistants through the years included: Pamela Willis, Erin Gentry, Tamara Guenther, Melissa Dolan, Nicole Angiel, Nicole Prodoehl, Stacy Morris, Lauren Kuhn, Liz Pomfret, Paul Macoun, Rebecca Thomas, Marm Kilpatrick, Doug Nowacek, Robin Baird, Stacey Dozono, Miranda Buck, Katie Rohrer, Amanda Searby, Leandra de Sousa, Dennis Schmidt, Dave Tyre, Bill \& Donna MacKay, Lisa Lamb, Michael Richlen, Jodi Udd, Morgan Heim, Mariya Sweetwyne.

Special thanks to WHOI's education department for emotional and financial support through the years. Special thanks to Dean Farrington for guidance at several critical junctures. The Joint Committee for Biological Oceanography provided important guidance, and the necessary flexibility for me to pursue the engineering needed to accomplish this research.

Funding for the research in this thesis was provided by grants from WHOI's Rinehart Coastal Research Center in 1995 and 1999, a grant from WHOI's Ocean Ventures Fund in 1998, an NSF graduate fellowship to the author, grant CC-S-611002001-C from the Office of Naval Resarch, and broad financial support from WHOI's education department. Special thanks to the Bureau of Land Management for the use of the Turn Point Research Station. All field work was conducted under research authorizations from the National Marine Fisheries Service (US) and the Department of Fisheries and Oceans (Canada). 


\section{TABLE OF CONTENTS}

Abstract

$\begin{array}{ll}\text { Acknowledgements } & 7\end{array}$

Table of Contents 9

CHAPTER 1: GENERAL INTRODUCTION

$\begin{array}{ll}1.1 \text { Background } & 13\end{array}$

$\begin{array}{ll}1.2 \text { Orcinus orca } & 15\end{array}$

$\begin{array}{ll}\text { 1.3 Introduction to thesis research } & 18\end{array}$

$\begin{array}{ll}1.4 \text { References } & 20\end{array}$

CHAPTER 2: WITHIN-POD VARIATION IN THE SOUND PRODUCTION OF A POD OF KILLER WHALES, ORCINUS ORCA

2.1 Abstract

$\begin{array}{ll}2.2 \text { Introduction } & 26\end{array}$

$\begin{array}{ll}2.3 \text { Methods } & 31\end{array}$

2.4 Results $\quad 37$

$\begin{array}{ll}\text { 2.4.1 Call usage } & 38\end{array}$

$\begin{array}{lll}2.4 .2 \text { Call structure } & 38\end{array}$

$\begin{array}{lll}2.5 \text { Discussion } & \cdot & 46\end{array}$

$\begin{array}{ll}2.6 \text { Acknowledgements } & 50\end{array}$

2.7 References $\quad 51$

2.8 Appendix $\quad 56$ 
CHAPTER 3: A SMALL TOWED BEAMFORMING ARRAY TO IDENTIFY VOCALIZING RESIDENT KILLER WHALES (ORCINUS ORCA) CONCURRENT WITH FOCAL BEHAVIORAL OBSERVATIONS

Abstract

$\begin{array}{ll}\text { Introduction } & 60\end{array}$

Methods 61

System Design $\quad 62$

Broad-band frequency-domain beamforming algorithm 63

Integration of visual and acoustic observations 64

$\begin{array}{ll}\text { In-situ calibration } & 67\end{array}$

$\begin{array}{ll}\text { Results } & 67\end{array}$

$\begin{array}{ll}\text { Discussion } & 70\end{array}$

$\begin{array}{ll}\text { Acknowledgements } & 74\end{array}$

References $\quad 75$

CHAPTER 4: REPERTOIRE-SHARING IN FREE-RANGING KILLER WHALES

4.1 Introduction 77

$\begin{array}{ll}\text { 4.2 Methods } & 78\end{array}$

$\begin{array}{ll}4.3 \text { Results } & 80\end{array}$

$\begin{array}{ll}\text { 4.4 Discussion } & 82\end{array}$

$\begin{array}{ll}4.5 & \text { Acknowledgements }\end{array}$

4.6 References $\quad 85$

CHAPTER 5: SOURCE LEVELS AND ESTIMATED ACTIVE SPACE OF THE ACOUSTIC REPERTOIRE OF RESIDENT KILLER WHALES (ORCINUS ORCA)

5.1 Abstract

5.2 Introduction

5.3. Materials and Methods 93

5.3.1 Source level calculation 
$\begin{array}{ll}5.4 \text { Results } & 100\end{array}$

$\begin{array}{ll}5.5 \text { Discussion } & 106\end{array}$

$\begin{array}{lr}5.6 \text { Acknowledgements } & 112\end{array}$

$\begin{array}{ll}5.7 \text { References } & 113\end{array}$

CHAPTER 6: DIRECTION-OF-MOVEMENT CUEING VIA DIFFERENTIAL DIRECTIONALITY IN ACOUSTIC SIGNALS PRODUCED BY FREE-RANGING KILLER WHALES, ORCINUS ORCA

$\begin{array}{ll}6.1 \text { Introduction } & 119\end{array}$

$\begin{array}{ll}6.2 \text { Methods } & 121\end{array}$

$\begin{array}{ll}6.3 \text { Results } & 122\end{array}$

$\begin{array}{ll}6.4 \text { Discussion } & 125\end{array}$

$\begin{array}{ll}6.5 \text { References } & 128\end{array}$

CHAPTER 7: SUMMARY AND CONCLUSIONS

$\begin{array}{ll}7.1 \text { Thesis summary } & 131\end{array}$

$\begin{array}{ll}\text { 7.1.1 Summary by chapter } & 132\end{array}$

7.1.1.1. Chapter two 132

7.1.1.2 Chapter three $\quad 133$

7.1.1.3. Chapter four 134

7.1.1.4. Chapter five 134

$\begin{array}{ll}\text { 7.1.1.5. Chapter six } & 135\end{array}$

$\begin{array}{ll}\text { 7.1.2. Conclusions } & 136\end{array}$

$\begin{array}{ll}\text { 7.2 Suggestions for future research } & 138\end{array}$

7.3 References $\quad 141$

APPENDIX: WHALES LENGTHEN SONGS IN RESPONSE TO SONAR 147

$\begin{array}{ll}\text { BIOGRAPHICAL NOTE } & 149\end{array}$ 


\section{CHAPTER 1: GENERAL INTRODUCTION}

\subsection{Background}

Many species of social animals live in groups with stable, often kin-related members (Trivers, 1985). Group-living may enhance individual members' fitness through such benefits as increased foraging efficiency (Stephens \& Krebs, 1986) or predator detection (Bertram, 1978). Descriptions of signaling systems in several groupliving mammals suggest that communication between individuals in the group help them reap benefits of group living (alarm calls, food calls) and stay in contact with each other (isolation calls, movement calls, monitoring calls, affiliative exchanges; Wilkinson \& Boughman, 1998; Boinski, 1993; Janik \& Slater, 1998). Different functions of the signaling system are often accomplished using specific sounds in a repertoire. In rhesus macaques a number of calls (warbles, chirps, and harmonic arches) are produced upon the discovery of preferred foods, while other sounds (grunts and coos) are used when animals are separated or during affiliative interactions (Hauser \& Marler, 1993; Rendall et al., 1996).

Several common themes in signal design and use have been observed in signaling systems used by group-living taxa. Signals are sufficiently loud to be audible to conspecifics over typical separation distances (birds: Brenowitz, 1982; Wiley \& Richards, 1982; baboons: Cheney et al., 1996). The signals often have design features for locatability so that receivers can determine the position of the signaler (birds: Richards, 1981; Nelson \& Stoddard, 1998; rhesus macaques: Brown et al., 1979). Distinctiveness by individual (vervet monkeys: Cheney \& Seyfarth, 1980; bottlenose dolphin, Smolker et al., 1993) or group (greater spear-nosed bat: Boughman, 1997) is necessary for animals to rejoin preferred associates when other animals are in the area. Lastly, the signals are used in the appropriate context in a manner which helps individuals confirm that their message has been received (e.g. timing and acoustic matching of signals in pygmy marmosets; Snowdon \& Cleveland, 1984). 
Despite common themes, diversity of signaling systems across group-living species reflects the diversity of ecological conditions in which the signaling system is set. The signal itself is affected by reverberation and absorption as it passes through the environment (Fig. 1). Environmental effects on signal transmission as well as background noise cause certain signal types to be preferred in different environments. For example, acoustic communication is often favored in heavily-wooded forests (birds), dark caves (bats), and in the marine realm (fish and marine mammals) where other types of signals (visual, electrical, chemical) are quickly attenuated or dispersed by the environment. Besides the signal channel, other ecological conditions such as prey distribution and the probability of signal interception by predators or prey profoundly affect both design and use of the signaling system.

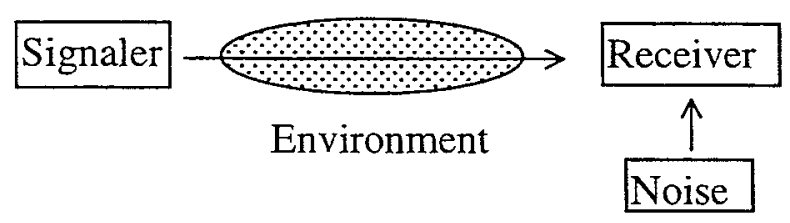

Figure 1. A simple model of communication.

Much of our understanding of signaling systems have come from studies of terrestrial species (Bradbury \& Verhencamp, 1998), so it would be useful to assess to what extent the "rules" of signal system design apply to organisms outside the terrestrial environment. The signal propagation conditions and ecology of the marine environment are quite different from the terrestrial environment, and are likely to have important influences on signaling systems (Urick, 1983). Use of the comparative method can be a powerful technique for elucidating the key features in the interaction between the ecological setting and signaling system design (Harvey \& Pagel, 1991). Similarities and differences in signal design and use among species solving similar problems in different 
ecological conditions help us understand which ecological factors affect the signaling system and how they affect it.

\subsection{Orcinus orca}

The killer whale (Orcinus orca) is an excellent species for a comparative study of signaling systems in group-living mammals because they have interesting similarities and differences with better-studied group-living terrestrial and marine species. Also, because killer whales have been held in captivity, several basic studies of their auditory perception have been carried out (Hall \& Johnson, 1972; Bain \& Dalheim, 1994; Symanski et al., 1999). Killer whales live in extremely stable groups with no male dispersal from the natal group, and only gradual separation of mothers and daughters (Bigg et al., 1990). While many terrestrial mammals live in stable groups, dispersal from the group is the norm, typically biased towards male dispersal (Dobson, 1982; Smuts et al., 1986). The stable natal groups in killer whales also contrasts sharply with bottlenose dolphin social structure in which males typically disperse from the natal group and form long-term malemale associations (Smolker et al., 1992). Group-distinctive calling has been described in killer whales and may be similar to that observed in greater spear-nosed bats, but it remains to be tested whether killer whales attend to group-distinctive cues (Ford, 1991; Boughman, 1997).

Natural markings (the shape of the dorsal fin, wounds, scars, and saddle-patch shape) allow for photographic and visual identification of individual killer whales (Bigg et al., 1990; Olesiuk et al., 1990). Based upon photo-identification and behavioral observations ongoing since 1973, killer whales in coastal northeast Pacific waters have been classified into two sub-types based upon preferred prey, behavior and morphology. Mammal-eating "transients" tend to travel in small groups and make long dives, while fish-eating "residents" associate in larger groups and make shorter dives (Bigg et al., 1987; Morton, 1990; Hoelzel, 1993). Although ranges of these two types of killer 
whales overlap and they have been observed within kilometers of each-other, interactions between them appear to be extremely rare.

The life history and population dynamics of resident killer whales are well understood for a wild animal population (Olesiuk et al., 1990). The photo-identification effort has identified two communities of inshore resident killer whales (fig. 2). In recent years, a community of offshore killer whales that appear to feed on fish has been discovered (Ford et al., 1994). Individuals from different communities have not been observed to interact although animals are occasionally observed in the range of the other community. As of the 1990 census, there were 112 animals identified in the southern resident community and 215 animals in the northern resident community (Bigg et al., 1990).

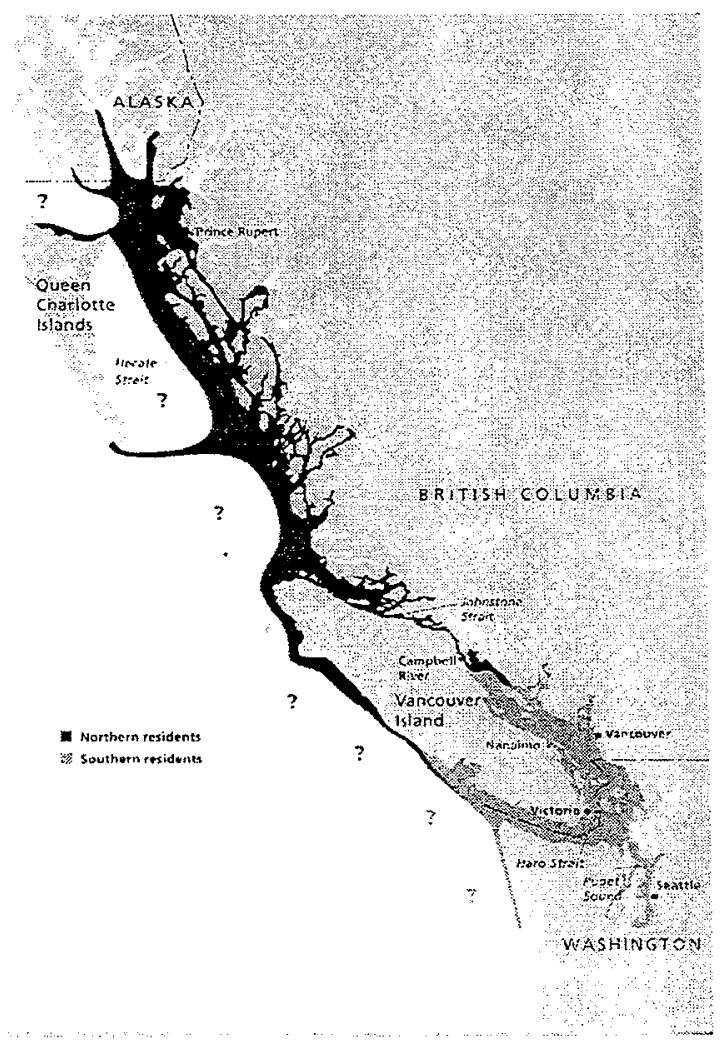

Figure 2: Map showing ranges of resident killer whales in the NE Pacific. From Ford et al. (1994). 
This thesis only explores the behavior of the fish-eating or resident killer whales, although there may be illustrative comparisons to be made between the two types. For example, the marine mammal prey of transients have much more sensitive hearing than the fish prey of residents. This differential risk of interception of sounds appears to have lead to more cryptic use of echolocation by transients (Barrett-Lennard et al., 1996). Other differences in vocal behavior include reduced calling activity in transients, except immediately following prey capture and during play behavior (Morton, 1990).

The basic unit of social organization in resident killer whales is the matrilineal subgroup, which consists of males of all ages and juvenile to young adult females in association with their mother (Bigg et al., 1990). The matrilineal subgroup is extremely stable over the lifetime of the mother although female offspring gradually spend more time away from their mother once they have offspring of their own. Pods are defined as any set of individuals that associate with each other on $50 \%$ or more of days of observation effort and consist of 1 to 9 or more matrilineal subgroups (Bigg et al., 1990). The genetic relationship between matrilineal subgroups within a pod is not known and it is not known whether preferential associations between pods reflect matrilineal relatedness (Bigg et al., 1990; Ford, 1991). When multiple pods are in the same area, a variety of associations among members of different pods are observed, including associations among males of various ages (Rose, 1992), adolescent females with young juveniles (Waite, 1988), and individuals of similar ages (Bain, 1988).

Killer whales produce whistles, echolocation clicks and pulsed calls, but pulsed calls dominate their vocal repertoire (Schevill \& Watkins, 1966; Steiner et al., 1979; Ford, 1991). In many calls, killer whales produce both a low and a high frequency component (the 'independent tone' of Hoelzel \& Osborne, 1986; the 'tone' of Ford, 1987). The low frequency component appears to derive from echolocation-like pulses repeated at $24 \mathrm{~Hz}$ to $2.4 \mathrm{kHz}$ (Watkins, 1967; Ford, 1987). It is possible to classify calls to one of several discrete types by visual inspection of the time-frequency contour of a sound spectrogram as well as by aural recognition (Ford, 1989). Stable pod-specific call 
repertoires have been described in the resident population, with differences among pods which interact socially (Ford, 1991). Killer whale pods produce a repertoire of 7-17 call types, with two types of repertoire differences between pods: 1.) some call types are not shared by different pods (different call types) and 2.) some call types are shared between pods, but consistently differ in some acoustic parameter(s), such as duration of a terminal component (different call "sub-types"). A similar pattern of call-type sharing was found in killer whales off Norway (Strager, 1995).

In contrast to many primate signaling systems in which different signal types reflect the context and motivation of the signaler (Hauser \& Marler, 1993), production of different call types by killer whale groups appears to be less strongly influenced by group activities (Bain, 1986; Ford, 1989). Members of matrilineal subgroups regularly disperse, apparently to forage, and later reunite for social and resting activities (Hoelzel, 1993; Ford, 1989). Calls and echolocation clicks are produced in all behavioral contexts, but calling rates tend to be highest during foraging and socializing activities and lowest during resting activities (Ford, 1989). No call type correlates exclusively with any behavioral category of the group (Ford, 1989), although relative production rates of different call types and whistles do vary with behavioral category (Bain, 1986; Morton et al., 1986; Ford, 1989). The weak association between call type production and behavior led Ford $(1989,1991)$ to suggest that discrete calls function to maintain pod cohesion and coordinate activities, and that the repertoire enhances the efficiency of the system by providing a group-specific marker or badge.

\subsection{Introduction to thesis research}

The findings of the previous research discussed above strongly suggest that killer whale calls function as contact calls. However, many basic features of the structure and use of killer whale calls remain unknown, largely due to the difficulty inherent in identifying signaling animals or locating sources of underwater sound. With a single hydrophone, it is generally only possible to record sounds from a group of animals and 
the breakthrough studies of Ford $(1989,1991)$ were possible because he could visually identify the pod that produced the sounds he recorded. This thesis relies upon rigorous attention to the spatial sampling of underwater sound, and demonstrates that many of the difficulties studying underwater sound can be overcome.

In chapter one, in order to investigate the mechanisms leading to pod-specific calling, I compare the structure and use of calls by the three matrilineal subgroups which comprise pod A1. In this chapter recordings were made from subgroups which were isolated from other pod members (Miller \& Bain, in press). In chapter two, I demonstrate and detail a method to identify vocalizing resident killer whales by linking visual observations of whale position to the angle-of-arrival of sounds on a small towed beamforming hydrophone array. Because the array is towed, calling animals can be identified during focal behavioral observations (Miller \& Tyack, 1998). In chapter three, I compare the repertoire of calls produced by the three members of matrilineal subgroup W2 to assess whether group members share the group repertoire of calls.

Chapters four and five describe basic structural features of killer whale sounds. In chapter four, I calculated the source levels of calls and whistles to estimate the range over which receiving killer whales can detect conspecific calls in quiet conditions. Spatial sampling was critical for chapter four, as the range from the signaler to a calibrated hydrophone must be measured for source level to be calculated. I measured the range to signalers by triangulating the angle-of-arrival of sounds on two beamforming hydrophone arrays towed in series. In chapter five, I explore how signal directionality affects the frequency-structure of killer whale calls depending on the orientation of the signaler relative to the receiver (Schevill \& Watkins, 1966). If the degree of directionality varies with frequency, then a receiving killer whale might use frequency-content cues to determine the orientation and/or direction-of-movement of the signaler. I carefully positioned the towed hydrophone array in front of a group of animals moving in one direction and allowed the group to pass the array and boat. The angle-of-arrival of sounds on the array was used to determine whether a sound came from animals moving toward or away from the boat. 
This thesis represents a transition from the description of sounds produced by groups of animals to quantitative observation of signals produced by an identified individual or by animals at a measured range or orientation to the receiver. Modern ethological sampling methods require quantitative observations made in carefully chosen or measured conditions (Altmann, 1974). Much can be learned from these detailed observations and clear, testable hypotheses can be formulated. Ultimately, a true understanding of animal signaling systems requires playback experiments to assess how the animals respond to signals in a natural context (Cheney \& Seyfarth, 1980; Tyack, 1983). The appendix contains a report of the response of singing humpback whales to playback of a U.S. Navy sonar, and demonstrates that it is possible to measure the behavioral responses of individual whales in controlled experiments at sea (Miller et al., 2000). The data reported in this thesis will be useful in the design and presentation of realistic stimuli to test specific hypotheses of signal function in killer whales.

\subsection{References:}

Altmann, J. 1974. Observational study of behavior: sampling methods. Behaviour 49: 227-267.

Bain, D. E. 1986. Acoustic behavior of Orcinus: sequences, periodicity, behavioral correlates and an automated technique for call classification. In: Behavioral Biology of Killer Whales. (Eds. B. C. Kirkevold \& J. S. Lockard), New York: Alan R. Liss, Inc., pp. 335-371.

Bain, D.E. 1988. An evaluation of evolutionary processes: studies of natural selection, dispersal, and cultural evolution in killer whales (Orcinus orca). Ph.D. dissertation, University of California, Santa Cruz.

Bain, D. E. and Dalheim, M. E. 1994. Effects of masking noise on detection thresholds of killer whales. In: Marine Mammals and the Exxon Valdez. (Ed. T. R. Loughlin) San Diego: Academic Press, pp. 243-256.

Barrett-Lennard, L.G., Ford, J.K.B., and Heise, K.A. 1996. The mixed blessing of echolocation: differences in sonar use by fish-eating and mammal-eating killer whales. Anim. Behav. 51: 553-565. 
Bertram, B.C.R. 1978. Living in groups: predators and prey. In: Behavioral Ecology: an Evolutionary Approach (J.R. Krebs \& N.B. Davies, eds.). Sunderland, Mass.: Sinauer Assoc., Inc., pp. 494.

Bigg, M.A., Ellis, G.M., Ford, J.K.B., and Balcomb, K.C. III. 1987. Killer Whales: Genealogy and Natural History in British Columbia and Washington State. Nanaimo: Phantom Press.

Bigg, M.A., Olesiuk, P.F., Ellis, G.M., Ford, J.K.B., and Balcomb, K.C. 1990. Social organization and genealogy of resident killer whales (Orcinus orca) in the coastal waters of British Columbia and Washington State. Rep. Int. Whal. Commn. Special Issue 12: 383-405.

Boinski, S. 1993. Vocal coordination of troop movement among white-faced capuchin monkeys, Cebus capucinus. Am. J. Primatol. 30: 85-100.

Boughman, J.W. 1997. Greater spear-nosed bats give group-distinctive calls. Behav. Ecol. Sociobiol. 40: 61-70.

Bradbury, J.W. and Vehrencamp, S.L. 1998. Principles of Animal Communication. Sunderland, MA: Sinauer Ass., Inc. pp. 882.

Brenowitz, E.A. 1982a. The active space of red-winged blackbird song. J. Comp. Physiol. 147: 511-522.

Brown, C.H., Beecher, M.D., Moody, D.B., and Stebbins, W.C. 1979. Locatability of vocal signals in old old monkeys: design features for the communication fo position. J. comp. Physiol. Psych. 93 (5): 806-819.

Cheney, D. L. and Seyfarth, R. M. 1980. Vocal recognition in free-ranging vervet monkeys. Anim. Behav. 28: 362-367.

Cheney, D.L., Seyfarth, R.M. and Palombit, R. 1996. The function and mechanisms underlying baboon 'contact' barks. Anim. Behav. 52: 507-518.

Dobson, F.S. 1982. Competition for mates and predominant juvenile male dispersal in mammals. Anim. Behav. 30: 1183-1192.

Ford, J.K.B. 1987. A catalogue of underwater calls produced by killer whales (Orcinus orca) in British Columbia. Can. Data Rep. Fish. Aquat. Sci. No. 633.

Ford, J.K.B. 1989. Acoustic behavior of resident killer whales (Orcinus orca) off Vancouver Island, British Columbia. Can. J. Zool. 67: 727-745. 
Ford, J.K.B. 1991. Vocal traditions among resident killer whales Orcinus orca in coastal water of British Columbia. Can. J. Zool. 69: 1454-1483.

Ford, J.K.B., Ellis, G.M., and Balcomb, K.C. 1994. Killer Whales: The Natural History and Genealogy of Orcinus orca in British Columbia and Washington State.

Vancouver: UBC Press, pp. 102.

Hall, J. and Johnson, C. S. 1972. Auditory thresholds of a killer whale Orcinus orca Linnaeus. J. Acoust. Soc. Am. 51: 515-517.

Harvey, P.H. and Pagel, M.D. 1991. The Comparative Method in Evolutionary Biology. Oxford: Oxford University Press, pp. 239.

Hauser, M.D. and Marler, P. 1993. Food-associated calls in rhesus macaques (Macaca mulatta) I. socioecological factors. Behav. Ecol. 4 (3): 194-205.

Hoelzel, A.R. 1993. Foraging behavior and social group dynamics in Puget Sound killer whales. Anim. Behav. 45: 581-591.

Hoelzel, A.R., and Osborne, R.W. 1986. Killer whale call characteristics: implications for cooperative foraging strategies. In: Behavioral Biology of Killer Whales (B.C. Kirkevold \& J.S. Lockard, eds.) New York: Alan R. Liss, Inc. pp. 373-403.

Janik, V.M and Slater, P.J.B. 1998. Context-specific use suggests that bottlenose dolphin signature whistles are cohesion calls. Anim. Behav. 56: 829-838.

Miller, P. J. O. and Bain, D. E. in press. Within-pod variation in the sound production of a pod of killer whales (Orcinus orca). Anim. Behav.

Miller, P. J. O., Biassoni, N., Samuels, A., and Tyack, P. L. 2000. Whale songs lengthen in response to sonar. Nature 405: 903.

Miller, P. J. and Tyack, P. L. 1998. A small towed beamforming array to identify vocalizing resident killer whales (Orcinus orca) concurrent with focal behavioral observations. Deep-Sea Res. II 45: 1389-1405.

Morton, A.B. 1990. A quantitative comparison of the behaviour of resident and transient forms of the killer whale off the central British Columbia coast. Rep. Int. Whal. Commn. Sp. Issue 12: 245-248. 
Morton, A. B., Gale, J. C., and Prince, R. C. 1986. Sound and behavioral correlations in captive Orcinus orca. In: Behavioral Biology of Killer Whales. (Eds. B. C.

Kirkevold \& J. S. Lockard), New York: Alan R. Liss, Inc. pp. 303-333.

Nelson, B. S. and Stoddard, P. K. 1998. Accuracy of auditory distance and azimuth perception by a passerine bird in natural habitat. Anim. Behav. 56: 467-477.

Olesiuk, P.F., Bigg, M.A., and Ellis, G.M. 1990. Life history and population dynamics of resident killer whales (Orcinus orca) in the coastal waters of British Columbia and Washington State. Rep. Int. Whal. Commn. Special Issue 12: 209-243.

Rendall, D., Rodman, P.S., and Emond, R.E. 1996. Vocal recognition of individuals and kin in free-ranging rhesus monkeys. Anim. Behav. 51: 1007-1015.

Richards, D.G. 1981. Estimation of distance of singing conspecifics by the Carolina wren. Auk 98: 127-133.

Rose, N.A. 1992. The social dynamics of male killer whales (Orcinus orca) in Johnstone Strait, British Columbia. Ph.D. thesis. University of California, Santa Cruz.

Schevill, W. E. and Watkins, W. A. 1966. Sound structure and directionality in Orcinus (killer whale). Zoologica 51: 71-76.

Smolker, R.A., Richards, A.F., Commor, R.C., and Pepper, J.W. 1992. Sex differences in patterns of association among Indian Ocean bottlenose dolphins. Behaviour 123: 38-69.

Smolker, R.A., Mann, J., and Smuts, B.B. 1993. Use of signature whistles during separations and reunions by wild bottlenose dolphin mothers and infants. Behav. Ecol. Sociobiol. 33: 393-402.

Smuts, B.B., Cheney, D.L., Seyfarth, R.M., Wrangham, R.W., and Struhsaker, T.T. (eds.) 1986. Primate Societies. Chicago: U. Of Chicago Press, pp. 578.

Snowdon, C.T. and Cleveland, J. 1984. "Conversations" among pygmy marmosets. Am. J. Primat. 7: 15-20.

Steiner, W., Hain, J., Winn, H., and Perkins, P. 1979. Vocalizations and feeding behavior of the killer whale (Orcinus orca). J. Mammal. 60: 823-827.

Stephens, D. and Krebs, J.R. 1986. Foraging Theory. Princeton, NJ: Princeton U. Press. 
Strager, H. 1995. Pod-specific call repertoires and compound calls of killer whales, Orcinus orca Linnaeus, 1758, in the waters of northern Norway. Can. J. Zool. 73 : 1037-1047.

Symanski, M. D., Bain, D. E., Kiehl, K., Pennington, W., Wong, S., and Henry, K. R. 1999. Killer whale (Orcinus orca) hearing: auditory brainstem response and behavioral audiograms. J. Acoust. Soc. Am. 106 (2): 1134-1141.

Trivers, R. 1985. Social Evolution. Menlo Park, CA, The Benjamin/Cummings Publishing Co., Inc. pp. 462.

Tyack, P. L. 1983. Differential response of humpback whales, Megaptera novaeangliae, to playback of song or social sounds. Behav. Ecol. Sociobiol. 13: 49-55.

Urick, R.J. 1983. Principles of Underwater Sound. New York: McGraw-Hill.

Waite, J.M. 1988. Alloparental care in killer whale (Orcinus orca). Master's Thesis, University of California, Santa Cruz.

Watkins, W. A. 1967. Harmonic interval: fact or artifact in spectral analysis of pulse trains. In: Marine Bio-acoustics, Vol. 2 (Ed. W. N. Tavolga), Oxford: Pergamon Press, pp. 15-42.

Wiley, R. H. and Richards, D. G. 1982. Adaptations for acoustic communication in birds: sound transmission and signal detection. In: Acoustic Communication in Birds, Vol. 2. (Ed. by D.E. Kroodsma \& E.H. Miller) New York: Academic Press, pg. 131-181.

Wilkinson, G.S. and Boughman, J.W. 1998. Social calls coordinate foraging in greater spear-nosed bats. Anim. Behav. 55: 337-350. 


\section{CHAPTER 2: WITHIN-POD VARIATION IN THE SOUND PRODUCTION OF A POD OF KILLER WHALES, ORCINUS ORCA}

This chapter is in press to be published in Animal Behaviour with David E. Bain as coauthor.

\subsection{Abstract}

Pod-specific calling behaviour of resident killer whales has been shown to include: discrete call types not shared among pods, different production rates of shared call types, and differences in the detailed structure of shared call types. To investigate the mechanisms leading to pod-specific calling, we compared the repertoire and structure of calls produced by three different matrilineal-units within the same pod, and described call features encoding matrilineal-unit distinctiveness. The three matrilineal units had different production rates of shared calls, including one call type used almost exclusively by one matrilineal unit. Cross-validated discriminant function analyses revealed matrilineal-unit distinctive structure in five of the six shared call types examined, with duration of the terminal component being the most distinctive feature for all call types containing a terminal component. Calls generally consist of low- and high-frequency components that may follow different time-frequency contours. In our sample, a particular high-frequency contour was consistently paired with a particular low-frequency contour, both contours had roughly equal overall variability, and each contained independent matrilineal unit distinctive information. The only call type that did not differ structurally between matrilineal units is reportedly used more in inter-pod meetings than in intra-pod contexts. The differences in calling behaviour between matrilineal units were similar in form to previously described differences between pods, although more subtle. These results suggest that pod-specific calling behaviour in resident killer whales arises primarily as a consequence of accumulated drift or divergence between highly cohesive matrilineal units as they gradually separate into different pods. 


\subsection{Introduction}

Several recent studies have shown that certain features of communication signals are shared within socially interactive groups due to a process of vocal convergence (e.g. D-note in chick-a-dee calls, Nowicki 1989; spectra of greater spear-nosed bat, Phyllostomus hastatus, screech calls, Boughman 1997; time-frequency contours of bottlenose dolphin, Tursiops truncatus, signature whistles, Smolker 1993). These groupdistinctive behaviour patterns result from the combination of a mechanism for vocal convergence and social interactions which promote group stability (Snowdon \& Hausberger 1997). As a practical matter, identifying the actual group among which vocal convergence occurs can be difficult because sharing on a fine scale can result in largerscale patterns as a by-product or 'epi-phenomenon' (Andrew 1962). For example, chaffinch, Fringilla coelebs, song dialects (Slater et al. 1980; Williams \& Slater 1990) and colony-distinctive screech calls in greater spear-nosed bats (Boughman 1997) may reflect differences between groups composed of neighbours or harems, respectively. Our goal here is to investigate group-specific calling behaviour in resident killer whales, a case where the groups are composed of matrilines. Specifically, we explore whether differences in calling behaviour exist among matrilines that compose pods, and identify which call features encode distinctiveness.

Natural markings on killer whales (the shape of the dorsal fin, the shape of the grey patch below the fin known as the saddle, wounds and scars) allow for photographic and visual identification of individuals (Bigg et al. 1990; Olesiuk et al. 1990). Based upon extensive behavioural and genetic evidence, killer whales in the northeastern Pacific have been classified into two sub-types: 'residents' which primarily prey upon fish, and 'transients' which primarily prey upon marine mammals (Bigg et al. 1987; Ford et al. 1998; Hoelzel 1998). This study only addresses the vocal behaviour of resident killer whales (hereafter killer whales).

Killer whale social structure is typified by a nested hierarchy of stable 
interactions. The basic unit of social organization is the 'matrilineal group', which consists of a mother, all of her male offspring, and young female offspring (Bigg et al. 1990). Surface association patterns of killer whales show that offspring of both sexes travel with their mothers more often than with any unrelated individual throughout their lives, and dispersal from a matrilineal group has not been documented in 20 years of intensive observation (Bain 1988; Bigg et al. 1990; Ford et al. 1994). Males remain in close association with their mothers throughout life, but females with offspring of their own gradually spend more time away from their mother, eventually forming their own matrilineal group. Matrilineal groups associate with each other on a temporary basis, and 'pods' consist of one to nine matrilineal groups observed together on $50 \%$ or more of observation days (mostly in the summer; Bigg et al. 1990). The pod level of association is fairly stable, but increased observer effort in the summer biases association data towards pod associations as killer whale aggregations appear to be particularly large in the summer compared to the rest of the year (D. B., personal observation). On a still wider scale, pods that have been observed to interact socially are considered to be part of the same community (Bigg et al. 1990). In this study, we use the term 'matrilineal unit' (MU) to refer to a matrilineal group plus any surviving members of the mother's natal matrilineal group.

Killer whales produce whistles and echolocation clicks, but pulsed calls dominate their vocal behaviour (Schevill \& Watkins 1966; Diercks et al. 1971; Steiner et al. 1979; Ford 1989). Calls have a complex structure consisting of multiple parts in time and frequency (Fig. 1). All calls contain a low-frequency component (LFC), which appears to be a burst-pulse sound with sidebands ranging to $10 \mathrm{kHz}$ or higher (Watkins 1967; Ford \& Fisher 1982). The LFC is composed of multiple temporal parts separated by shifts in the pulse repetition rate, which ranges from 80 to $2400 \mathrm{~Hz}$ (Ford 1987). A feature of some calls is the 'terminal note' which is a relatively short feature at the end of the call separated by a discontinuity in slope or frequency of the LFC. Many calls also contain a high-frequency component (HFC) which consists of a fundamental ranging from 2 to 12 


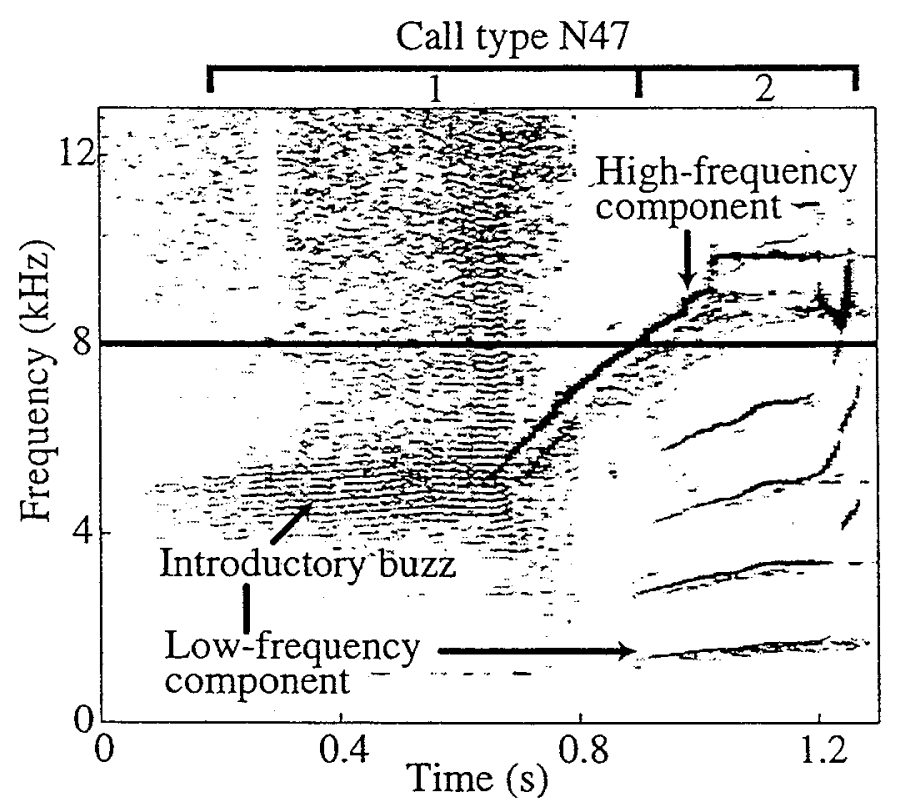

Figure 1. Spectrogram of a killer whale call with an effective filter bandwidth of $40 \mathrm{~Hz}$. This exemplar shows the presence of two different contours, the low- and high-frequency components. The low-frequency component is divided into two parts, part one (the introductory buzz) and part two, based upon the shift in the pulse repetition rate (Ford 1987; Watkins 1967). The high-frequency component starts at roughly $0.6 \mathrm{~s}$ and $5 \mathrm{kHz}$, then rises to $10 \mathrm{kHz}$. Reverberation is present and is particularly apparent in frequency modulated portions of the call. The line at $8 \mathrm{kHz}$ marks the upper frequency limit of Ford's (1987) spectrographic analyses of killer whale calls.

$\mathrm{kHz}$ and multiple harmonics ranging to $100 \mathrm{kHz}$ or more (Hoelzel \& Osborne 1986; Bain $\&$ Dalheim 1994). Although a beampattern has not been measured, the HFC appears to be significantly more directional than the LFC (Schevill \& Watkins 1966; Bain \& Dalheim 1994). Stereotyped calls are composed of distinctive combinations of low- and highfrequency components, which researchers have used to classify calls to discrete types by visual inspection of spectrograms and aural recognition (Bain 1986; Ford 1987). Call type classification has relied primarily upon inspection of the entire LFC and portions of the HFC below $8 \mathrm{kHz}$ (Ford 1987), and it is unknown if the entire HFC is stereotyped within 
each call type.

Ford (1987, 1989, 1991; Ford \& Fisher 1982) recorded calls from identified pods and described pod-specific repertoires of 7-17 call types per pod (Ford \& Fisher 1982; Ford 1991). Repertoire differences among pods are of two forms: call types not shared (different call types), and call types that are shared but differ consistently in some structural variable (different call sub-types). Structural differences in the terminal note of shared calls accounted for almost all of these call sub-types (Ford 1987, 1991). Ford (1991) grouped pods that shared any call types or sub-types into acoustic clans, and identified four different acoustic clans off Vancouver Island, three of which socially interact. Pods within clans have varying degrees of repertoire similarity and Ford (1991) suggested that repertoire similarity reflects matrilineal relatedness. Pods also differed in relative production rates of shared calls.

Ford (1991) proposed that the pattern of pod-specific calling is a product of cultural drift that results from the appearance of errors and innovations in vocal learning and transmission of these changes across generations (Slater 1989). There is convincing evidence for vocal learning in bottlenose dolphins and humpback whales, Megaptera novaeangliae, and growing evidence that killer whales also learn their vocalizations (Janik \& Slater 1997). A young Icelandic killer whale produced the calls of an older British Columbia whale after being placed in a pool with it, although these were not part of her natal repertoire (Bain 1988). In another captive study, a young killer whale produced calls that matched those of its mother, but not those of its father's pod to which it had never been exposed (Bowles et al. 1988). Members of pods occasionally produce sounds from other pod's repertoires, which may be an example of vocal mimicry (Ford 1991, page 1476). Two resident MUs appear to have made similar alterations to the LFC of one call type over a 12 year period, consistent with some degree of horizontal learning across MUs (Deecke et al. in press). However, because members of pods are related, and evidence exists that killer whales are highly inbred (Hoelzel 1998), some researchers have pointed out that Mendelian genetic inheritance of calls is consistent with pod-specific 
calling behaviour (Janik \& Slater 1997). A genetic transmission mechanism seems unlikely, however, as the pattern of call sharing observed by Ford (1991) would break down unless call structure was genetically coded in an unusual manner (mtDNA), or the mating system was highly restrictive.

In this study we explore the mechanisms of pod-specific calling by comparing the repertoires and the structure of calls produced by MUs from the same pod. MUs naturally separate by distances sufficient to obtain recordings from a single MU without employing acoustic localization techniques (e.g. Miller \& Tyack 1998). A finding that differences in calling behaviour exists between MUs would provide new evidence to support the model that pod-specific calling is a consequence of the gradual accumulation of errors and innovation in inter-generational transmission of vocal traits. Alternatively, a finding of no differences between MUs would suggest that pod-specific calling arises from rare but large changes in the vocal behaviour of the entire pod. No differences between MUs would also be evidence that vocal convergence occurs at the level of the pod, possibly as a consequence of horizontal learning from other pod members (Cavalli-Sforza \& Feldman 1981).

We assess whether potential differences between MUs parallel differences among pods, as this would provide stronger support that MU differences eventually lead to podlevel differences (Ford 1991). Thus, we compare relative rates of call type usage, especially exploring if any call types are not shared between MUs. We test for structural differences in shared call types, and assess whether similar structural features of calls differ between MUs and pods (Ford 1991). An additional aim of the structural analyses was to measure and describe the variability in the HFC because most analyses of killer whale calls have not considered the entire HFC. 


\subsection{Methods}

The subjects for this study were the members of the three MUs that make up pod A1 (Bigg et al. 1990). Pod A1 is most similar acoustically to pods A4 and A5, and is the most commonly observed pod in the study area, Johnstone Strait and the adjacent waters off Vancouver Island, British Columbia (Ford 1991). At the time of this study, pod Al consisted of three MUs, named A12, A30 and A36 (Table 1). Association measures of these three units from data collected annually from 1973 to 1987 show that A30 and A36 were more affiliative to each other than either was to A12 (Fig. 2). Association levels may also reflect matrilineal relatedness between the MUs (Bigg et al. 1990).

\begin{tabular}{|lllll|}
\hline Matrilineal unit & Individual & Sex & Estimated birth year (range)* & Live offspring \\
A12 & A12 & F & $1936(1935-1945)$ & A31, A33, A34 \\
A12 & A31 & M & $1959(1957-1961)$ & \\
A12 & A33 & M & 1971 & \\
A12 & A34 & F & 1975 & A30 \\
A30 & A02 & F & $1912(1911-1934)$ & A06, A38, A39, A50 \\
A30 & A30 & F & $1951(1949-1952)$ & \\
A30 & A06 & M & $1965(1963-1966)$ & \\
A30 & A38 & M & 1970 & A32, A37, A46 \\
A30 & A39 & M & 1975 & \\
A30 & A50 & F & 1984 & \\
A36 & & & & \\
A36 & A36 & F & $1950(1942-1951)$ & \\
A36 & A20 & M & $1953(1952-1956)$ & \\
A36 & A32 & M & $1965(1963-1966)$ & \\
A36 & A37 & M & 1977 & \\
\hline
\end{tabular}

Table 1. Identity, sex, estimated birth year, and relatedness of the individuals in A1 pod at the time of the study. *Individuals whose birth-year was observed are not given a range. See (Bain, 1988) and Bigg et al. (1990) for determination of estimated age and relatedness. 


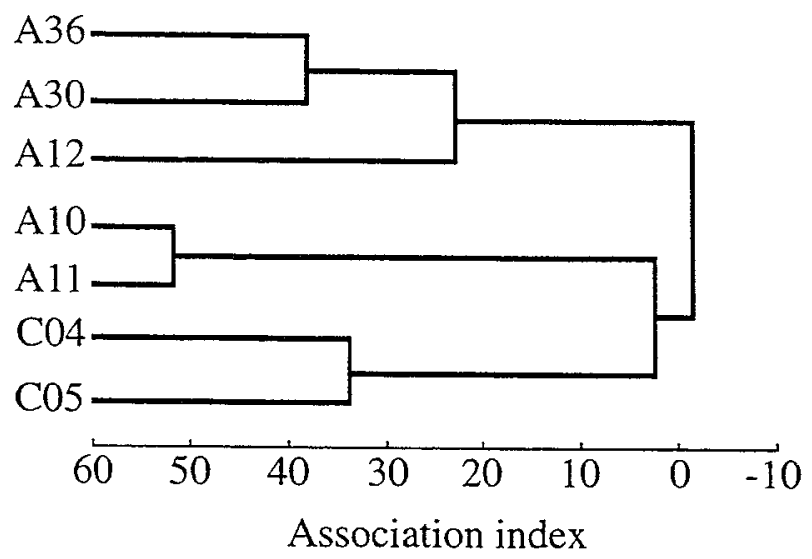

Figure 2. Association dendogram of the MUs (A12, A30 and A36) in pod A1 based upon data collected from 1973 to 1987 (Bigg et al. 1990). The nearest neighboring clusters to pod A1 (containing matrilineal-units A10, A11, C04 and C05) are also shown. Note that A12 is the relative outlier of the three MUs in A1 pod.

Recordings were made in 1984 and 1985 from each of the three MUs on an opportunistic basis when they were acoustically isolated from other pod members. Whales were approached briefly for visual recognition by standard markings, and photographed for later confirmation of field identifications. The research vessel (a $5.5 \mathrm{~m}$ C-Dory) was stopped approximately $400 \mathrm{~m}$ in front of the isolated MU, a hydrophone array was deployed, and recordings were made with a Brüel \& Kjaer (B\&K) 8104 hydrophone connected to a B\&K 2635 charge amplifier and a Hewlett-Packard 3968A tape recorder (flat $\pm 3 \mathrm{~dB}, 500 \mathrm{~Hz}-64 \mathrm{kHz}$ ). We re-identified and tracked whales visually when they surfaced near the array using standard and non-standard marks, such as bends in and relative heights of the dorsal fins, or right-side saddle patterns. To decrease the probability that our sample was dominated by one vocalizing individual, we conducted 
multiple recording sessions of each MU. In addition, John Ford provided two recordings (both of the A12 subgroup) from 1979 and 1981 made with equivalent field techniques.

We transferred recordings to cassette (flat $\pm 3 \mathrm{~dB}, 100 \mathrm{~Hz}-15 \mathrm{kHz}$ ) for analysis of call-type usage and acoustic structure. We performed spectrogram analysis on a Kay Sonagraph Model 5500 (frequency limit of $16 \mathrm{kHz}$, fast fourier transform (FFT) bandwidth of $113 \mathrm{~Hz}$, and $48 \mathrm{~dB}$ dynamic range). We identified call types by visual inspection of the spectrogram contours and aural comparison to known call types following the methods and naming system devised by Ford (1987). We assigned any calls that were not clearly a member of a defined call type and any whistles to type 0 . To test whether calls were used in the same relative proportions by each subgroup, we performed a chi-square analysis. We used post-hoc analyses to determine which call types were most likely to be responsible for any differences found (Zar 1984).

We carried out the structural analysis of shared calls by measuring multiple timefrequency variables of the six call types $(\mathrm{N} 1, \mathrm{~N} 2, \mathrm{~N} 4, \mathrm{~N} 5, \mathrm{~N} 7$ and N9) for which we had an adequate sample from all three MUs (Fig. 3). We had three primary goals in choosing which time and frequency variables to measure from call spectrograms. The first was to choose points that would roughly describe the LFC and HFC contours. The second was to choose points previously measured by Ford (1987). The third goal was to take several measures of the pulse-repetition rate of the LFC and the fundamental of the HFC at the same point in time. We obtained LFC pulse-repetition rates by measuring the side-band interval (SBI; Watkins 1967) while we measured HFC frequency points on the . fundamental. We computed variables to estimate the slope of the HFC from the difference between successive HFC frequency measures. To describe the stereotypy of calls, we compared the coefficient of variation (CV) of time versus frequency and SBI measures as well as the CVs of LFC and HFC variables. 
Figure 3. Structural variables measured for six call types shared by the MUs within pod A1. Spectrograms have an effective filter bandwidth of $113 \mathrm{~Hz}$, and the line at $8 \mathrm{kHz}$ marks the upper frequency limit of Ford's (1987) spectrographic analyses of killer whale calls. Numbers on the spectrogram show where measures were taken in addition to duration measures of the call and each low-frequency component part (boundaries shown above each spectrogram). Single numbers are frequency (high-frequency component) or side-band interval (low-frequency component) measures only, except variable 9 of call type N4 and variable 11 of call type N5 which are both measures of the sharpness of the HFC peak. Pairs of numbers are frequency and time measures, respectively. Descriptions of the numbered variables are given in the Appendix. 

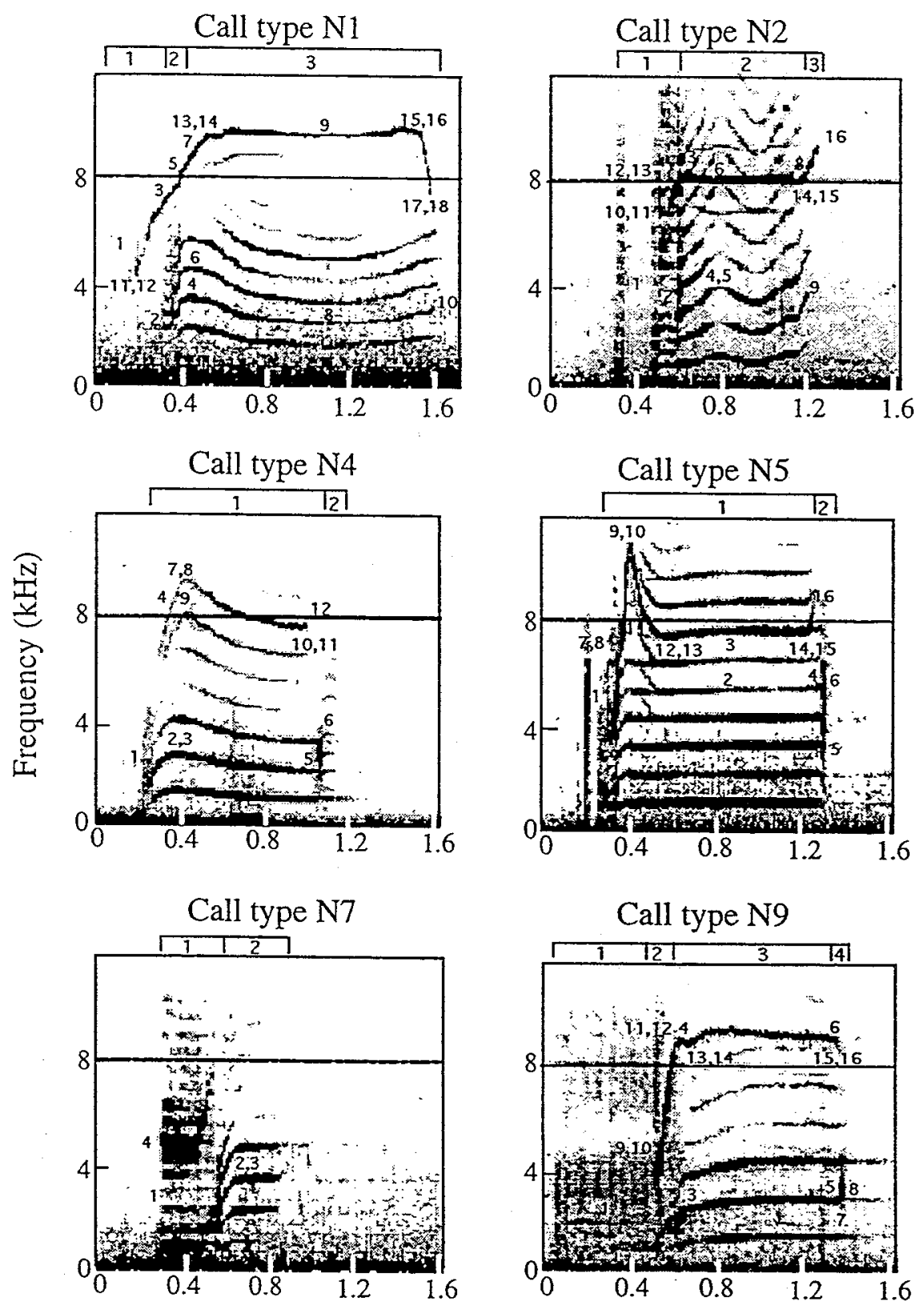

Time (s) 
To test for differences among MUs in the structure of the six shared call types, we measured the probability that an excluded or 'jackknifed' call would be correctly classified to its source MU based upon a prediction rule created from the other calls (Smith et al. 1982; Efron 1983). We conducted a separate analysis for each call type using the variables measured for that type. We generated the prediction rule using stepwise discriminant function analysis (DFA) carried out with SPSS for Windows Release 6.0. Stepwise DFA reduces the number of variables used to create the discriminant function, which improves the accuracy of the prediction rule (Lachenbruch \& Mickey 1968; Smith et al. 1982). Tolerance was set to 0.001, $F$-to-enter was 3.84, and $F$-to-remove was 2.71 . The algorithm selected the variable with the greatest $F$ score (above 3.84) for use in the DFA and continued to select variables until all that were acceptable were included. The DFA used the components identified above to create two uncorrelated linear functions consisting of variable coefficients that minimized Wilks' lambda (also known as the $U$ statistic), so that the function scores of calls from different MUs differed as much as possible.

After classifying calls to $\mathrm{MU}$, we statistically tested whether the matrix of predicted versus actual source MU was better than that expected by chance (Efron \& Gong 1983). Jackknifing and other forms of cross-validation, which remove and predict blocks of data based upon the remaining data, is necessary to reduce the well-known bias (on the order of $n^{-1}$ ) which results when the same data points are used to construct and evaluate a discriminant prediction rule (the 'resubstitution estimator'; Lachenbruch \& Mickey 1968). Jackknifing reduces the bias of the resubstitution estimator to order $n^{-2}$, so for $N=10$, the bias is reduced from $\sim 10 \%$ to $\sim 1 \%$ (Efron 1983). Jackknifing of single data points is preferred over removing large blocks of data by some statisticians because the combined discriminant function is more similar to each function used to classify cases, and jackknifing is more robust in cases where sample sizes are small (Lachenbruch \& Mickey 1968). When a priori grouping is possible, the DFA prediction method is more powerful than principal components analysis (PCA) at testing for differences between 
groups, particularly when differences are subtle and only occur on a subset of the variables measured.

To assess which call features encode MU distinctiveness for each call type, we calculated the stepwise discriminant functions using all replicates of that call type and examined the importance of each function and the correlation between the variables and functions (Norusis 1986). We compared the intra-pod variability we observed with the inter-pod variability reported by Ford (1987) to assess whether certain call features tend to be particularly important in the development of group-specific calling behaviour. To assess more directly the relative MU distinctiveness of the LFC and HFC, we also conducted stepwise DFA using measures from only one contour. For each call type, we calculated the percentage correctly classified using measures from the LFC, the HFC and the LFC and HFC together. When no discriminant function was formed because no variables were entered using the stepwise criteria, we used the percentage correct expected by chance (33.3\%). We compared the MU distinctiveness of each component using the percentage of calls correctly classified from each data subset across all calltypes.

\subsection{Results}

We analysed over 18 hours of active sound production. Of 1784 calls identified to type, structural variables of 516 calls were clear enough to be measured. A total of 412 calls were used in the DFA as not all variables could be measured from each of the 516 calls. In particular, the HFC of calls was occasionally missing from the spectrogram, possibly due to greater directionality of the HFC. Each measured call type occurred at least once in a mean of 8.06 (minimum of four) separate recording sessions from each $\mathrm{MU}$, providing a reasonably representative sample (Table 2 ). 


\begin{tabular}{|c|c|c|c|}
\hline \multirow[b]{3}{*}{ Call Type } & \multicolumn{3}{|c|}{$\mathrm{MU}$} \\
\hline & A30 & A36 & A 12 \\
\hline & Calls (sessions) & Calls (sessions) & Calls (sessions) \\
\hline $\mathrm{N1}$ & $18(8)$ & $9(4)$ & $15(7)$ \\
\hline N2 & $20 \quad(7)$ & $13(5)$ & (9) \\
\hline N4 & $50(10)$ & $33(6)$ & $(11)$ \\
\hline N5 & 21 (9) & $35 \quad(6)$ & $(11)$ \\
\hline N7 & $23(9)$ & $23(4)$ & $(12)$ \\
\hline N9 & (8) & $49(7)$ & $(12)$ \\
\hline
\end{tabular}

Table 2. The number of measured calls and recording sessions (in parentheses) by call type and matrilineal unit (MU)

\subsubsection{Call usage}

As a group, A1 pod's call usage closely matched that observed by Ford (1991). Discrete stereotyped calls dominated the sound production of each MU with the 0 category of whistles and nonstereotyped calls accounting for less than $5 \%$ of sound production overall (Fig. 4). There were significant differences in call between among the three subgroups $\left(\chi_{30}^{2}=195.8, P<0.001\right)$. A large contribution to this difference may be from call types $\mathrm{N} 2, \mathrm{~N} 4, \mathrm{~N} 5, \mathrm{~N} 7, \mathrm{~N} 47$ and the 0 category, although the remaining calls showed significant variability as well $\left(\chi_{18}^{2}=31.6, P<0.05\right)$. One call type $(\mathrm{N} 47)$ was made almost exclusively by MU A30. Although the other MUs were observed to make this call rarely, it does not appear to be a common call in their repertoire.

\subsubsection{Call structure}

Within a given call type, the contour of the HFC was highly stereotyped (Fig. 5) and could be used as an accurate means of identifying call type. Using measures from both the LFC and HFC, the CVs of time variables were greater than those of SBIfrequency variables $\left(\bar{X}_{\text {timc }}=39.2, \bar{X}_{\text {frequency }}=12.4 ; t_{64}=5.84, P<0.001\right)$. The C.V.'s of 


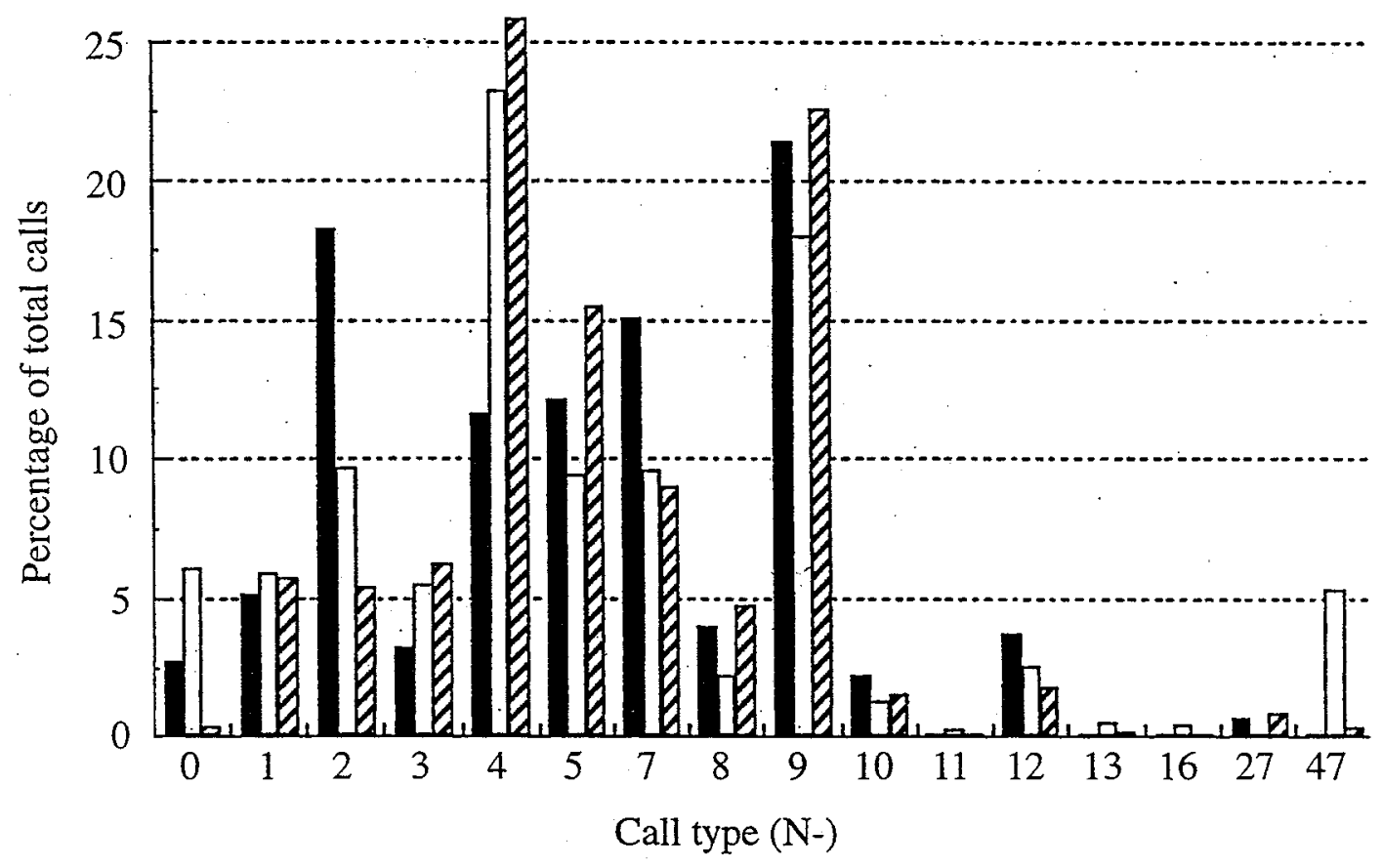

Figure 4. Histogram of call type usage by the three MUs in pod A1. Call type 0 is an 'other' category which includes whistles and calls that did not clearly fall into one of the

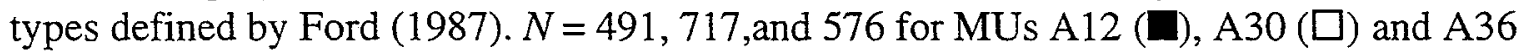
$(\bigotimes)$, respectively.

time variables did not differ significantly between the LFC and HFC ( $\bar{X}_{\mathrm{LFC}}=36.7, \bar{X}_{\mathrm{HFC}}$ $=42.8 ; t_{39}=0.74, P=0.46$, power $=50 \%$ ), nor $\mathrm{did}$ the $\mathrm{CVs}$ of SBI/frequency variables $\left(\bar{X}_{\mathrm{LFC}}=17.8, \bar{X}_{\mathrm{HFC}}=8.9, t_{31}=1.91, P=0.07\right.$, power $\left.=82 \%\right)$, although the latter approached significance. This result suggests that the HFC is at least as stereotyped as the LFC.

A total of 21 variables were entered into the DFA using the stepwise procedure (Table 3), 11 of which came from the LFC (five SBI and six time variables) and 10 of which came from the HFC (eight frequency and two time variables). For call types N1, 


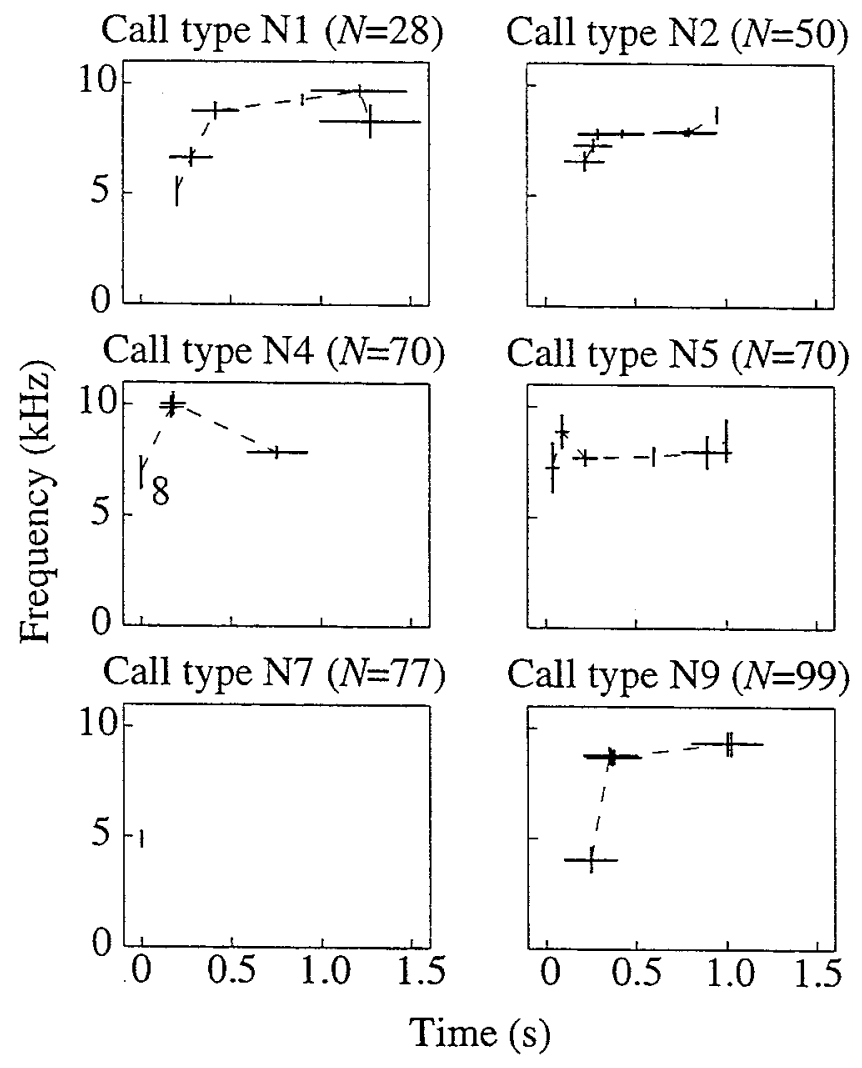

Figure 5. Stereotypy by call type of the high-frequency component (HFC) of killer whale calls. The middle of each bar is the mean of the time and frequency variables measured on the HFC contour, and the length of the bar is \pm 1 SD for time measures (horizontal bars) and \pm 2 SD for frequency measures (vertical bars). Sample sizes are given above each box, except one variable noted within the N4 box. The dashed line connects the time-frequency means to roughly recreate the HFC contour. Note the combination of stereotypy within each call type and distinctiveness across call types.

N4, N5, N7 and N9, stepwise DFA correctly predicted source MU of jackknifed calls above random accuracy, but did not do so for call type N2 (Table 4). For all call types except N1, calls produced by MU A12 were most likely to be assigned to the correct group. Figure 6 is a two-dimensional plot of all cases according to their values from the discriminant functions. 
Terminal note duration was the most important variable in predicting source MU for the three call types with such a note (N4, N5 and N9; Table 5). SBI variables were the most important for call types N1 and N2, and the duration of the upsweep was the most important feature for call type N7. Because each call type used a unique variable set in the DFA, we tested whether the number of variables measured from the call influenced classification success. We found no correlation between the percentage of calls correctly classified and the number of variables measured $(r=0.27, N=6, P>0.5$, power $=0.87$ ), suggesting that distinctiveness of call structure was not strongly influenced by the number of variables measured.

We compared the structural differences among MUs within pod A1 with those among pods A1, A4 and A5 reported by Ford (1987). As mentioned above, terminal note duration was the most important classification variable for all three calls with terminal notes (N4, N5 and N9), matching Ford's (1987) extensive use of terminal note variation to define different call sub-types. Because Ford's (1987) spectrogram analysis cut off at 8 $\mathrm{kHz}$, only 12 of the 21 variables included in the DFA were also measured by Ford. Overall, nine of the 12 variables entered into the DFA (75\%), but only 19 of 42 variables not entered (45\%), differed across pods.

There was no difference in MU distinctiveness between the LFC and HFC based upon stepwise DFA of the partitioned data set (Fig. 7). Across the six call types, the percentage of correctly classified calls using measurements from single contours was the same (paired t test: $t_{5}=-0.543, P>0.5$ ). We therefore averaged these single component results and compared the average to the percentage correct using both components together. The combination of both contours was more effective at predicting source $\mathrm{MU}$ than the average of the single contours alone (paired $t$ test: $t_{5}=9.677, P<0.001$ ). This strongly suggests that both the LFC and HFC are group distinctive, and that at least some of the distinctiveness in each contour is independent of that in the other. 


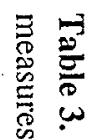

苨

$\exists$

苞蛋

劳 8

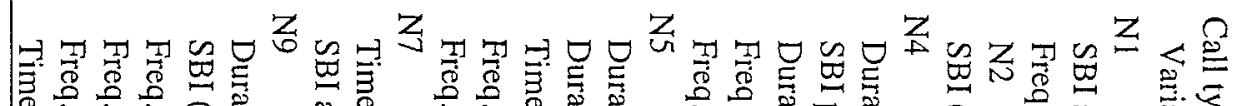

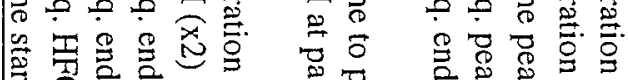
$\stackrel{7}{3}$

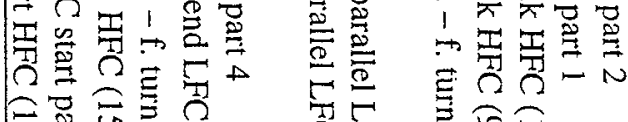

兽

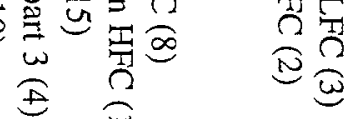

泀

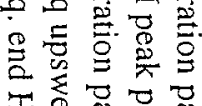

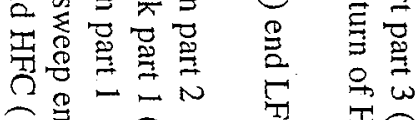

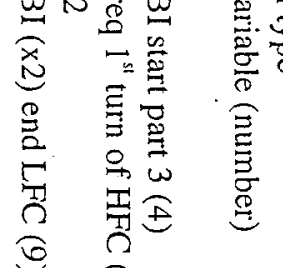

웅

产

苨

氶

空

它

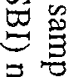

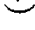

$\stackrel{\overparen{c}}{\stackrel{n}{\omega}}$

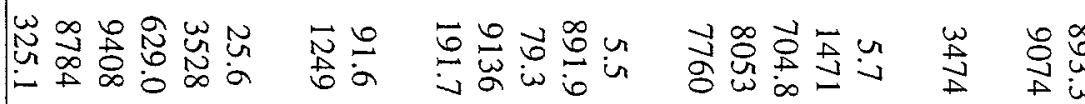

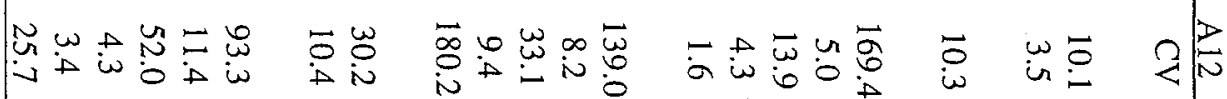

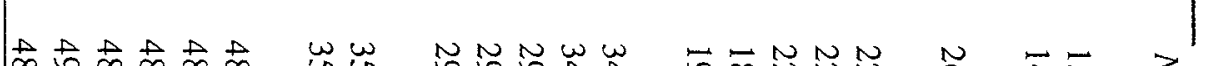

究

is

ซै

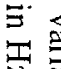

乙

要

兽

苛

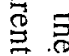

产

i

ैㅡㄹ

$\infty \infty \infty$

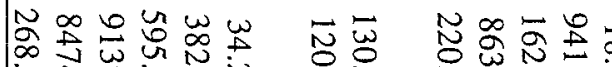

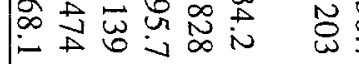

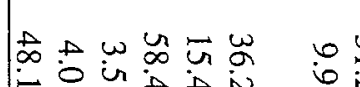

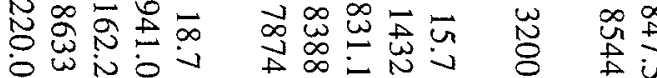

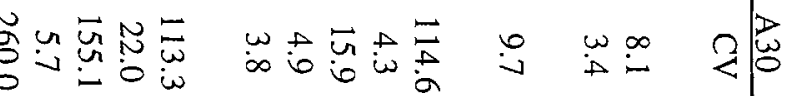

$\omega \omega \omega \omega \omega \omega$,

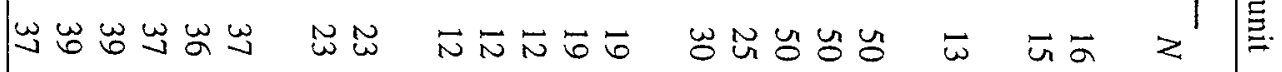

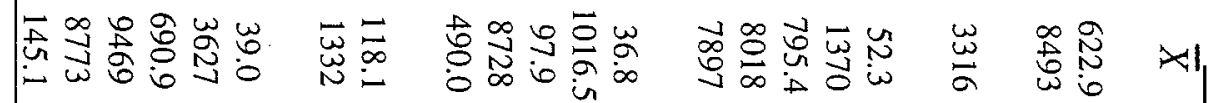

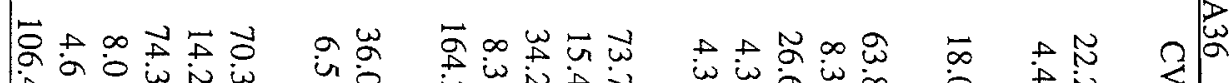

穴急

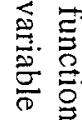

氶

$A$ a

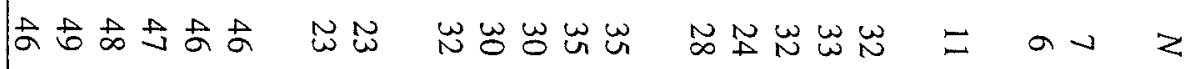

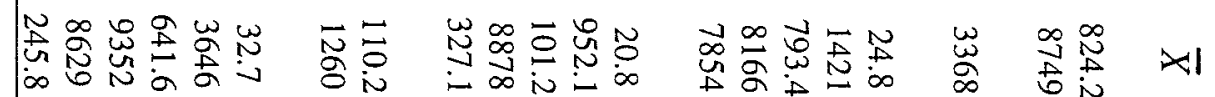

$\frac{9}{9}$

궁

3

赵

@

U⿺辶寸

w

营 
Predicted unit

$\underline{\text { Actual unit }}$ A12 $\mathrm{A} 30 \quad \mathrm{~A} 36 \quad$ \% correct

N1

$\begin{array}{lllll}\mathrm{A} 12 & 10 & 3 & 1 & 71.4\end{array}$

$\begin{array}{lllll}\text { A30 } & 1 & 11 & 1 & 84.6\end{array}$

$\begin{array}{lllll}\text { A36 } & 0 & 0 & 4 & 100.0\end{array}$

Total \% correct $=80.6 \%, \mathrm{G}_{4}=29.57, \mathrm{p}<0.001$

N2

$\begin{array}{lllll}\text { A12 } & 17 & 6 & 3 & 65.4\end{array}$

$\begin{array}{lllll}\text { A30 } & 6 & 6 & 3 & 40.0\end{array}$

$\begin{array}{lllll}\text { A36 } & 2 & 7 & 2 & 18.2\end{array}$

Total \% correct $=48.1 \%, \mathrm{G}_{4}=8.213, \mathrm{p}<0.10$

N4

$\begin{array}{lcccc}\text { A12 } & 16 & 2 & 0 & 88.9 \\ \text { A30 } & 4 & 19 & 3 & 73.1 \\ \text { A36 } & 2 & 3 & 17 & 77.3\end{array}$

Total $\%$ correct $=78.8 \%, \mathrm{G}_{4}=61.93, \mathrm{p}<0.001$

\begin{tabular}{ccccc} 
& \multicolumn{5}{c}{$\mathrm{N} 5$} & & \\
$\mathrm{~A} 12$ & 25 & 4 & 0 & 86.2 \\
$\mathrm{~A} 30$ & 4 & 0 & 6 & 0.0 \\
$\mathrm{~A} 36$ & 8 & 6 & 16 & 53.3
\end{tabular}

Total \% correct $=59.4 \%, \mathrm{G}_{4}=16.23, \mathrm{p}<0.005$

N7

$\begin{array}{lllll}\mathrm{A} 12 & 23 & 5 & 7 & 65.7\end{array}$

$\begin{array}{lllll}\text { A30 } & 9 & 10 & 4 & 43.5\end{array}$

$\begin{array}{lllll}\text { A36 } & 8 & 4 & 11 & 47.8\end{array}$

Total \% correct $=54.3 \%, \mathrm{G}_{4}=12.93, \mathrm{p}<0.025$

N9

$\begin{array}{lllll}\mathrm{A} 12 & 37 & 3 & 2 & 88.1\end{array}$

$\begin{array}{lllll}\text { A30 } & 8 & 16 & 7 & 51.6\end{array}$

$\begin{array}{lllll}\text { A36 } & 8 & 11 & 21 & 52.5\end{array}$

Total \% correct $=65.5 \%, \mathrm{G}_{4}=57.12, \mathrm{p}<0.001$

Table 4. Results of the jackknife predictions for each call type 

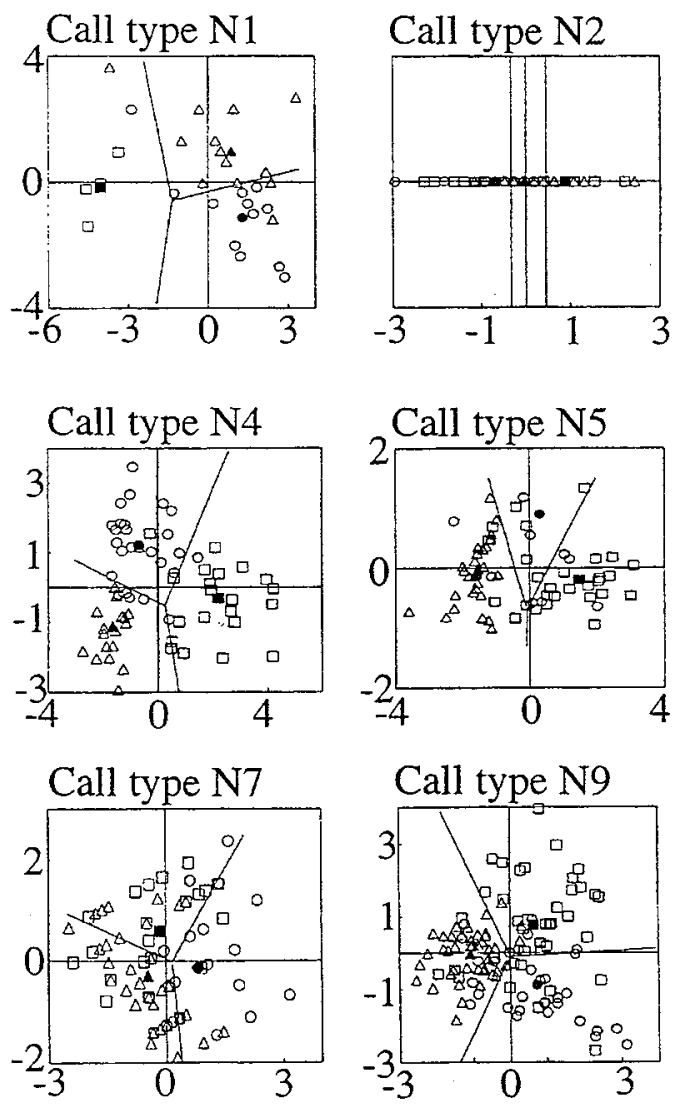

Figure 6. Discriminant function plots. This figure displays the discriminant function scores of each call from which structural measures were taken. Call scores $(\Delta: A 12 ; O$ : A30; $\square$ : A36) and each MUs centroid (mean discriminant score; $\mathbf{A}: \mathrm{A} 12 ; \mathbf{O}: \mathrm{A} 30 ; \mathbf{\square}$ : A36) are shown. The two-dimensional field is broken into three regions, which are the territories for each MU. Correctly classified calls are in the same territory as the MUs centroid, while misclassified calls are in the territory of a different centroid. Note that call type N2 has only one discriminant function, so the plot is divided into three onedimensional territories 


\begin{tabular}{|c|c|c|c|c|}
\hline \multirow[b]{2}{*}{ Call type / variable } & \multicolumn{2}{|c|}{ \% Variance } & \multicolumn{2}{|c|}{ Correlation } \\
\hline & Function 1 & Function 2 & Function 1 & Function 2 \\
\hline N1 & 75.06 & 24.94 & & \\
\hline SBI start part $3(4)$ & & & *0.9999 & 0.0077 \\
\hline Freq. $1^{\text {st }}$ turn $\mathrm{HFC}$ (13) & & & 0.3966 & $* 0.9180$ \\
\hline N2 & 100.00 & & & \\
\hline SBI (x2) end LFC (9) & & & $* 1.0000$ & \\
\hline N4 & 73.33 & 26.67 & & \\
\hline Duration part 2 & & & $* 0.7806$ & -0.2085 \\
\hline SBI peak part 1 (2) & & & $*_{-0} 0.2860$ & -0.2297 \\
\hline Duration part 1 & & & 0.1719 & $* 0.4596$ \\
\hline Freq. upsweep end HFC (12) & & & -0.0896 & $* 0.4065$ \\
\hline Freq. end HFC (10) & & & 0.0794 & $* 0.1140$ \\
\hline N5 & 93.72 & 6.28 & & \\
\hline Duration part 2 & & & $* 0.5804$ & -0.2761 \\
\hline Duration part 1 & & & $* 0.2805$ & 0.0321 \\
\hline Time peak HFC (10) & & & 0.0883 & $* 0.8856$ \\
\hline Freq. peak HFC (9) & & & -0.2036 & $*-0.4329$ \\
\hline $\begin{array}{l}\text { Freq. end - freq. turn HFC (14 - } \\
\text { 12) }\end{array}$ & & & 0.0551 & $*_{-0.2287}$ \\
\hline N7 & $68.11 \%$ & $31.89 \%$ & & \\
\hline Time to parallel LFC (3) & & & $* 0.7777$ & 0.6286 \\
\hline SBI at parallel LFC (2) & & & -0.3857 & *0.9226 \\
\hline N9 & $64.11 \%$ & $35.89 \%$ & & \\
\hline Duration part 4 & & & $* 0.5326$ & -0.0012 \\
\hline SBI (x2) end LFC (8) & & & $* 0.2639$ & -0.1867 \\
\hline Freq. end - freq. turn HFC (15-13) & & & $* 0.1422$ & 0.1239 \\
\hline Freq. end $\mathrm{HFC}(15)$ & & & 0.0990 & $* 0.5988$ \\
\hline Freq. HFC start part 3 (4) & & & -0.2732 & $* 0.5443$ \\
\hline Time start HFC (10) & & & -0.4811 & $*_{-0.5049}$ \\
\hline
\end{tabular}

Table 5. Importance of acoustical variables in the discriminant function analysis. The relative importance of each variable can be assessed as a combination of the percentage variance explained by each function and the correlation between the variable and the functions. Thus, the first variable listed is the most important for discriminating subgroups. Numbers in parentheses are the variable number from Fig. 3 and the Appendix. *Correlation values were statistically significant. 


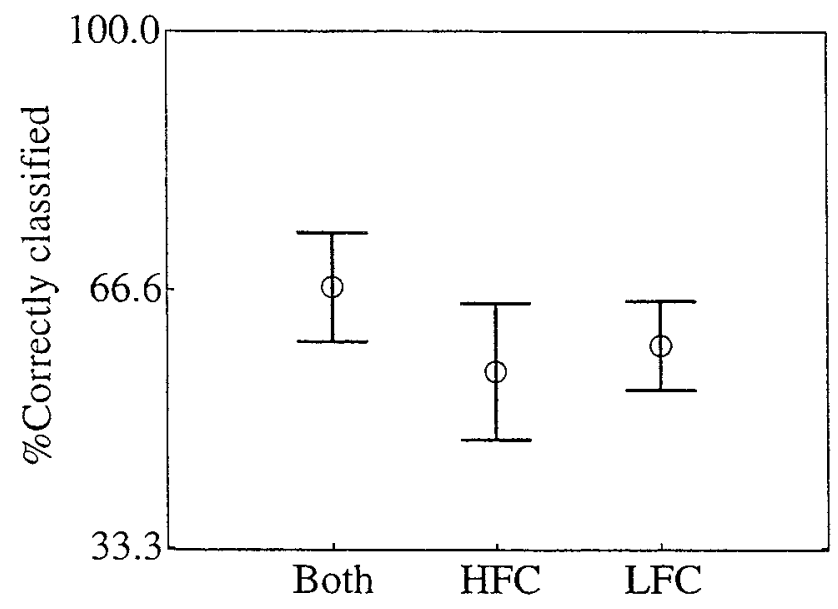

Figure 7. Mean $\pm S E$ percent of calls correctly classified to MU depending on which component was used in the DFA. Percentage correct was the same for HFC only and LFC only (paired $t$ test: $t_{5}=-0.543, P>0.5$ ). Across all call types, percentage correct was significantly higher when both contours were used together than the mean of the two single component scores $\left(t_{5}=9.677, P<0.001\right)$.

\subsection{Discussion}

These findings strongly support the hypothesis that pod-specific calling behaviour in killer whales results from differences between matrilineal units that accumulate over time. Differences between MUs resulted from apparently gradual changes in call structure and changes in call repertoire (Ford 1991). Five of the six call types we analysed had MU specific structural features (Table 4), suggesting that details of call production are somewhat flexible but are MU distinctive. Differences in call usage rates were apparent for many call types, and call type N47 was used primarily only by MU A30 (Fig. 5). It is unclear whether N47 is an entirely new call that was created within the A30 lineage, a major modification of another existing call, such as call type N9 (see Figs 1, 3), or an ancestral call that was dropped by the other MUs.

The differences in call usage and structure between MUs in pod A1 are more 
subtle than the differences between pods described by Ford (1991), but are qualitatively similar. The very rare production of call type $\mathrm{N} 47$ by the other MUs in pod Al is similar to the rare production of other pods' calls observed by Ford (1991). Terminal note duration was the most important structural variable distinguishing MUs for all three call types with a terminal note (N4, N5 and N9), which matches Ford's (1991, page 1478) finding that terminal notes are consistently the most important variable defining different call sub-types, especially among pods A1, A4 and A5. Other variables that differed among MUs within A1 pod did not vary as consistently among pods A1, A4 and A5 (six did, three did not), suggesting that other parts of calls may be more stable than the terminal note. Higher variability has also been observed in terminal components of song for several bird species (e.g. song sparrows, Melospiza melodia, Horning et al. 1993). The qualitative similarity of MU differences and pod differences add support to our conclusion that pod differences result from differences on the MU level that accumulate over generations until matrilines dissociate into pods (Bigg et al. 1990; Ford 1991).

We found that MU A12 was the most vocally distinct and the outlier in terms of association within pod A1 over the course of the study (Table 4 \& Fig. 2). Since Bigg et al. (1990) found that association levels correlate with matrilineal relatedness, the A12 lineage may have had more generations to accumulate vocal distinctiveness. Alternatively, the more frequent association of the MU A30 with MU A36 may have led to greater vocal similarity due to horizontal cultural transmission between MUs (CavalliSforza \& Feldman 1981). The possibility of cultural transmission between MUs is also supported by Deecke et al.'s (1999) finding that association patterns of MUs correlate with acoustic similarity of the LFC of call type N4 based upon a neural net prediction technique. Similarly, Deecke et al. (in press) report that two MUs (A12 and A30) altered the LFC of one call type in a matching fashion across a 12 year period, which is consistent with horizontal cultural transmission.

Repertoires of sounds may be particularly efficient for encoding information about multiple levels of social affiliation (Hausberger 1997). In this study, call type N2 
was the only type that we found to have no MU distinctiveness. This same call type previously was shown to be used more often during meetings between pods than in any other context (Ford 1989). Use of stable, shared calls when pods meet may serve to signal group size, spatial distribution and emotional state to members of other pods, as in Australian magpies, Gymnorhina tibicen, which increase caroling during inter-group interactions apparently to signal their group size and willingness to act in concert (Brown \& Farabaugh 1991). Increased production of stable call types in large diverse groups could provide a feedback mechanism to reduce drift of stable call types relative to more variable, distinctive call types which are produced more in small groups. In this case, the range of $\mathrm{MU}$ distinctiveness across different call types may provide a highly accurate 'badge' of relatedness or affiliativeness to each group (Ford 1991), and the functional use of the badge in different social settings supports its stability.

The contour of the HFC was highly consistent within each call type, with overall variability in time and frequency similar to that of the LFC. Audiograms of killer whale hearing ability suggest that the most sensitive frequencies for hearing in killer whales (15 - $20 \mathrm{kHz}$ ) are approximately the same as the range of the second harmonic of the HFC, which may contain more energy than the fundamental (Hall \& Johnson 1972; Symanski et al. 1999). Carefully designed playback experiments are needed to test perception and function of the group-distinctive nature of killer whale calls.

In some calls the HFC did not appear in the spectrogram with the LFC, which is consistent with previous observations of greater directionality of the HFC than the LFC (Schevill \& Watkins 1966; Bain \& Dalheim 1994). Different levels of directionality in the LFC and HFC could provide a cue communicating the orientation of a signalling animal relative to the receiver, which may be helpful for maintaining group cohesion in this mobile species (Hunter et al. 1986).

These results provide some support for the hypothesis that killer whales learn the detailed structure of their calls and that group specificity is due to cultural evolution. Although we do not rule out a genetic mechanism to explain similarities within and 
differences between MUs, the restrictions this would place on the mating system would be more extreme than that postulated for pod-specific calling, and are inconsistent with what is believed about the life history of the species. MU distinctiveness is more parsimoniously explained by learning, where vocal similarity arises as a consequence of exposure to the sounds of tutors. Stable MUs provide a setting where development of learned vocal traits can be shaped by exposure to sounds produced by other members of the MU, and where affiliative interactions support call sharing and vocal similarity (Snowdon \& Hausberger 1997).

It is not known why resident killer whale MUs are so stable, with no cases of dispersal by either sex over a 20 -year period (Ford et al. 1994). The lack of male dispersal is particularly unusual in mammals (Dobson 1982; Rose 1992). Transient killer whales occur in smaller groups with less matrilineal stability, suggesting that prey type and distribution may be an important influence on group size (Bain 1988; Ford et al. 1998; Baird \& Dill 1995; Nichol \& Shackleton 1996). Members of kin groups of killer whales might also mutually benefit from alloparental care or other reciprocal activities (Waite 1988; Ford 1991). Vocal similarity seems to be correlated with the multi-layered structure of killer whale society, and ultimately to the social interactions that contribute to the stability of the social structure. 


\subsection{Acknowledgments}

We give special thanks to the late Mike Bigg. In addition to providing valuable advice and information throughout the field work, the climate of sharing, cooperation and openness he created proved invaluable to the progress of research on this species during his lifetime. The late Ken Norris provided valuable advice and support to D.B. in his role as dissertation adviser. Special thanks are also due to Janice Waite for many months of dedicated work in the field. Field assistance was also provided by Vickie Annen, David Briggs, Patty Gallagher, Tom Jefferson, Tom Kieckhepfer, Lance Morgan, Becky Rumsey, Joe Terrazino and Rebecca Welsh. Logistical support was generously provided by Jim Borrowman and Bill MacKay of Stubbs Island Charters. Jeff Jacobsen and Paul Spong provided valuable advice. We thank John Ford for his advice, for providing recordings and for use of his sound analysis facilities at the Vancouver Aquarium Marine Science Center; Mike Beecher for the use of his facilities in the Animal Behavior Program at the University of Washington and for critical advice; and Salvatore Cerchio, Christopher Clark, John Ford, Vincent Janik, P.L. Schwagmeyer, Peter Tyack, Walter Wilczynski, and two anonymous referees for comments on the manuscript. This work was supported in part by NSF graduate fellowships to both authors, and a Doctoral Dissertation Research Improvement Grant to D.B (NSF Grant OCE-850119). This work was also supported by gifts from Joseph Long and the Hewlett-Packard Company Foundation to the University of California at Santa Cruz, and a donation from HewlettPackard Company. Finally, D.B. would like to thank the Marine World Foundation for the use of its facilities to develop some of the techniques used in this study and financial and moral support. The research presented here was evaluated by the Animal Behavior Society's Animal Care Committee and approved on 6 March 2000. This is contribution \#10156 of the Woods Hole Oceanographic Institution. 


\subsection{References}

Andrew, R. J. 1962. Evolution of intelligence and vocal mimicking. Science, 137, 585589.

Bain, D. E. 1986. Acoustic behavior of Orcinus: sequences, periodicity, behavioral correlates and an automated method for call classification. In: Behavioral Biology of Killer Whales (Ed. by B. C. Kirkevold \& J. S. Lockard), pp. 335-371. New York: A. R. Liss.

Bain, D. E. 1988. An evaluation of evolutionary processes: studies of natural selection, dispersal, and cultural evolution in killer whales (Orcinus orca). Ph.D. thesis. University of California, Santa Cruz.

Bain, D. E. \& Dahlheim, M. E. 1994. Effects of masking noise on detection thresholds of killer whales. In: Marine Mammals and the Exxon Valdez (Ed. by T. R. Loughlin), pp. 243-256. San Diego: Academic Press.

Baird, R. W. \& Dill, L. M. 1995. Occurrence and behaviour of transient killer whales: seasonal and pod-specific variability, foraging behaviour and prey handling. Canadian Journal of Zoology, 73, 1300-1311.

Bigg, M. A. ,Ellis, G. M., Ford, J. K. B., \& Balcomb, K. C. III. 1987. Killer Whales: Genealogy and Natural History in British Columbia and Washington State. Nanaimo, British Columbia: Phantom Press.

Bigg, M. A., Olesiuk, P. F., Ellis, G. M., Ford, J. K. B. \& Balcomb, K. C. 1990. Social organization and genealogy of resident killer whales (Orcinus orca) in the coastal waters of British Columbia and Washington State. Report of the International Whaling Commission, Sp. Issue 12, 383-405.

Boughman, J. W. 1997. Greater spear-nosed bats give group-distinctive calls. Behavioral Ecology and Sociobiology 40, 61-70.

Bowles, A. E., Young, W. G. \& Asper, E. D. 1988. Ontogeny of stereotyped calling of a killer whale calf, Orcinus orca, during her first year. Rit Fiskideildar, 11, 251-275.

Brown, E. D. \& Farabaugh, S. M. 1991. Song sharing in a group-living songbird, the Australian magpie, Gymnorhina tibicen. Part III. Sex specificity and individual specificity of vocal parts in communal chorus and duet songs. Behaviour, 118, 244-274. 
Cavalli-Sforza, L. L. \& Feldman, M. W. 1981. Cultural Transmission and Evolution: A Quantitative Approach. Princeton, New Jersey: Princeton University Press.

Deecke, V. B., Ford, J. K. B., \& Spong, P. 1999. Quantifying complex patterns of bioacoustic variation: use of a neural network to compare killer whale (Orcinus orca) dialects. Journal of the Acoustical Society of America, 105, 2499-2507.

Deecke, V. B., Ford, J. K. B., \& Spong, P. in press. Dialect change in resident killer whales (Orcinus orca): implications for vocal learning and cultural transmission. Animal Behaviour.

Diercks, K. J., Trochta, R. T., Greenlaw, C. F. \& Evans, W. E. 1971. Recording and analysis of echolocation signals. Journal of the Acoustical Society of America, 49, 1729-1732.

Dobson, F. S. 1982. Competition for mates and predominant juvenile male dispersal in mammals. Animal Behaviour, 30, 1183-1192.

Efron, B. 1983. Estimating the error rate of a prediction rule: improvement on crossvalidation. Journal of the American Statistical Association, 78, 316-331.

Efron, B. \& Gong, G. 1983. A leisurely look at the bootstrap, the jackknife and crossvalidation. American Statistician, 37, 36-48.

Ford, J. K. B. 1987. A catalogue of underwater calls produced by killer whales (Orcinus orca) in British Columbia. Canadian Data Report of Fisheries and Aquatic Sciences, Number 633.

Ford, J. K. B. 1989. Acoustic behavior of resident killer whales (Orcinus orca) in British Columbia. Canadian Journal of Zoology, 67, 727-745.

Ford, J. K. B. 1991. Vocal traditions among resident killer whales (Orcinus orca) in coastal waters of British Columbia. Canadian Journal of Zoology, 69, 1454-1483.

Ford, J. K. B., Ellis, G. M., and Balcomb, K. C. III. 1994. Killer Whales: the Natural History and Genealogy of Orcinus orca in British Columbia and Washington State. Vancouver: UBC Press.

Ford, J. K. B., Ellis, G. M., Barrett-Lennard, L. G., Morton, A. B., Palm, R. S., and Balcomb, K. C. III. 1998. Dietary specialization in two sympatric populations of killer whales (Orcinus orca) in coastal British Columbia and adjacent waters. 
Canadian Journal of Zoology, 76, 1456-1471.

Ford, J. K. B. and Fisher, H. D. 1982. Killer whale (Orcinus orca) dialects as an indicator of stocks in British Columbia. Report of the International Whaling Commission, 32, 671-679.

Hall, J. D. \& Johnson, C. S. 1972. Auditory thresholds of a killer whale Orcinus orca Linnaeus. Journal of the Acoustical Society of America, 51, 515-517.

Hausberger, M. 1997. Social influences on song acquisition and sharing in the European starling (Sturnus vulgaris). In: Social Influence on Vocal Development (Ed. by C.T. Snowdon \& M. Hausberger), pp. 128-156. Cambridge: Cambridge University Press.

Hoelzel, A. R. 1998. Low genetic variation among killer whales (Orcinus orca) in the Eastern North Pacific and genetic differentiation between foraging specialists. Heredity, 89, 121-128.

Hoelzel, A. R. \& Osborne, R. W. 1986. Killer whale call characteristics: implications for cooperative foraging strategies. In: Behavioral Biology of Killer Whales (Ed. by B. C. Kirkevold \& J. S. Lockard), pp. 373-403. New York: A. R. Liss.

Horning, C. L., Beecher, M. D., Stoddard, P. K. \& Campbell, S. E. 1993. Song perception in the song sparrow: importance of different parts of the song in song type classification. Ethology , 94, 46-58.

Hunter, M. L. Jr., Kacelnik, A., Roberts, J., \& Vuillermoz, M. 1986. Directionality of avian vocalizations: a laboratory study. Condor, 88, 371-375.

Janik, V. M. \& Slater, P. J. B. 1997. Vocal learning in mammals. Advances in the Study of Behavior, 26, 59-99.

Lachenbruch, P. A. \& Mickey, M. R. 1968. Estimation of error rates in discriminant analysis. Technometrics, 10, 1-11.

Miller, P.J. \& Tyack, P.L. 1998. A small towed beamforming array to identify vocalizing resident killer whales (Orcinus orca) concurrent with focal behavioral observations. Deep-sea Research II, 45, 1389-1405

Nichol, L. M. \& Shackleton, D. M. 1996. Seasonal movements and foraging behaviour of northern resident killer whales (Orcinus orca) in relation to the inshore 
distribution of salmon (Oncorhynchus spp.) in British Columbia. Canadian Journal of Zoology, 74, 983-991.

Norusis, M. J. 1986. Advanced Statistics with SPSS/PC+. Chicago: SPSS.

Nowicki, S. 1989. Vocal plasticity in captive black-capped chickadees: the acoustic basis and rate of call convergence. Animal Behaviour, 37, 64-73.

Olesiuk, P. F., Bigg, M. A. \& Ellis, G. M. 1990. Life history and population dynamics of resident killer whales (Orcinus orca) in the coastal waters of British Columbia and Washington State. Report of the International Whaling Commission, Sp. Issue 12, 209-243.

Rose, N. A. 1992. The social dynamics of male killer whales, Orcinus orca, in Johnstone Strait, British Columbia. Ph.D. thesis, University of California, Santa Cruz.

Schevill, W. \& Watkins, W. 1966. Sound structure and directionality in Orcinus (killer whale). Zoologica, 51, 71-76.

Slater, P. J. B. 1989. Bird song learning: causes and consequences. Ethology, Ecology and Evolution, 1, 19-46.

Slater, P. J. B., Ince, S. A., \& Colgan, P. W. 1980. Chaffinch song types: their frequencies in the population and distribution between the repertoires of different individuals. Behaviour, 75, 207-218.

Smith, H. J., Newman, J. D., Hoffman, H. J., \& Fetterly, K. 1982. Statistical discrimination among vocalizations of individual squirrel monkeys (Saimiri sciureus). Folia Primatologica, 37, 267-279.

Smolker, R.A. 1993. Acoustic communication in bottlenose dolphins. Ph.D. thesis, University of Michigan.

Snowdon, C. T. \& Hausberger, M. 1997. Introduction. In: Social Influence on Vocal Development (Ed. by C.T. Snowdon \& M. Hausberger), pp. 1-6. Cambridge: Cambridge University Press.

Steiner, W., Hain, J., Winn, H. \& Perkins, P. 1979. Vocalizations and feeding behavior of the killer whale (Orcinus orca). Journal of Mammalogy, 60, 823-827.

Symanski, M. D., Bain, D. E., Kiehl, K., Pennington, S., Wong, S., \& Henry, K. R. 1999. Killer whale (Orcinus orca) hearing: auditory brainstem response and behavioral 
audiograms. Journal of the Acoustical Society of America, 106, 1134-1141.

Waite, J. M. 1988. Alloparental care in killer whales (Orcinus orca). Master's thesis, University of California, Santa Cruz.

Watkins, W.A. 1967. The harmonic interval: fact or artifact in spectral analysis of pulse trains. In: Marine Bioacoustics. Vol. 2 (Ed. by W.N. Tavolga), pp. 15-43. New York: Pergammon Press.

Williams, J. M. and Slater, P. J. B. 1990. Modelling bird song dialects: the influence of repertoire size and numbers of neighbors. Journal of Theoretical Biology, 145, 487-496.

Zar, J. H. 1984. Biostatistical Analysis. Englewood Cliffs, New Jersey: Prentice Hall. 


\subsection{Appendix}

Table A1. Description of the numbered variables measured from each call type.

\begin{tabular}{|c|c|c|}
\hline Call type & Variable number* & Description \\
\hline \multirow[t]{18}{*}{ N1 } & 1 & SBI part 1 \\
\hline & 2 & SBI part 2 \\
\hline & 3 & Freq. HFC start part 2 \\
\hline & 4 & SBI start part 3 \\
\hline & 5 & Freq. HFC start part 3 \\
\hline & 6 & SBI peak part 3 \\
\hline & 7 & Freq. HFC peak part 3 \\
\hline & 8 & SBI middle part 3 \\
\hline & 9 & Freq. HFC middle part 3 \\
\hline & 10 & SBI end part 3 \\
\hline & 11 & Freq. start HFC \\
\hline & 12 & Time start HFC \\
\hline & 13 & Freq. $1^{\text {st }}$ turn HFC \\
\hline & 14 & Time $1^{\text {st }}$ turn HFC \\
\hline & 15 & Freq. $2^{\text {nd }}$ turn HFC \\
\hline & 16 & Time $2^{\text {nd }}$ turn HFC \\
\hline & 17 & Freq. end HFC \\
\hline & 18 & Time end HFC \\
\hline \multirow[t]{17}{*}{$\mathrm{N} 2$} & 1 & SBI part 1 \\
\hline & 2 & SBI end part 1 \\
\hline & 3 & Freq. HFC end part 1 \\
\hline & 4 & SBI peak part 2 \\
\hline & 5 & Time peak part 2 \\
\hline & 6 & Freq. HFC peak part 2 \\
\hline & 7 & SBI end part 2 \\
\hline & 8 & Freq. end part 2 \\
\hline & 9 & SBI $(x 2)$ end LFC \\
\hline & 10 & Freq. start HFC \\
\hline & 11 & Time start HFC \\
\hline & 12 & Freq. $1^{\text {st }}$ turn HFC \\
\hline & 13 & Time $1^{s t}$ turn HFC \\
\hline & 14 & Freq. $2^{\text {nd }}$ turn HFC \\
\hline & 15 & Time $2^{\text {nd }}$ turn HFC \\
\hline & 16 & Freq. upsweep end HFC \\
\hline & 1 & SBI start part 1 \\
\hline
\end{tabular}




\section{Appendix (cont)}

Table A1 (cont)

\begin{tabular}{|c|c|c|}
\hline Call type & Variable number* & Description \\
\hline \multirow[t]{9}{*}{ N4 (cont) } & 2 & SBI peak part 1 \\
\hline & 3 & Time peak part 1 \\
\hline & 4 & Freq. HFC peak part 1 \\
\hline & 5 & SBI end part 1 \\
\hline & 6 & SBI part 2 \\
\hline & 7 & Freq. peak HFC \\
\hline & 8 & Time peak HFC \\
\hline & 9 & $\Delta \mathrm{t}$ at $320 \mathrm{~Hz}$ below peak HFC \\
\hline & 10 & Freq. end HFC \\
\hline \multirow[t]{16}{*}{ N5 } & 11 & Time end HFC \\
\hline & 12 & Freq. upsweep end HFC \\
\hline & 1 & SBI start part 1 \\
\hline & 2 & SBI middle part 1 \\
\hline & 3 & Freq. HFC middle part 1 \\
\hline & 4 & SBI end part 1 \\
\hline & 5 & $\Delta \mathrm{f} 1^{\text {st }}$ peak of $3^{\text {rd }}$ sideband \\
\hline & 6 & SBI part 2 \\
\hline & 7 & Freq. start HFC \\
\hline & 8 & Time start HFC \\
\hline & 9 & Freq. peak HFC \\
\hline & 10 & Time peak HFC \\
\hline & 11 & $\Delta \mathrm{t}$ at $560 \mathrm{~Hz}$ below peak HFC \\
\hline & 12 & Freq. turn $\mathrm{HFC}$ \\
\hline & 13 & Time turn HFC \\
\hline & 14 & Freq. end HFC \\
\hline \multirow[t]{4}{*}{ N7 } & 15 & Time end HFC \\
\hline & 16 & Freq. upsweep end HFC \\
\hline & 1 & SBI part 1 \\
\hline & 2 & SBI at parallel LFC \\
\hline \multirow[t]{6}{*}{ N9 } & 3 & Time to parallel LFC \\
\hline & 4 & Freq. HFC in part 1 \\
\hline & 1 & SBI part 1 \\
\hline & 2 & SBI part 2 \\
\hline & 3 & SBI start part 3 \\
\hline & 4 & Freq. HFC start part 3 \\
\hline
\end{tabular}




\section{Appendix (cont)}

Table A1 (cont)

\begin{tabular}{|lll|}
\hline Call type & Variable number* & Description \\
\hline N9 (cont) & 5 & SBI end part 3 \\
& 6 & Freq. HFC end part 3 \\
& 7 & SBI part 4 \\
8 & SBI (x2) end LFC \\
9 & Freq. start HFC \\
10 & Time start HFC \\
11 & Freq. peak HFC \\
12 & Time peak HFC \\
13 & Freq. turn HFC \\
14 & Time turn HFC \\
15 & Freq. end HFC \\
16 & Time end HFC \\
\hline
\end{tabular}

* See Fig. 3. 


\section{CHAPTER 3: A SMALL TOWED BEAMFORMING ARRAY TO IDENTIFY}

VOCALIZING RESIDENT KILLER WHALES (ORCINUS ORCA) CONCURRENT WITH FOCAL BEHAVIORAL OBSERVATIONS.

Reprinted from Deep-Sea Research II, Volume 45, Number 7, Patrick J. Miller and Peter L. Tyack, A small towed beamforming array to identify vocalizing resident killer whales (Orcinus orca) concurrent with focal behavioral observations. pp. 1389-1405, copyright 1998 with permission from Elsevier Science. 


\title{
A small towed beamforming array to identify vocalizing resident killer whales (Orcinus orca) concurrent with focal behavioral observations
}

\author{
Patrick J. Miller*, Peter L. Tyack \\ Biology Department, Rodfield 1-32, MS\# 34, Woods Hole Oceanographic Institution, Woods Hole \\ MA 02543, USA
}

Received 15 March 1997; received in revised form 15 September 1997; accepted 1 October 1998

\begin{abstract}
Investigations of communication systems benefit from concurrent observation of vocal and visible behaviors of individual animals. A device has been developed to identify individual vocalizing resident killer whales (Orcinus orca) during focal behavioral observations. The device consists of a 2-m, 15-element hydrophone array, which is easily towed behind a small vessel, on-board multi-channel recorders, and real-time signal processing equipment. Acoustic data from the hydrophones are digitized and processed using broadband frequency-domain beamforming to yield frequency-azimuth (FRAZ) and "directo-gram" displays of arriving sounds. Based upon statistical analysis of independent portions of typical killer whale calls, the precision of the angle-of-arrival estimate ranges from $\pm 0^{\circ}$ to $\pm 2.5^{\circ}$ with a mean precision of $\pm 1.5^{\circ}$. Echolocation clicks also are resolved precisely with a typical $-6 \mathrm{~dB}$ mainlobe width of $\pm 2.0^{\circ}$. Careful positioning of the array relative to the animals minimizes the effects of depth ambiguities and allows identification of individual sources in many circumstances. Several strategies for identifying vocalizing individuals are discussed and an example of a successful identification is described. Use of the array with resident killer whales did not interfere with vessel maneuverability, animal tracking, or behavioral sampling of focal individuals. This localization technique has promise for advancing the abilities of researchers to conduct unbiased behavioral and acoustic sampling of individual free-ranging cetaceans. (C) 1998 Elsevier Science Ltd. All rights reserved.
\end{abstract}

\section{Introduction}

In order to effectively investigate a communication system, it is necessary to observe signal production of identified animals (Marler, 1961). Terrestrial ethologists are able

*Corresponding author. Tel: (508) 289-3482; fax: (508) 457-2134; E-mail: omalley@cetacea.whoi.edu 
to localize sound in air to identifiable individuals or are able to observe motor actions indicative of sound production. In contrast, even though individuals of many cetacean species are visually identifiable (Bigg et al., 1990; IWC, 1990), ethologists studying cetacean communication face barriers to locating the source of an underwater vocalization. The human ear cannot locate underwater sounds, and cetaceans seldom show visible movements related to sound production even when they can be observed underwater. This situation has led to attempts to identify the source of a signal using many techniques, including hydrophone arrays, acoustic tags, temporary capture, and bubble stream observation (Watkins and Schevill, 1972; Speisberger and Fristrup, 1990; Tyack, 1985; Sayigh et al., 1990; Caldwell et al., 1990).

Temporary capture has been useful for recording certain vocalizations from individuals, but most ethologists would prefer to study communication in a natural context. Bubble streams concurrent with vocalizations may be effective in identifying signalers in captive settings, but it can be difficult to obtain a sufficient sample size of sounds (McCowan, 1995; Caldwell et al., 1990). Bubble streams may function as a visual signal in cetaceans (Pryor, 1991), and Caldwell et al. (1990) noted that bubble streams occur most often when a dolphin is excited and vocalizing loudly. Bubble stream techniques may, therefore, obtain a biased sample of sounds.

Acoustic tags and hydrophone arrays offer more promise for systematic identification of the source of signals in undisturbed free-ranging animals. Acoustic tags have been used to identify signalers in captive settings (Tyack, 1985; Tyack and Recchia, 1991), and have been deployed on wild elephant seals (Fletcher et al., 1996). Increased miniaturization of recording equipment and improved attachment techniques may yield identifiable recordings from relatively undisturbed free-ranging cetaceans. Nevertheless, a non-attached system for identifying signalers would have several advantages, including more flexible sampling of behavior, identification of more than one signaler, and reduced disturbance of the subjects.

Fixed hydrophone arrays have been used to localize cetacean sounds (Watkins and Schevill, 1974; Clark, 1983; Clark et al., 1986; Freitag and Tyack, 1993). While these systems often allow for precise localization of sound sources in 2 or 3 dimensions, systematic identification of signaling animals while observing surface behavior has been problematic because of difficulties integrating data from arrays with close follows of individual animals. Arrays of hydrophones that can be towed offer the potential for sound-source identification as one follows particular individuals or groups. To date, however, their use has primarily been limited to improving census estimates of animals [Leaper et al., 1992, Spikes and Clark, 1996, Fristrup and Clark, in press, but see Sayigh et al., 1993].

In this paper, we report on the design and implementation of a small towed linear array to identify vocalizing resident ${ }^{1}$ killer whales. This system incorporates several

\footnotetext{
${ }^{1}$ There are two forms of killer whales that frequent the waters off Vancouver Island, Canada: "residents" that specialize on fish prey, and "transients" that specialize on marine mammal prey (Bigg et al., 1987; cf. Baird and Dill, 1996).
} 
design goals for integrating acoustic localization with visual behavioral sampling, including:

- easy to deploy from a small vessel suitable for focal behavioral sampling,

- ability to make high-quality continuous recordings of vocal behavior while underway,

- rapid indication of the angle-of-arrival of animal sounds using beamforming. This system is designed to identify which individual produces a vocalization and to place sound production in its behavioral context. The diving behavior of resident killer whales and typical travel patterns along shorelines make it possible to use a single linear array to identify vocalizing individuals in many circumstances. While there are some aspects of this application that are particular to resident killer whales, with modest changes the system would also be useful for observing many other cetacean species.

\section{Methods}

\subsection{System design}

The system consists of a short $(\sim 2 \mathrm{~m})$ rigid linear array of 15 Benthos $^{\odot}$ AQ-2TS hydrophones, which is towed in a $10 \mathrm{~m}$ oil-filled tube at the end of a $20 \mathrm{~m}$ Cortland Cable $^{\mathfrak{O}}$ kevlar cable with fairing for vortex shedding (Fig. 1). The tube also contains custom pre-amps with $40 \mathrm{~dB}$ gain and a depth sensor. The physical structure of the array was designed for use while collecting behavioral data and for ease of repair in the field. It can be deployed and recovered manually from a small $(8-\mathrm{m})$ boat, and high-quality signals can be obtained at speeds up to $10 \mathrm{kn}(5 \mathrm{~m} / \mathrm{s})$. The array is short and rigid to provide good performance when maneuvering. The depth of the array is maintained by two lengths of heavy chain $(\sim 16 \mathrm{~kg}$. each) attached to the kevlar cable. The array maintains a steady depth of approximately $5 \mathrm{~m}$ at speeds from $0.5-3.0 \mathrm{kn}$ $(0.25-1.50 \mathrm{~m} / \mathrm{s})$, and decreases with increasing speed.

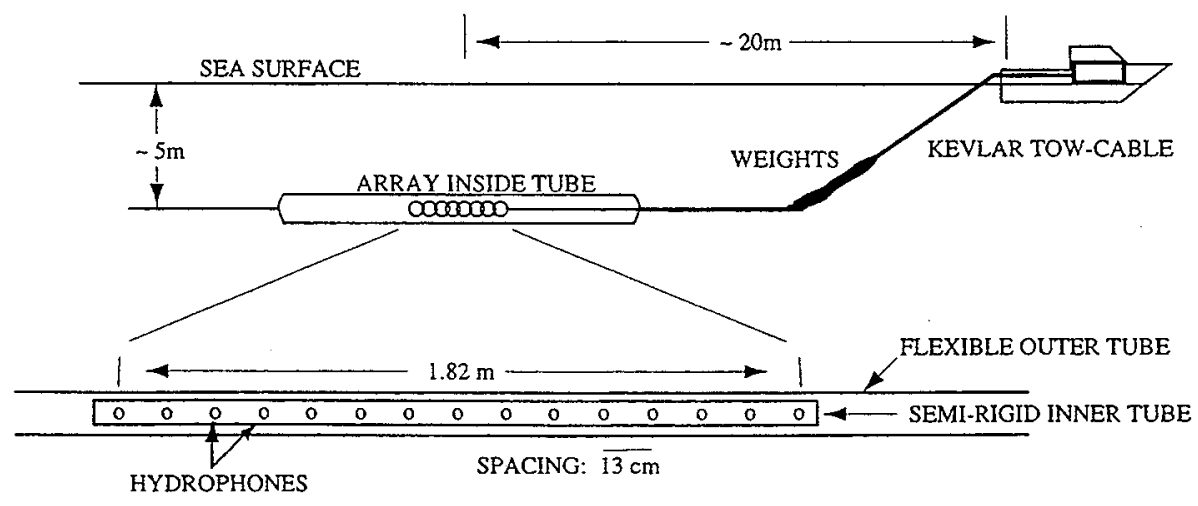

Fig. 1. System dimensions and design. 


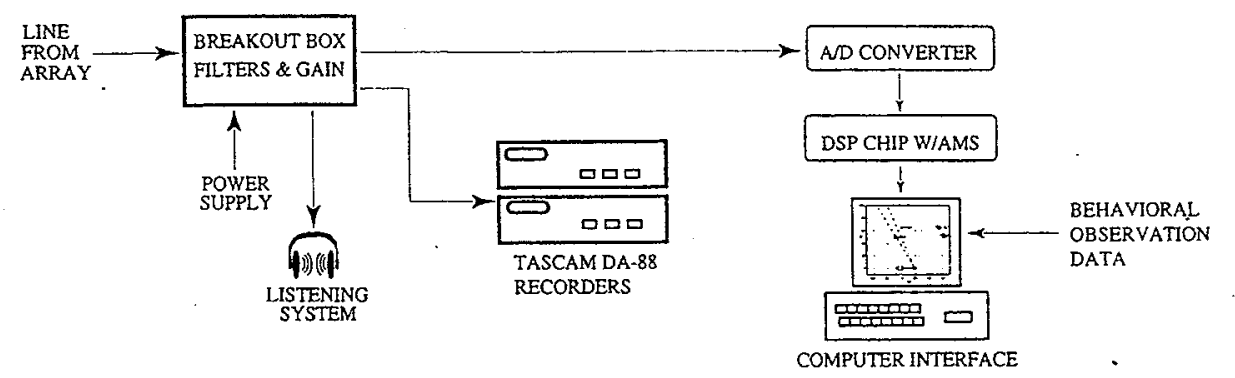

Fig. 2. On-board recording and real-time analysis system.

The signal from each hydrophone is fed into a separate channel of a pair of Tascam ${ }^{\circ}$ DA-88 8-track digital recorders, an audio listening system, and a computer acquisition system for real-time analysis (Fig. 2). The 16-bit (96 dB dynamic range) digital recorders have a flat response from $10 \mathrm{~Hz}-22 \mathrm{kHz}$, with $8 \mathrm{x}$ over-sampling for linear-phase digital anti-alias filtering. The simultaneous-sample-and-hold A/D converters are synched within and between units, and have a measured phase shift of $<0.2^{\circ}$ at $10 \mathrm{kHz}$ across all channels. The sounds recorded on the DA-88's can be downloaded digitally using a precision conversion system which maintains the channel synchronization on a sample-by-sample basis across both recorders.

Real-time data acquisition hardware consists of a WHOI-designed 16-channel audio rate $\mathrm{A} / \mathrm{D}$ converter and a high-performance digital signal processor board (Texas Instruments ${ }^{\mathscr{O}}$ : TMS320c40). An extensive real-time software environment (AMS) is used to control the processor board (Grund and Johnson, 1995). A local network allows for integration of acoustic data processed on the board and sightings data from observers, with data logging capabilities. A LINUX workstation is used as a graphical user interface to control signal processing parameters and display data.

\subsection{Broad-band frequency-domain beamforming algorithm}

Sounds are analyzed to identify the angle-of-arrival of sounds on the array using a broadband, frequency-domain beamforming algorithm. Frequency-domain beamforming is equivalent to electronically "looking" in a particular direction, at a particular frequency, and measuring how much energy is coming from that direction and frequency. A sound from a particular direction has a phase shift from one sensor to the next depending on the angle of arrival and the frequency of the sound. By subtracting the phase shift and summing energy across the array, we calculate the amount of energy arriving from that direction at that frequency (Johnson and Dudgeon, 1993).

The expected phase shifts based upon the angle of arrival $(\theta)$ on the array of a signal at a particular frequency can be mathematically represented by "steering vectors". In the frequency-domain, multiplying the array data with the steering vectors effectively performs the time-domain subtraction of the phase-shifts required for beamforming. The equation for a steering vector $\mathrm{e}$ for a plane wave at a given frequency bin $(f)$ and 
angle of arrival $(\theta)$ is

$$
\mathrm{e}_{f, \theta}=\exp \left(-\mathrm{i} \frac{2 \pi}{\mathrm{sr}}\left[f \frac{\sin (\theta) \mathbf{x}}{c}\right]\right)
$$

where exp is the natural exponent, $\mathrm{i}$ is $\sqrt{-1}$, sr is the sampling rate $(\mathrm{Hz}), f$ is the frequency bin $(\mathrm{Hz}), \theta$ is the angle of arrival where $0^{\circ}$ is broadside to the array, $\mathbf{x}$ is the vector of sensor locations, and $c$ is the speed of sound. The bracketed terms [ $]$ in the exponent mathematically describe the phase shifts across the array at angle $\theta$ and frequency $f$, and $2 \pi f /$ sr is equivalent to $\omega$ as described in Johnson and Dudgeon (1993, p. 135; see Oppenheim et al., 1983, p. 25).

The $n$ channels of array data $\left[y_{1}(t), \ldots, y_{n}(t)\right]$ are windowed using a Hamming window and transformed into the frequency domain using a Fast Fourier Transform (FFT). Only the positive frequency values of the FFT are used. The values from one frequency bin $(f)$ across the array are arranged into a vector: $\mathbf{Y}(t, f)$, where $t$ refers to the time index of the FFT block. These values are then windowed using a Hamming window:

$$
\mathrm{WY}=\left[\begin{array}{c}
w_{1} Y_{1}(t, f) \\
w_{2} Y_{2}(t, f) \\
\vdots \\
w_{n} Y_{n}(t, f)
\end{array}\right]
$$

Windowing the array has an analogous effect to windowing a time series prior to Fourier analysis in reducing sidelobe height at the cost of increasing mainlobe width (Johnson and Dudgeon, 1993).

The windowed FFT values across the array (WY) are then multiplied by the steering vectors (e) and summed (the inner product). The steered response power at each $\theta$ and $f$ is calculated by multiplying $\mathbf{e}^{\prime} \mathbf{W Y}$ with its conjugate transpose (Johnson and Dudgeon, 1993):

$$
\mathbf{P}_{j, \theta}=\mathbf{e}^{\prime} \mathbf{W Y Y} \mathbf{Y}^{\prime} \mathbf{W}^{\prime} \mathbf{e}
$$

By steering across all angles for each frequency bin, the output of the beamforming algorithm is power at each angle for each frequency, which can easily be displayed as a frequency-azimuth (FRAZ) plot. Power arriving as a function of angle is calculated by summing across all of the frequencies for each angle, giving the steered response power for each FFT block. The steered response power can be displayed versus time as a "directo-gram". Angle-of-arrival estimates from independent portions of a call can be compared to obtain the variance of the angle-of-arrival estimate, giving a statistical measure of precision. With short sounds such as echolocation clicks, the width of the mainlobe of the steered response power at $-6 \mathrm{~dB}$ from the peak is a common measure of precision (Johnson and Dudgeon, 1993).

\subsection{Integration of visual and acoustic observations}

The results from the beamformer must be combined with visual observations to identify which animal made the sound. The position of surfacing animals relative to 
the array can be accurately determined by measuring the distance and angle of the animal relative to the boat using a Bushnel1 ${ }^{\oplus}$ laser range-finder and a $\mathrm{KVH}^{\mathrm{T}}$ digital hand-held compass. Animals are only visible when they come to the surface to breathe, so locations between surfacings must be estimated. This estimation is made by interpolation of the positions of the surfacings preceding and following the sound(s), with the possible addition of a correction factor to account for the depth of the animal.

Because the hydrophone array is parallel to the surface of the water, sounds arriving from an animal at depth will come from an angle closer to broadside than would be predicted from the 2-D position of the animal. This change in angle as a function of depth $\left(\delta \theta_{\mathbf{d}}\right)$ approaches zero when the animal's position is close to broadside of the array, but increases when the animal is further from broadside (Fig 3). The magnitude of $\delta \theta_{\mathrm{d}}$ is also dependent on the depth of the whale and the distance from the array to the surface projection of the whale's location.

In time-depth recorder (TDR) studies of resident killer whale diving behavior, Baird (1994) found that dives of one minute or less (short dives) never exceeded $20 \mathrm{~m}$ depth. Because the short dives of resident killer whales have a repetitive time-depth relationship (Baird, 1994), it is possible to improve the accuracy of the predicted animal location by estimating the depth of the animal at the time of the vocalization by comparison to TDR records of animal dives. This depth estimate allows a prediction of $\delta \theta_{\mathrm{d}}$, which can be used as a correction factor to the predicted angle of the animal. Interestingly, an estimated track of the depth of a diving animal may be obtainable when the animal produces a continuous series of sounds, such as echolocation clicks. This can be achieved using a model to simultaneously estimate depth and angle constrained by TDR records, surface sightings and angle-of-arrival data of sounds from the diving whale.

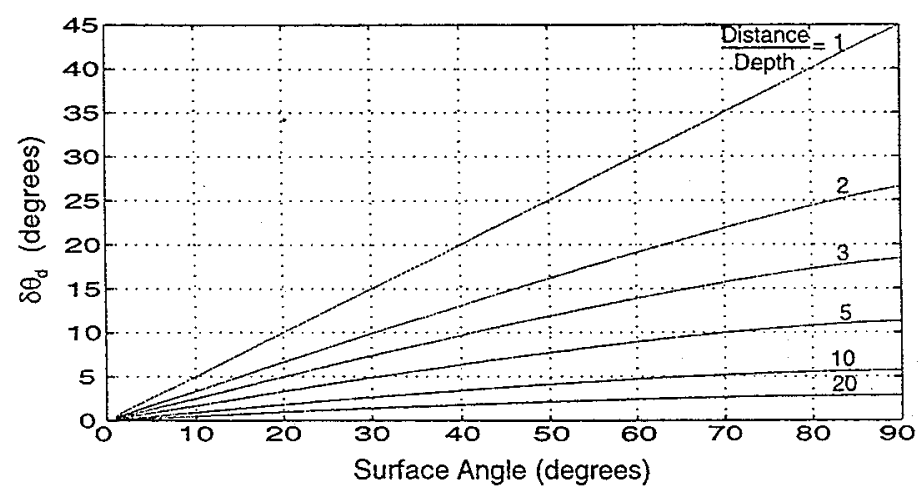

Fig. 3. The change toward broadside $\left(\delta \theta_{\mathrm{d}}\right)$ of the angle of arrival of a sound from an animal at depth. $0^{\circ}$ is directly broadside to the array, and the surface angle is either forward or astern of broadside. As the angle of the animal increases away from broadside, the effect of depth on the perceived angle of arrival becomes more severe. Axes to scale. 
In order to minimize the magnitude of $\delta \theta_{\mathrm{d}}$, it is desirable to position the boat such that the focal animal is about $100 \mathrm{~m}$ away, between $\pm 30^{\circ}$ of broadside to the hydrophone array. An animal at this position diving to $20 \mathrm{~m}$ depth would result in a maximum $\delta \theta_{\mathrm{d}}$ of $<5^{\circ}$. If the range to the whale was $15 \mathrm{~m}$, then the maximum $\delta \theta_{\mathrm{d}}$ would be about $15^{\circ}$, which is undesirably large. A broadside position and $100 \mathrm{~m}$ distance is ideal therefore to minimize $\delta \theta_{\mathrm{d}}$ while still maintaining the ability to identify the focal animal and observe its behaviors. The boat should also be positioned to place all animals on one side to eliminate the left-right ambiguity of the linear hydrophone array. Finally, when attempting to identify sources of sounds it is critical that the boat be steered in a straight line so that the orientation of the array matches that of the heading of the vessel as closely as possible.

Some of the strategies for positioning the hydrophone array relative to the whales include parallel travel with animals spaced in the direction of travel (Fig. 4A) and slow
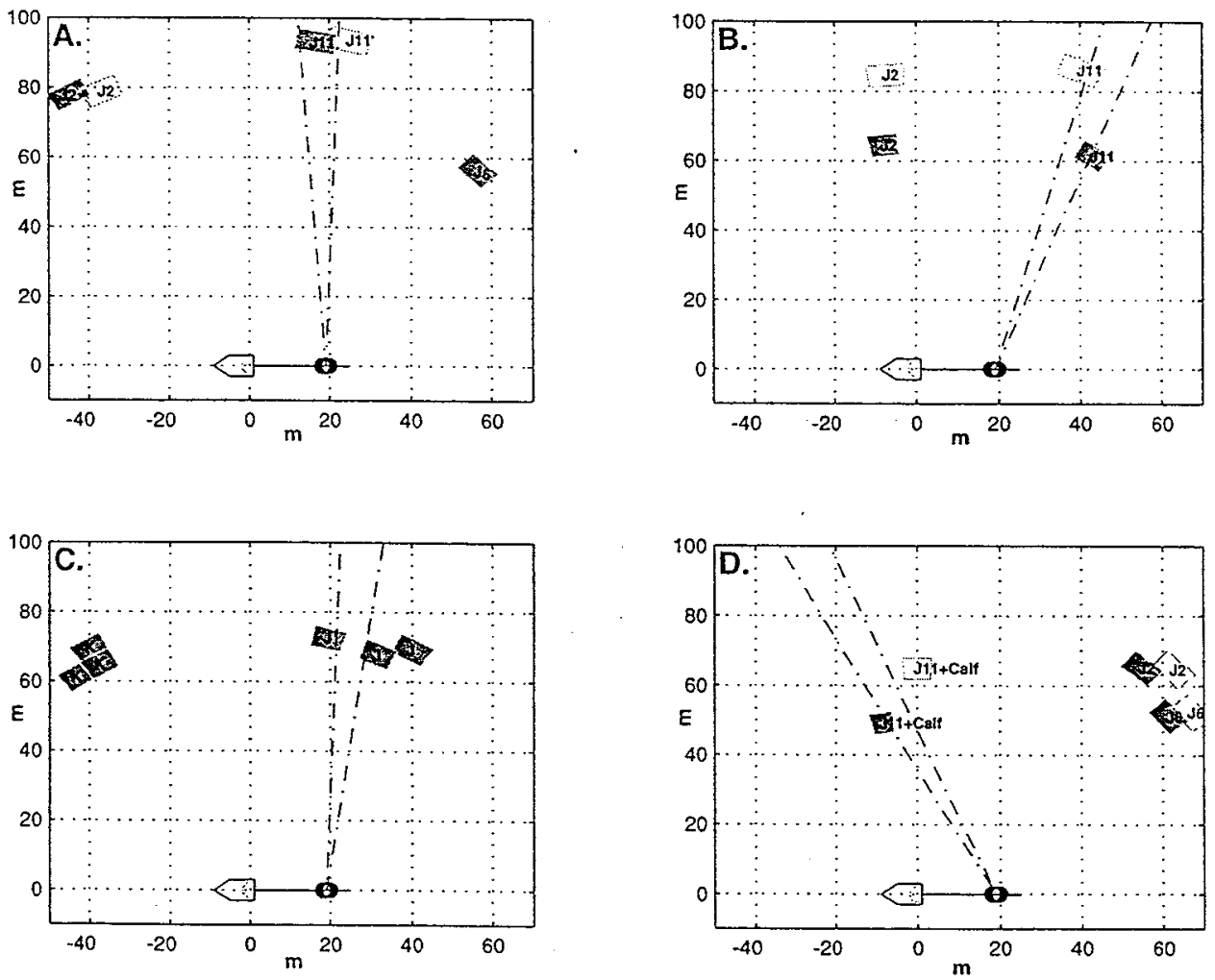

Fig. 4. Some strategies for positioning the boat to identify the individual or group which made a vocalization. Open shapes represent the location of the surfacing prior to the vocalization, while solid shapes represent the location of the whale surfacing following the vocalization. The whale locations are based upon sightings from the back of the boat with $\pm 3^{\circ}$ angle accuracy and $\pm 3 \mathrm{~m}$ distance accuracy. The angle of arrival is based upon an accuracy of $\pm 3^{\circ}$ (A) Whales individually separated in the direction of travel; (B) whales individually separated across the direction of travel; (C) two pods travelling near each other; (D) mother-calf pair separated from the rest of the pod. See text for further explanation. 
passes in front of animals spaced perpendicular to the direction of travel (Fig. 4B). The former is the preferred method to obtain focal behavioral observations simultaneous with sounds; and in this case, identification of the caller is possible only when the animals are spaced in the direction of travel. Slow passes in front of animals are useful for obtaining sounds directly in front of an animal. Even if animals are too closely spaced to identify the source, it is still possible to ascribe sounds to a group of animals. This can be useful for resolving vocalizations from subgroups such as different pods travelling together (Fig. 4C) and mother-calf groups (Fig. 4D).

\subsection{In-situ calibration}

Because several variables required by this method are estimated, i.e. the speed of sound and the underwater orientation of the array, it is important to calibrate the angle-of-arrival estimate with a sound source at a known or easily measured location. One of the main goals of calibration is to measure and correct for any consistent bias in the orientation of the array while driving straight. A convenient sound emanates from the ship's propeller, which should arrive at a consistent angle on the array (after correcting for $\delta \theta_{\mathrm{d}}$ ). Use of a sound projector that has a calibrated source level is particularly useful for measuring the sensitivity of each hydrophone in-situ, and to measure any directional effects the array system has on sounds arriving from different angles.

\section{Results}

The system was deployed in the summer of 1996 as part of the marine mammal monitoring component of the Haro Strait Frontal Dynamics Experiment. A $9 \mathrm{~m}$ vessel was used to deploy the array and monitor the behavior and travel patterns of resident killer whales. The concurrent behavioral observations were designed to detect changes in behavior as a consequence of underwater sounds used in the experiment (Miller, 1996; Miller and Willis, 1997).

Throughout the monitoring period, we collected $14330 \mathrm{~min}$ focal sessions and tracked animals for $183 \mathrm{~h}$ on $47 \mathrm{~d}$ of whale encounters. We obtained acoustic recordings of killer whales sounds for $15 \mathrm{~h}$ over $10 \mathrm{~d}$ with no impact on our ability to collect behavioral data. As the behavioral sampling protocol was not designed to collect acoustic data, we sought to position the focal animal at $+15^{\circ}$ of broadside at distances between $50-130 \mathrm{~m}$. This position was successfully maintained throughout the sampling period (Fig. 5). This result strongly suggests that it is generally possible to position the boat in an ideal fashion for both behavior and/or acoustical observation of a focal animal.

Broadband FRAZ analysis of killer whale social calls recorded on the array was effective for resolving their angle of arrival (Fig 6). The broad peaks of the lowfrequency components of the call $(A)$ are vertically aligned with the narrower peaks of the high-frequency components of the call $(B)$. Grating lobes $(C)$ appear when the spatial sampling by an array is fewer than 2 sensors per wavelength, analogous to 

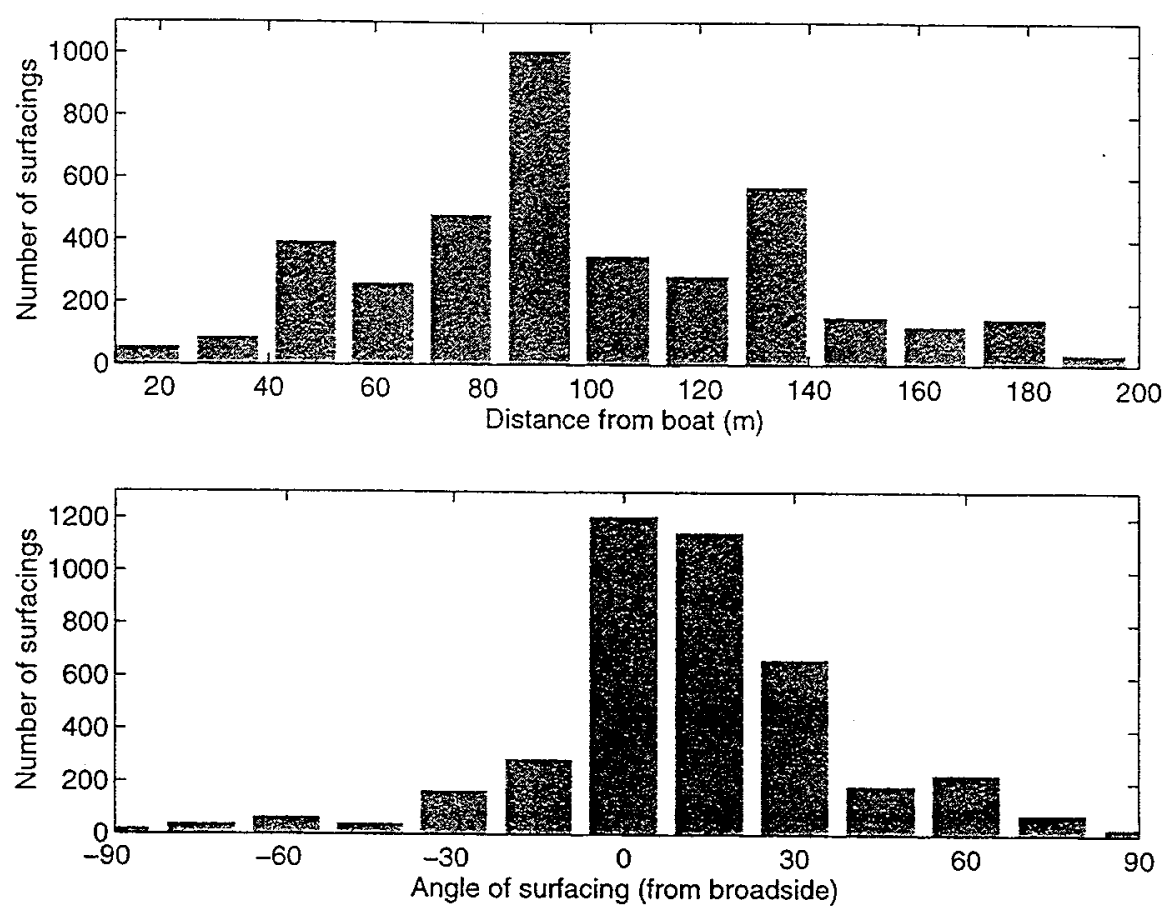

Fig. 5. Top: histogram of the distance from the boat to whale surfacing locations. Bottom: histogram of the angle of whale surfacings relative to the boat, where 0 refers to directly broadside the boat.

aliasing a time signal when digitally sampling at a rate less than twice the frequency of interest (Oppenheim et al., 1983). With narrow-band sounds, grating lobes are indistinguishable from the true peak, but the presence of the unambiguous low-frequency peaks allows selection of the correct set of high-resolution, high-frequency peaks.

Examination of the steered response power from independent FFT blocks from the same call shows that a consistent, precise estimate of the angle of arrival can be obtained by searching for peak power versus angle (Fig. 7). Confidence intervals of the angle of arrival can be generated using the variance of the peaks around the mean of the peaks. In Fig. 7, the standard deviation of the peaks is 0.4268 , which is equivalent to a $95 \%$ confidence interval of about $\pm 0.9^{\circ}$. We measured the $95 \%$ confidence interval of the angle of arrival for a sample of killer whale calls which was representative for signal-to-noise ratio (SNR) and bandwidth. The 95\% confidence interval ranged from $\pm 0^{\circ}$ to $\pm 2.5^{\circ}$, with a mean of $\pm 1.5^{\circ}(\mathrm{n}=11)$, and decreased with higher SNR and higher call bandwidth as is predicted by theory (Johnson and Dudgeon, 1993).

The broadband nature of echolocation clicks also allows us to solve for a precise angle of arrival, even though the grating lobes are more severe (Fig. 8). In the FRAZ display, only the mainlobe is linearly vertical, while the grating lobes are curved outwards. The steered response power of echolocation clicks have an unambiguous 


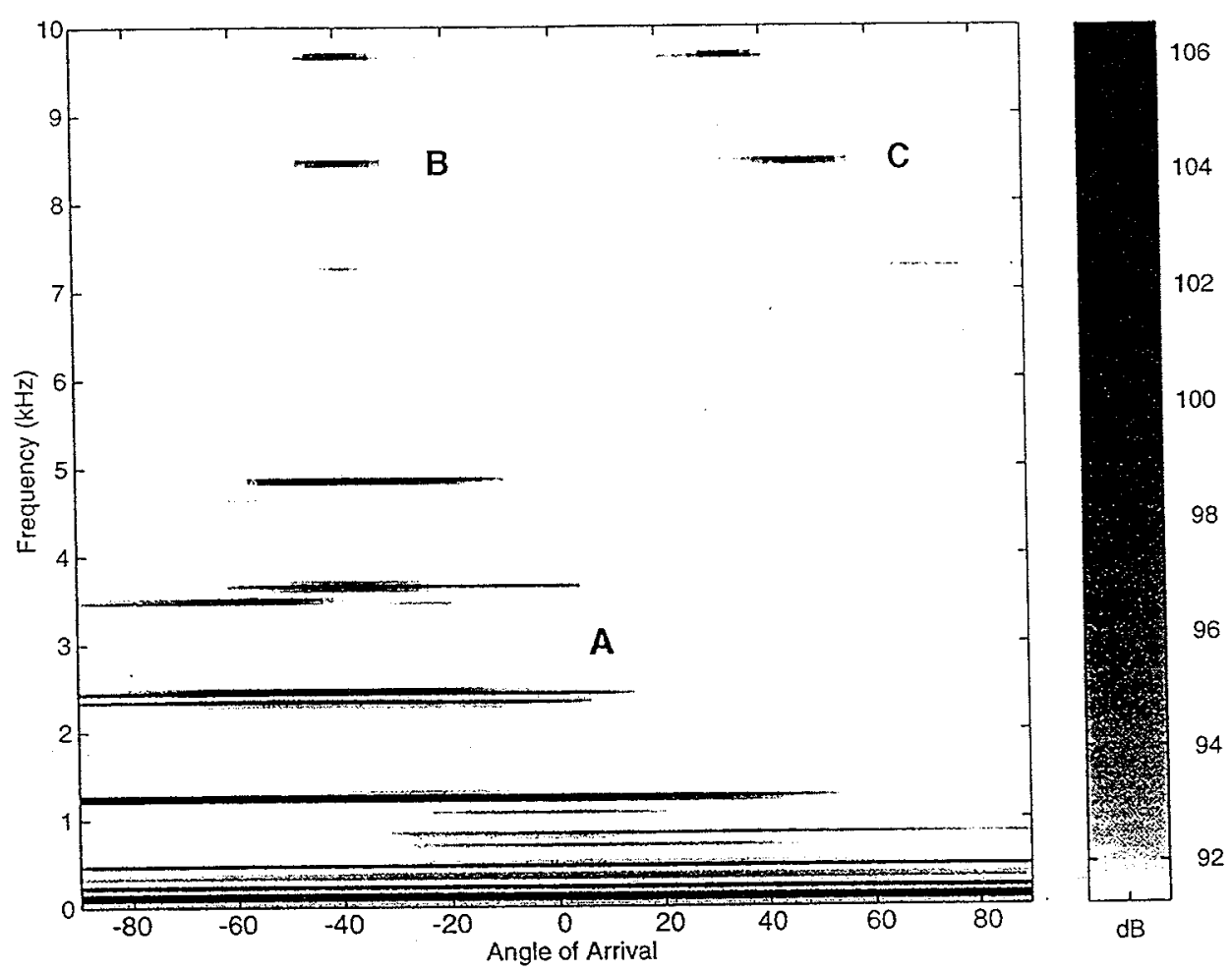

Fig. 6. Frequency-Azimuth (FRAZ) display of a killer whale call. The low-frequency components of the call (A) give broad peaks centered on the angle of arrival. At higher frequencies, the width of the peaks (B) decreases due to the decrease in the size of the wavelength relative to the hydrophone separations. Above $7 \mathrm{kHz}$, we observe the appearance of grating lobes (C). Grating lobes appear when the spatial sampling by an array is fewer than 2 sensors per wavelength. The levels reported are based on system component calibration and are accurate to $\pm 5 \mathrm{~dB}$. See text for further explanation.

peak at the true arrival because the power in the true arrival sums into the same angle bins, while the grating lobes are spread over many bins. Peaks in the steered response power of echolocation clicks are very narrow, with a typical $-6 \mathrm{~dB}$ mainlobe width of $\pm 2.0^{\circ}$ and a deep trough on both sides of the mainlobe (Fig 8, bottom).

One whale observation session will be described as an example of our ability to simultaneously observe the acoustic and surface behavior of animals, and to identify sources of vocalizations. On 21 July, 1996, we followed a group of animals as they traveled north of San Juan Island, WA. During this track we conducted three $30 \mathrm{~min}$ focal observation sessions on a particular individual whale-J11, a 24 y old female with a one-year-old calf. During these sessions we recorded: the time, distance, and bearing of each surfacing of $\mathrm{J} 11$; the number of calf surfacings; $\mathrm{J} 11$-calf distance; and an index of $J 11$-calf synchrony at surfacing. Scan data taken every five minutes during the focal session recorded the number of animals within 20 and $100 \mathrm{~m}$ of $\mathrm{J} 11$, and information on the number and movement patterns of boats near the focal animal. 


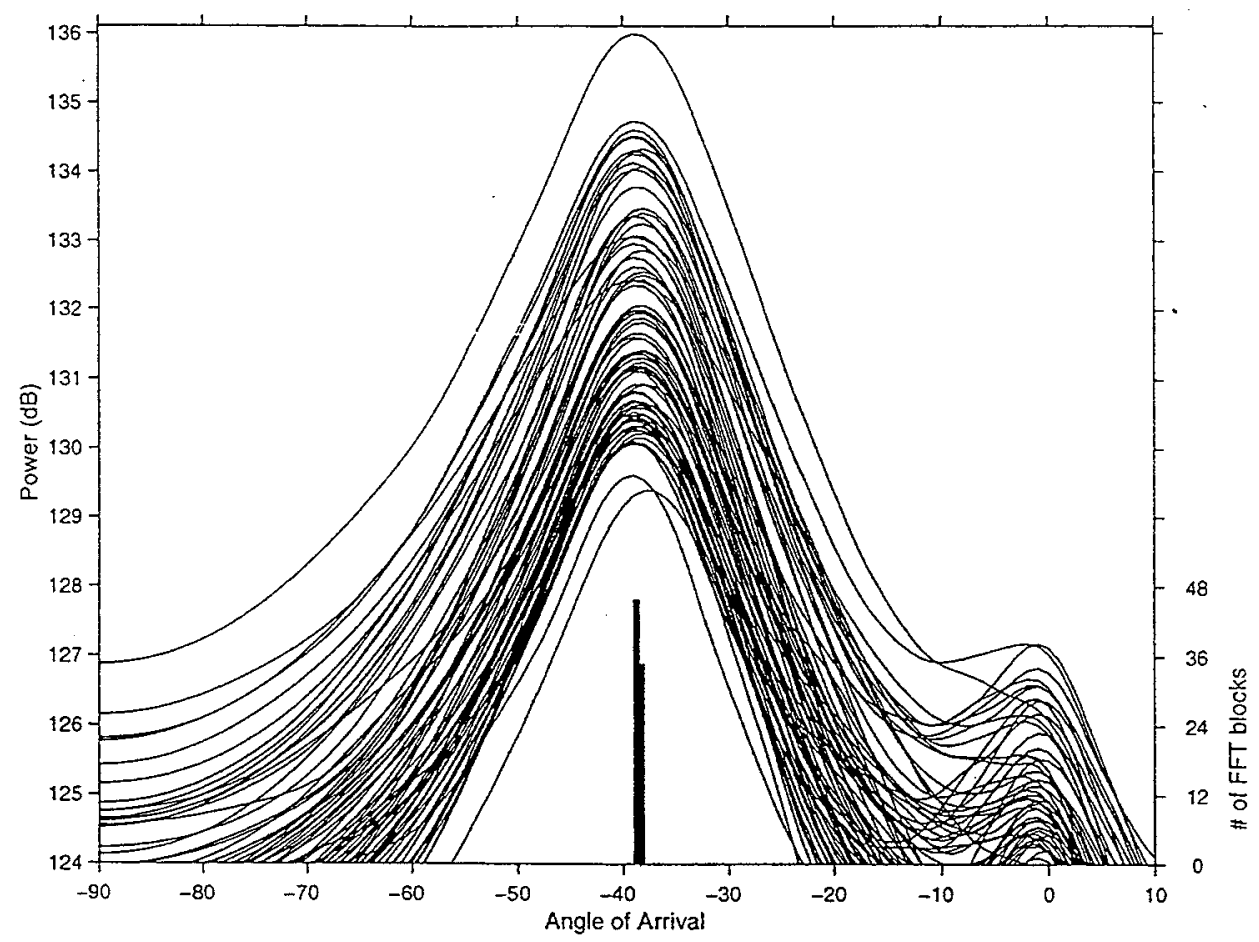

Fig. 7. Steered response power from independent blocks of a killer whale call with a histogram of the peaks of the steered response power. Each steered response power was calculated from $10.75 \mathrm{~ms}$ of sound data. Note the consistency of the peaks.

Respiration and mother-calf distance data from the final observation session are shown in the top part of Fig. 9. The middle part of Fig. 9 shows a subset of the data with a spectrogram of concurrent recordings from the hydrophone array, and the bottom part shows a "directo-gram" of the sounds. Inspection of the three calls centered around the last surfacing of the focal (from 15-20 s) shows that they are different call types (Ford, 1987). The angle of arrival for these three calls shows that the first two calls appear to come from approximately $-37^{\circ}$, while the third call came from $+38^{\circ}$. The angle of arrival of the third call is consistent with the position of J11 and her calf (Fig 10, lower right). Because of the nature of the behavioral sampling in this study, we did not obtain positions for animals other than the focal and therefore cannot identify the source animal(s) for previous two calls.

\section{Discussion}

Modern ethological methods for sampling animal behavior require unbiased recording of behaviors and identification of which individual produces each behavior. 

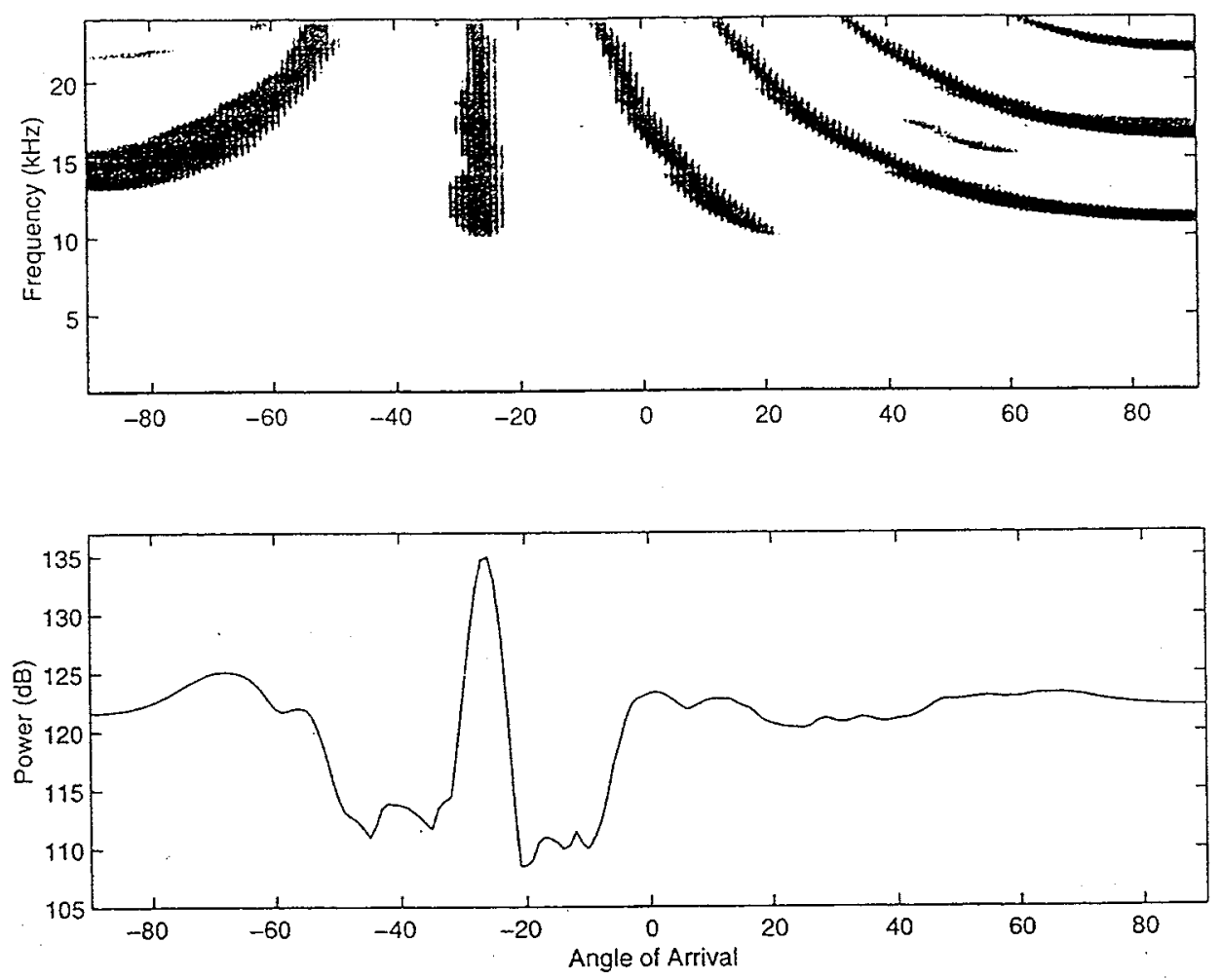

Fig. 8. Top: FRAZ display of a killer whale echolocation click. Note the vertical structure of the mainlobe versus the curved structure of the grating lobes. Bottom: Steered response power calculated from the FRAZ display above. Note the clear peak aligned with the mainlobe and the deep troughs next to the peak.

Marine mammals spend most of their time out of view, and surface behavior may not be indicative of behavior at depth. On the other hand it is easy to obtain a complete and unbiased recording of vocal behavior of marine mammal groups at sea, because sound travels so well in seawater. However, marine ethologists can seldom identify which individual is making a call in the wild (for exceptions, see Clark, 1983; Tyack, 1981; Dudzinski et al., 1995; Janik and Slater, 1995). It has even occasionally been difficult to verify species identification, since a boat following one species also may be hearing another species vocalizing far away.

Precise resolution of the angle of arrival of sounds after in-situ calibration combined with careful positioning of the hydrophone array to reduce depth uncertainties allows identification of the source of vocalizations in many situations using our system. Killer whales spaced 2 body lengths $(\sim 20 \mathrm{~m})$ apart at $100 \mathrm{~m}$ distance from the array provide roughly $11^{\circ}$ azimuthal separation, which is sufficient to confidently identify sources. Such separations are regularly observed in killer whales during many behaviors, and much greater separations are common. 

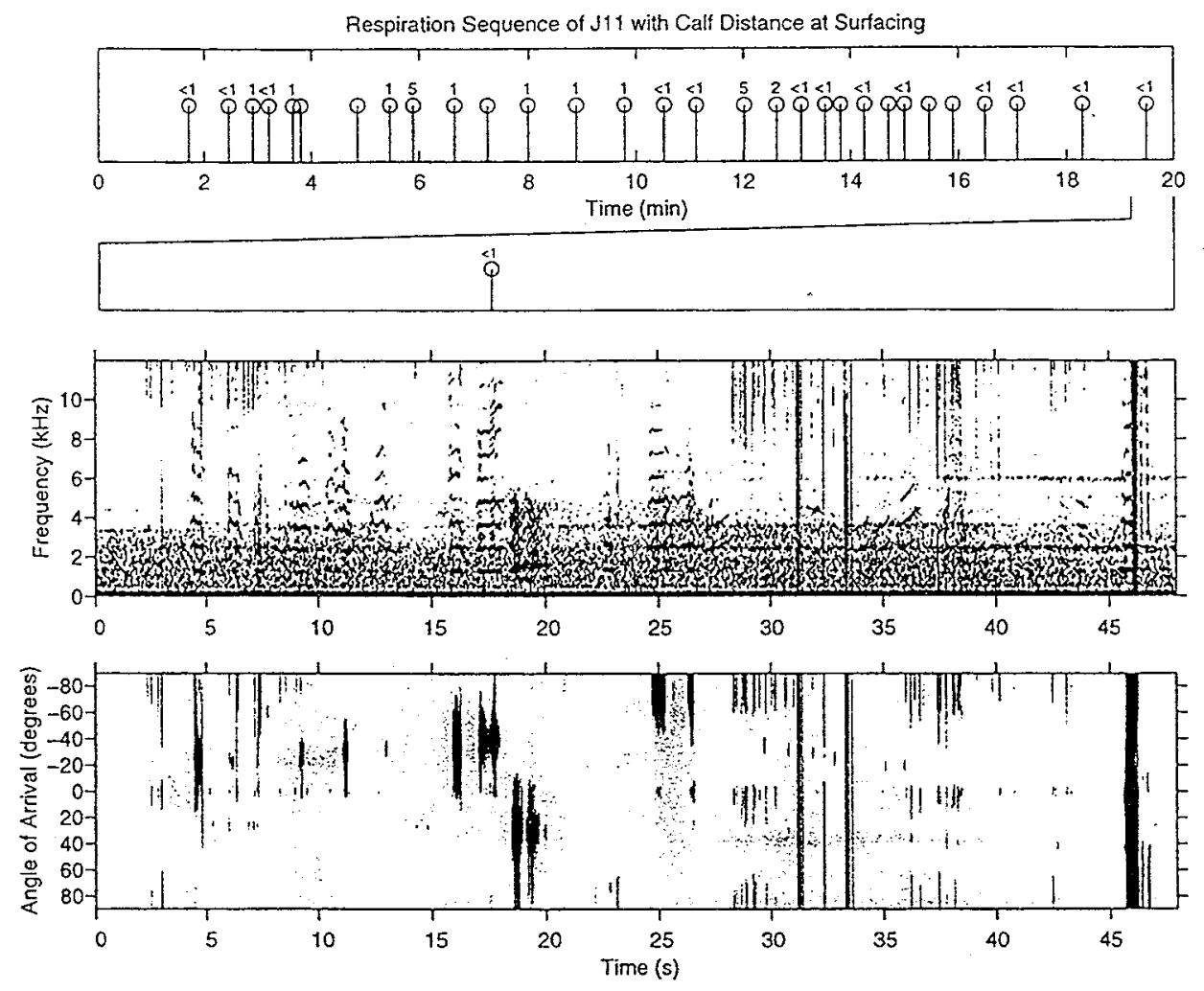

Fig. 9. Top: $20 \mathrm{~min}$ respiration sequence of $J 11$ with calf distance. Middle: spectrogram of sounds received on the array concurrent with the final $48 \mathrm{~s}$ of behavioral observations. Analyzing filter bandwidth is 93.75 Hz. Bottom: synchronous "directo-gram" of the killer whale sounds.

There has been recent success at applying focal animal sampling techniques (Altmann, 1974) for visible behaviors and associations of marine mammals in captivity (Samuels and Gifford, 1997) and in the wild (e.g. Waite, 1988; Rose, 1992; Smolker et al., 1993). Baird (1994) argues that visual observations can detect nearly every prey capture by transient killer whales, which enables all-event sampling. He also has used tagging to track the behavior of individual whales at depth. Our beamformer array is designed to integrate identified vocalizations with visual sampling of behavior and grouping patterns during follows of individual animals. It enables systematic identification of which individual produces a vocalization unless a call comes from an individual within a closely spaced group.

Terrestrial ethologists also face problems identifying calls from within close groups, and tags are a generally effective tool for solving this problem (Gautier and GautierHion, 1989). The towed-array method has considerable synergy with tagging techniques, especially to identify sounds from closely spaced animals. Attachment of TDR 

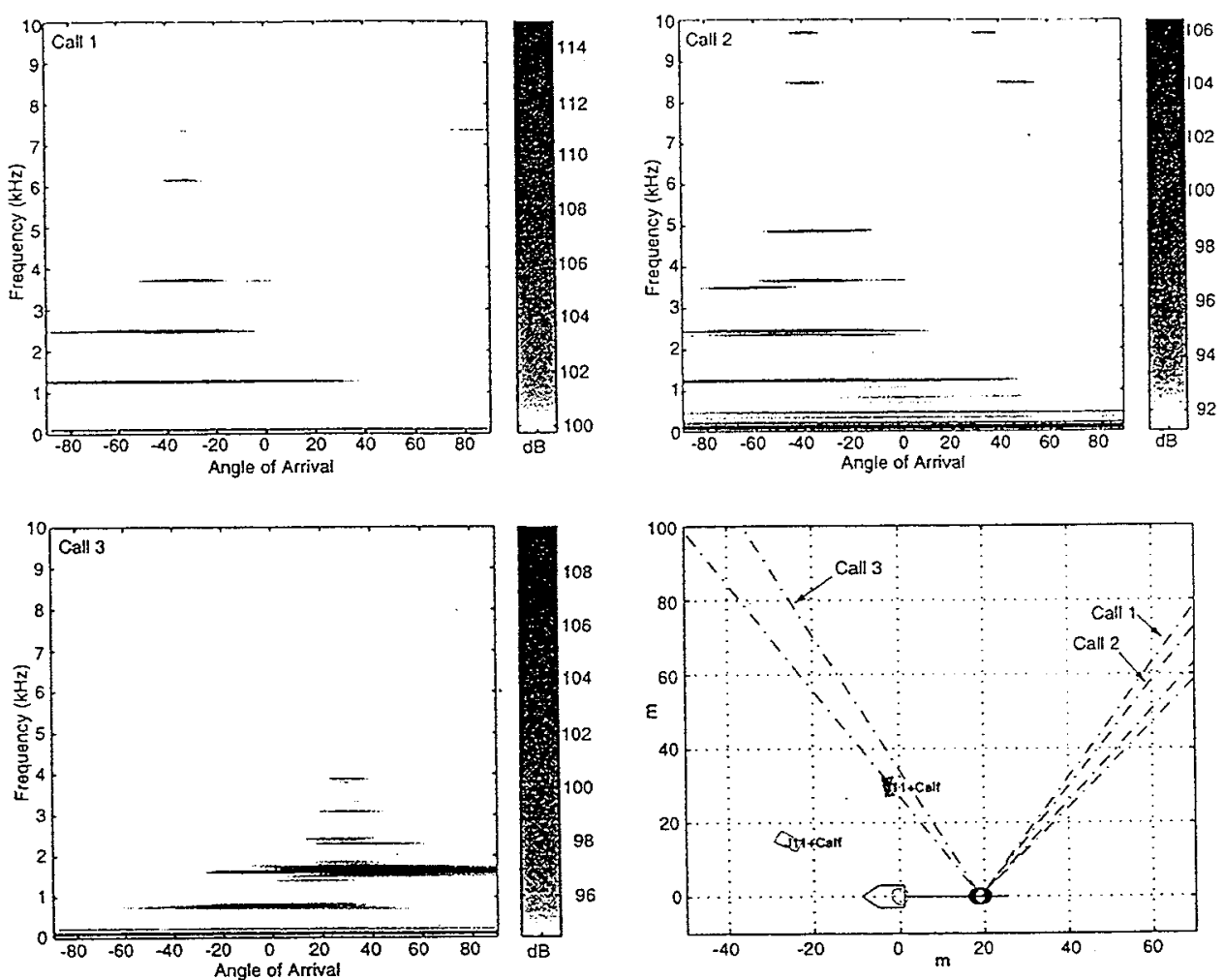

Fig. 10. FRAZ displays of the three calls centered around the last surfacing of $\mathrm{J} 11$. The box in the lower-right integrates the positions of the surfacings of $\mathrm{J} 11$ and her calf taken from the boat with the angle of arrival solution of the three calls. Accuracy parameters are the same as those in Fig. 4.

tags to whales provides a means to test algorithms for estimating the interaction between depth and azimuth in the passive beamformer. Transponder tags may be particularly well suited to track the three-dimensional movements of individuals. Acoustic transponders provide precise estimates of range, which is otherwise difficult to obtain from a linear array, and can be designed to telemeter depth measured with a pressure transducer (Watkins et al., 1993). The beamformer array can be used as a receiver for such a transponder tag, capable of estimating azimuth, with the added benefit of considerable array gain.

Other ways to improve our ability to identify which individual is vocalizing include overhead video recording and real-time display of the angle of arrival. Nowacek et al. (1995) used a remote video camera tethered to a large balloon to follow killer whales below the surface of the water, sometimes for the entire interval between surfacings. This ability to continuously observe whale orientation relative to the array will allow precise coordination of visual and acoustic data and is well suited for detailed analysis after the data has been collected. It may even be possible to investigate the 
transmission beam-pattern of free-ranging animals using this method. An alternative approach takes advantage of the field observers' sense of how animals are distributed by displaying angle of arrival data in real-time in the field. Unlike many current acoustic location systems, which may take over a minute to obtain a location, our system is designed for immediate and automatic localization, similar to what our natural hearing abilities achieve when we are following a terrestrial animal.

While a beamformer using a single linear array is well suited to estimating azimuth, it is less able to estimate range or depth of a sound source. There are several possible approaches to improving the estimation of range and depth of a sound source. Integration of data from several hydrophone arrays can allow triangulation of the source, as long as the inter-array configuration is measured with appropriate navigational fixes. A variety of deployment scenarios are possible:

- One vessel could tow two collinear arrays to increase the inter-array aperture.

- Two boats towing an array could maneuver around whales in order to optimize triangulation.

- A separate vessel could deploy a vertical array in front of the travelling whales.

A single strategically placed hydrophone could improve estimation of range, using time of arrival differences with respect to the array. Analysis of propagation effects, such as comparison of the time or angle of arrival of the direct path and the surface echo, may also be helpful for estimating depth.

Identification of vocalizing individuals will allow for more systematic investigations of killer whale communication systems, including exploration of mechanisms leading to the development of dialects and individual-specific characteristics in calls (Ford, 1991). Studies of killer whale calling behavior suggest that there are patterns in the series of call types produced (Ford, 1989). We will investigate whether these patterns are based on intra-group coordination of sound production or production by an individual animal. In addition, we will use this system to study acoustic and/or behavioral responses of cetaceans to anthropogenic noise and to identify and directly measure received levels of noise sources.

\section{Acknowledgements}

We are especially grateful to Pamela Willis for her help with data collection, manuscript review and figure preparation. David Bain, Fabrizio Borsani, Robert Catalano of Benthos, Inc., Kurt Fristrup, Matt Grund, Mark Johnson, Keith von der Heydt, and William Watkins gave invaluable advice for system design considerations. Thanks to Robin Baird for discussing the implications of his killer whale dive data. Thanks to Judy Kleindinst, Melissa Dolan, Nicole Angiel, Nicole Prodoehl, Stacy Morris, Lauren Kuhn, Liz Pomfret, Paul Macoun, Rebecca Thomas, Marm Kilpatrick, and Doug Nowacek for their assistance in the field. Kurt Fristrup and two anonymous reviewers made many helpful comments on earlier versions of this paper. Thanks to the US Bureau of Land Management for allowing us to use the Turn Point Research Station. Richard Osborne and The Whale Museum provided logistic 
support. Roche Harbor Resort gave us moorage, electricity, and fun. Seacoast Expeditions Ltd. (Victoria, B.C.) helped us find the whales. P. Miller was supported by an NSF Graduate Fellowship. This project received funds from WHOI's Coastal Research Center and grant \# CC-S-611002-001-C from the Office of Naval Research. This is contribution \#9438 of the Woods Hole Oceanographic Institution.

\section{References}

Altmann, J., 1974. Observational study of behavior: sampling methods. Behaviour 49, 227-267.

Baird, R.W., 1994. Foraging behavior and ecology of transient killer whales (Orcinus orca). Ph.D. Dissertation, Simon Fraser University.

Baird, R.W., Dill, L.M., 1996. Ecological and social determinants of group size in transient killer whales. Behavioral Ecology 7(4), 408-416.

Bigg, M.A., Ellis, G.M., Ford, J.K.B., Balcomb III, K.C., 1987. Killer Whales - a Study of their Identification, Genealogy, and Natural History in British Columbia and Washington State. Phantom Press, Nanaimo, BC

Bigg, M.A., Olesiuk, P.F., Ellis, G.M., Ford, J.K.B., Balcomb III, K.C., 1990. Social organization and genealogy of resident killer whales (Orcinus orca) in the coast waters of British Columbia and Washington State. Report of the International Whaling Commission (Special Issue) 12, 383-405.

Caldwell, M.C., Caldwell, D.K., Tyack, P.L., 1990. Review of the signature-whistle hypothesis for the Atlantic bottlenose dolphin. In: Leatherwood, S., Reeves, R.R. (Eds.), The Bottlenose Dolphin. Academic Press, New York, pp. 199-234.

Clark, C.W., 1983. Acoustic communication and behavior of the southern right whale. In: Payne, R.W. (Ed.), Behavior and Communication of Whales. Westview Press, Boulder, CO. pp. 163-198.

Clark, C.W., Ellison, W.T., Beeman, K., 1986. A preliminary account of the acoustic study conducted during the 1985 spring bowhead whale, Balaena mysticetus, migration off Point Barrow, Alaska. Report of the International Whaling Commission 36, 311-316.

Dudzinski, K.M., Clark, C.W., Würsig, B., 1995. A mobile video/acoustic system for simultaneous underwater recording of dolphin interactions. Aquatic Mammals 21(3), 187-193.

Fletcher, S., LeBoeuf, B.J., Costa, D.P., Tyack, P.L., Blackwell, S.B., 1996. Onboard acoustic recording from diving northern elephant seals. Journal of the Acoustical Society of America 100(4), 2531-2539.

Ford, J.K.B., 1987. A catalogue of underwater calls produced by killer whales (Orcinus orca) in British Columbia. Canadian Data Report of Fisheries and Aquatic Sciences 633.

Ford, J.K.B., 1989. Acoustic behavior of resident killer whales (Orcinus orca) off Vancouver Island, British Columbia. Canadian Journal of Zoology 67, 727-745.

Ford, J.K.B., 1991. Vocal traditions among resident killer whales (Orcinus orca). in coastal waters of British Columbia. Canadian Journal of Zoology 69, 1454-1483.

Freitag, L.E., Tyack, P.L., 1993. Passive acoustic localization of the Atlantic bottlenose dolphin using whistles and echolocation clicks. Journal of the Acoustical Society of America 93, 2197-2205.

Fristrup, K.M., Clark, C.W., 1997. Combining visual and acoustic survey data to enhance density estimation. Report of the International Whaling Commission 47: 933-936.

Gautier J.-P., Gautier-Hion, A., 1989. Vocal communication within a group of monkeys: an analysis by biotelemetry. In: Snowdon, C.T., Brown, C.H., Peterson, M.R. (Eds.), Primate Communication, Cambridge University Press, Cambridge, pp. 5-29.

Grund, M., Johnson, M., 1995. The AMS operating system: a prototyping environment for signal processing. IEEE International Workshop for Rapid Systems Prototyping, North Carolina.

IWC. 1990. Report of the workshop on Individual recognition and the estimation of cetacean population parameters. Report of the International Whaling Commission (Special Issue) 12, 3-40.

Janik, V.M., Slater, P.J.B., 1995. Whistle matching in wild bottlenose dolphins. Abstracts of the XXI Biennial Conference of the Society for Marine Mammology, Orlando, p. 57.

Johnson, D.H., Dudgeon, D.E., 1993. Array Signal Processing: Concepts and Techniques. In: Oppenheim, A.V. (Ed.), Prentice-Hall Signal Processing Series. Prentice Hall, Englewood Clifs, NJ. 
Leaper, R., Chappel, O., Gordon, J., 1992. The development of practical techniques for surveying sperm whale populations acoustically. Report of the International Whaling Commission 42, 549-560.

Marler, P. 1961. The logical analysis of animal communication. Journal of Theoretical Biology 1, $295-317$.

McCowan, B., 1995. A new quantitative technique for categorizing whistles using simulated signals and whistles from captive bottlenose dolphins (Delphinidae, Tursiops truncatus) Ethology 100, 177-193.

Miller, P.J., 1996. Request for a letter of authorization to allow activities that may result in the incidental harassment of a small number of marine mammals, including the draft plan for monitoring and mitigation. Unpublished document NMFS ID \# 032296A.

Miller, P.J., Willis, P.M., 1997. Preliminary report monitoring the effects of the Haro strait frontal dynamics experiment on marine mammais abundance, distribution, and behavior. Unpublished report presented to National Marine Fisheries Service, Silver Spring, MD

Nowacek, D.P., Lange, W.N., Wells, R.S., Tyack, P.L., 1995. A new method for studying cetacean behavior and acoustics: overhead video combined with underwater audio. Abstracts of the XXI Biennial Conference of the Society for Marine Mammology, Orlando, p. 84.

Oppenheim, A.V., Willsky, A.S., Young, I.T., 1983. Signals and Systems. In: Oppenheim. A.V. (Ed.). Signal Processing Series. Prentice Hall, Englewood Cliffs, NJ.

Pryor, K., 1991. Non-acoustic communication in small cetaceans: glance, touch, position, gesture. and bubbling. In: Thomas, J.A., Kastelein. R.A. (Eds.), Sensory Abilities of Cetaceans. Plenum Press. New York.

Rose, N.A., 1992. The social dynamics of male killer whales, Orcinus orca, in Johnstone Strait, British Columbia. PhD Dissertation. University of California, Santa Cruz.

Samuels, A., Gifford, T., 1997. A quantitative assessment of dominance relations among bottlenose dolphins. Marine Mammal Science 13(1), 70-99.

Sayigh L.S., Tyack P.L., Wells R.S., Scott M.D., 1990. Signature whistles of free-ranging bottlenose dolphins, Tursiops truncatus: stability and mother-offspring comparisons. Behavioral Ecology and Sociobiology 26, 247-260.

Sayigh, L.S., Tyack, P.L., Wells, R.S., 1993. Recording underwater sounds of free-ranging dolphins while underway in a small boat. Marine Mammal Science 9(2), 209-213.

Smolker, R.A., Mann, J., Smuts, B.B., 1993. Use of signature whistles during separation and reunions by wild bottlenose dolphin mothers and infants. Behavioral Ecology and Sociobiology 33, 393-402.

Spiesberger, J.L., Fristrup, K.M., 1990. Passive localization of calling animals and sensing of their acoustic environment using acoustic tomography. American Naturalist 135(1), 107-153.

Spikes, C.H., Clark, C.W., 1996. Whales '95 - revolutionizing marine mammal monitoring technology. Sea Technology April, 49-56.

Tyack, P.L., 1981. Interactions between singing Hawaiian humpback whales and conspecifics nearby. Behavioral Ecology Sociobiology 8, 105-116.

Tyack, P.L., 1985. An optical telemetry device to identify which dolphin produces a sound. Journal of the Acoústical Society of America 78(5), 1892-1895.

Tyack, P.L., Recchia, C.A., 1991. A datalogger to identify vocalizing dolphins. Journal of the Acoustical Society of America 90(3), 1668-1671.

Waite, J.M., 1988. Alloparental care in killer whales (Orcinus orca). Master's thesis, University of California, Santa Cruz.

Watkins, W.A., Daher, M.A., Fristrup, K.M., Howald, T.J., 1993. Sperm whales tagged with transponders and tracked underwater by sonar. Marine Mammal Science 9(1), 55-67.

Watkins, W.A., Schevill, W.E., 1972. Sound source location by arrival times on a non-rigid 3-dimensional hydrophone array. Deep-Sea Research 19, 691-706.

Watkins W.A., Schevill W.E., 1974. Listening to Hawaiian spinner porpoises, Stenella cf. longirostris. with a three-dimensional hydrophone array. Journal of Mammalogy 55, 319-328. 


\section{CHAPTER 4: REPERTOIRE-SHARING IN FREE-RANGING KILLER WHALES}

\subsection{Introduction}

Vocal sharing occurs when different individuals produce a similar sound type, and occurs in many group-living species (e.g. primates: Sugiura, 1993), territorial songbirds (e.g. great tit: Falls et al., 1982), and lekking species (e.g. anurans: Gèrhardt, 1974; humpback whales: Payne \& Payne, 1985). Vocal sharing can arise from species-specific genes for non-learned signals (Baptista, 1996) or from convergent vocal learning including mimicry (Andrew, 1962; Payne \& Payne, 1985; Hughes et al., 1998). Repertoire sharing is an extension of vocal sharing in which different individuals share more than one sound type (Beecher et al., 1996; Narins et al., 2000).

Vocal sharing may have important consequences on signaling systems. Sharing may improve the receiver's ability to identify environmental effects on a propagating signal, which may improve the receiver's ability to estimate the range to the signaler (Morton, 1982; Falls et al., 1982; McGregor et al., 1983; Shy \& Morton, 1986; but see Naguib, 1997, 1998; Wiley, 1998). Matched counter-calling occurs when a receiver responds to a signal by producing the same signal (Sugiura, 1993), and may provide a means for a respondent to direct a signal at the original caller (McGregor et al., 1992). Matched counter-calling also provides a possible mechanism for both signalers to confirm that their signal has been received. For example, the affiliative 'chuck' call is exchanged between squirrel monkeys in a tight temporal sequence, and structural modifications of peak frequency appear to code the chuck as either a request or a response to a request (Biben et al., 1986; Biben, 1993). Repertoire-matching occurs when a respondent replies with another of the repertoire of sound types it shares with the original signaler (Beecher et al., 1996). Repertoire-matching requires that the respondent know what sounds it shares with the original signaler, and may help the matching signalers recognize each other based upon their shared repertoire (Beecher et al., 2000). 
Vocal sharing also influences the mechanism by which individual identity is encoded. When a call is shared by multiple individuals, individual distinctiveness must be encoded in detailed structural modifications or spectral cues (Beecher et al., 1981; Beecher, 1989; McCracken, 1984; Rendall et al., 1996, 1998). In contrast to individual signature encoding in a shared call, bottlenose dolphins produce an individually distinctive whistle when they are isolated from other group members (Caldwell \& Caldwell, 1965; Janik \& Slater, 1998). Bottlenose dolphins may mimic the signature whistles of other individuals, possibly to label or direct signals to other individuals within their social group (Tyack, 1986).

The goal of this study was to confirm whether free-ranging killer whales share the calls in their matrilineal group's repertoire. Free-ranging resident killer whale pods produce a repertoire of 7-17 call types (Ford, 1991), and most of the types produced by a pod are produced separately by the matrilineal groups which compose pods (Chapter 2; Miller \& Bain, in press). Ford (1991) believed that all individuals in the free-ranging groups he observed shared all the calls in the group's repertoire. This view is supported by the fact that captive animals produce most or all of the sounds of the social group from which they were captured (Bain, 1986; Morton et al., 1986; Ford, 1991). However, because it is difficult to reliably identify which animal is signaling using a single hydrophone (Miller \& Tyack, 1998), and normal behavior may be altered by captivity (see Samuels \& Gifford, 1997), it is important to confirm repertoire-sharing with freeranging animals. In this study I used a recently developed towed-array system (Miller \& Tyack, 1998) to record sounds produced by identified killer whales from one matrilineal group consisting of three individuals. I classified calls to type (Ford, 1987), and compared the repertoire of each group member.

\subsection{Methods}

Sounds were recorded from identified individuals from matrilineal group W3, the only known matrilineal group from W-pod (Ford et al., 1994), using the methods 
described in Miller \& Tyack (1998). At the time of the study, matrilineal group W3 consisted of three individuals, a female (W3) who is the mother of two adult males (W2 \& W5; Ford et al., 1994). All recordings were made on four days in September, 1999 in Johnstone Strait, British Columbia from a $35 \mathrm{ft}$. research vessel. The array was positioned so that the focal subject was as isolated as possible in azimuth from all other animals in the area. At each surfacing, the position of the focal animal relative to the vessel was measured using laser range finders and a digital compass (Miller \& Tyack, 1998). The orientation of the focal whale to the array was also scored at each surfacing. The identity of the focal whale was determined in the field from differences in fin shape and saddle-patch markings (Ford et al., 1994), and photographs of the dorsal fin were used to confirm the field identifications.

The positions of other animals in the area were monitored during the follow, and a follow quality of 'high' was assigned when other animals were separated by at least $20^{\circ}$ of azimuth. To minimize the risk of misidentifying signalers, only 'high' quality portions of follows were analyzed. With ranges to the focal typically greater than $100 \mathrm{~m}, 20^{\circ}$ of separation in azimuth corresponds to at least $35 \mathrm{~m}$ of separation, so the focal animal was typically out of visual range with other pod members during the analyzed portions of the focal follows.

Broadband beamforming techniques were used to determine the angle-of-arrival of sounds received during the focal follow (see Miller \& Tyack, 1998). A predicted angle to the focal whale was calculated at one-second intervals by interpolating the position of the whale at the previous and subsequent surfacing. All calls with an angleof-arrival within $20^{\circ}$ of the predicted angle to the focal whale were scored as having been produced by the focal whale. During two follows, multiple callers could be identified based upon detailed voice notes recording the positions of non-focal individuals which were widely separated in azimuth.

All calls recorded during the follows were classified to type by aural recognition and visual inspection of spectrograms. Types were numbered using the system devised by Ford $(1987,1991)$. Any calls which did not clearly fall into one of the defined call 
types were classified as variable calls (Ford, 1989). One call type (N52) occurred repeatedly but was not previously catalogued, so a new number was assigned to this type. To assess repertoire sharing, the call types produced by each identified pod member were visualized with a histogram. The frequency of call-type production by the three individuals was compared using a chi-square test (Zar, 1984).

\subsection{Results}

Sounds were analyzed from a total of 23 'high'-quality focal follows. The total duration of the "high" quality follows was 274 minutes (mean follow duration: $11.9 \mathrm{~min}$, s.d.: $11.2 \mathrm{~min}$ ). Calls appeared to be produced in bouts, often as apparent exchanges between the focal and a non-focal whale. A total of 140 calls were produced by an identified caller, with many calls from each group member (Table 1).

\begin{tabular}{lrrr} 
& \multicolumn{3}{c}{ Individual } \\
\cline { 2 - 4 } Number of follows & 4 & W5 & W2 \\
\cline { 2 - 4 } Number of days & 1 & 2 & 4 \\
Minutes followed & 30.8 & 104.6 & 138.6 \\
Calls identified & 41 & 24 & 75
\end{tabular}

Table 1. Details of follows and identified calls from members of W-pod.

A total of eight stereotyped call types were recorded from matrilineal group W3 (Fig. 1). The frequency of call type production of the entire pod matched surprisingly well that reported by Ford (1991, fig. 16) from recordings of W-pod from 1981-1983. I did not observe call type N42, which was a very rare call in the sample reported by Ford (1991). Of the eight call types, N32 and N33 were the most common and together accounted for almost $80 \%$ of all calls produced. Variable calls accounted for roughly $10 \%$ of all calls. Overall, the frequency of call type production did not vary by individual (Fig. $1 ; \chi^{2}=20.8$, d.f. $=16, P=0.186$ ). Three of the call types (N32, N33 \& N34) were 

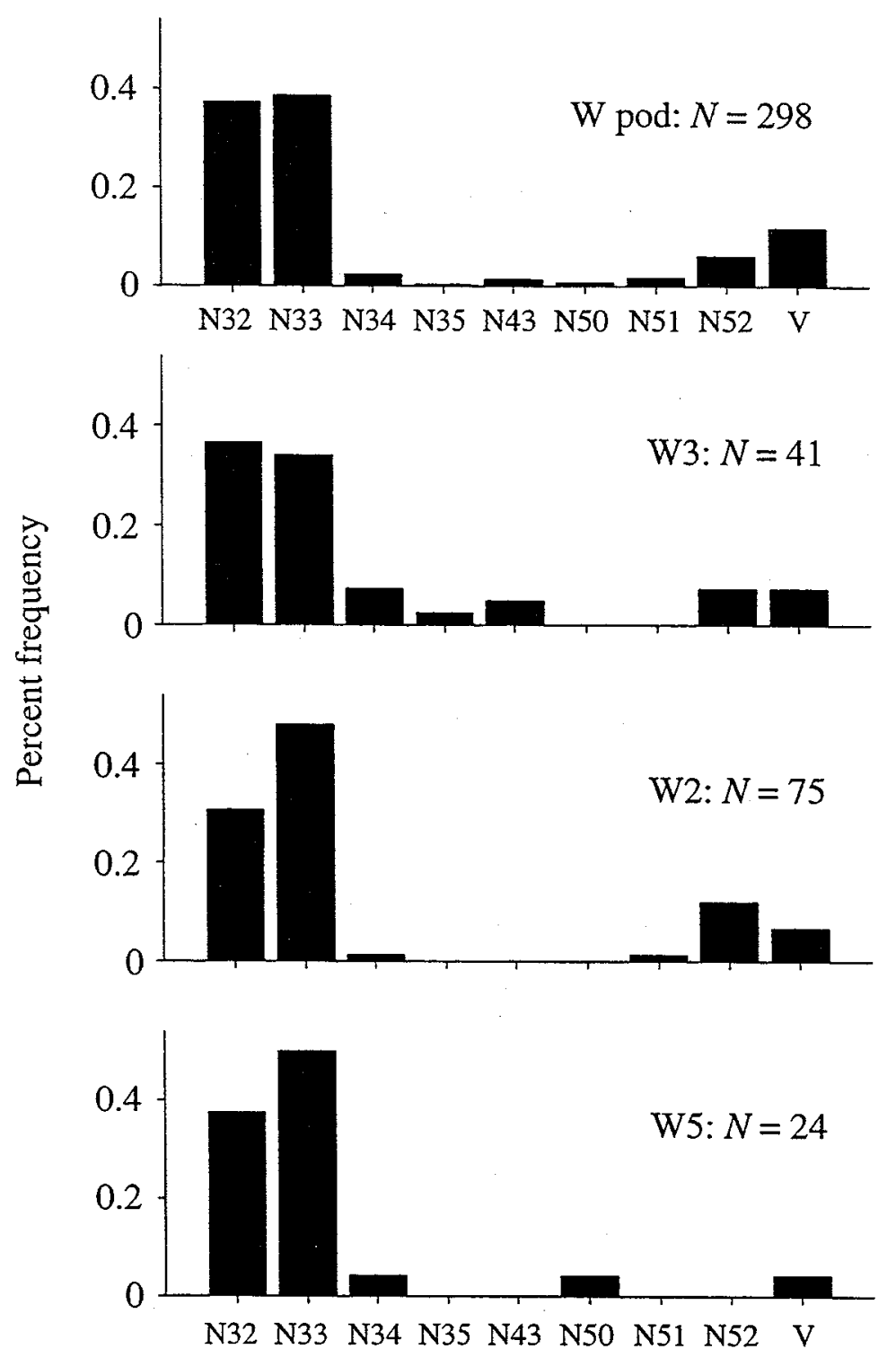

Call type

Figure 1. Percentage frequency of call types produced by the three members of W-pod, which consists entirely of the three individuals in matrilineal group W3. "V" refers to variable calls, i.e. calls that did not clearly match one of the stereotyped forms. Top panel: all calls from W-pod. Bottom three panels: calls from an identified individual. 
recorded from all three individuals (Fig. 1), one was recorded from two individuals (N52), and four were only recorded from one individual (N35, N43, N50 \& N51).

The types that were recorded from only one individual were quite rare in the total sample, so it is possible that these types are actually shared but that the sample of identified calls was too small to observe them from all three individuals. For example call type N51 was only observed from W2, and comprised $1.68 \%$ of the total W-pod sample. If we assume that the 65 calls recorded from $\mathrm{W} 3$ and $\mathrm{W} 5$ are a random sample of their repertoire, and that those individuals produce call types at the same frequency as the total pod sample, then there is a probability of $(1.00-0.0168)^{65}$ or 0.33 that call type N51 would not be observed from W3 or W5. Using the same analysis, the probabilities that types N35, N43, and N50 would only be observed from the one animal I observed them from are $0.71,0.26$, and 0.45 , respectively. Thus, while it is not possible to confirm that these types are shared by the members of W-pod, the probability that they are shared but that the sample was insufficient to detect them from more that one individual is quite high in all cases.

\subsection{Discussion}

This is the first study to document the calling behavior of identified individual free-ranging killer whales, and confirms that use of the towed array system developed by Miller \& Tyack (1998) allows sampling of the sound production of identified individuals in an efficient manner. The primary results of this study are that: 1.) the three members of W-pod share a number of calls in their repertoire, and 2.) rates of call type production did not vary by individual. Because the test of call-type production by individual treated each call as an independent observation, the sample size may be inflated if calls are serially dependent. Inflated sample size biases the statistic toward finding a difference, but as no difference was found we can disregard this concern. This study does confirm earlier wild and captive studies which suggested that members of stable killer whale groups share a repertoire of call types (Bain, 1986; Morton et al., 1986; Ford, 1991). 
Some call types were observed only from one of the three individuals, but there is a high probability in all cases that these types were not observed from more than one individual simply because they are rare. A larger sample of calls from these individuals is needed to confirm whether these other rare types are in fact shared. None of the call types produced by individuals in the W 3 matrilineal subgroup were observed to be produced by members of pod A1 (chapter 2; Ford, 1991), which supports Ford's (1991) suggestion that individuals in pods produce the pod-specific repertoire of call types.

Future analyses of this data set will assess individual distinctiveness of calls, and explore whether individuals counter-call with other pod members using matched countercalling or repertoire matching. On many occasions during these focal follows, calls of the same type appeared to be produced from different individuals in rapid succession, possibly as counter-calling bouts. Counter-calling may provide a means for individuals to direct calls at a particular receiver, i.e. the previous signaler (McGregor et al., 1992), and may also provides a means for signalers to confirm that their signal has been received (Biben et al., 1986; Biben, 1993).

Matched counter-calling may be particularly important due to the principle of "reciprocity" in sound propagation (Frisk, 1994). The effects of the environment on a signal propagating from a source to a receiver can be characterized by Green's functions. The Green's function is the solution to the wave equation in an inhomogeneous medium (Frisk, 1994). The "reciprocity principle" states that the Green's function is identical when the source and receiver are switched:

$$
\mathbf{G}\left(\mathbf{r}_{\mathbf{o}}, \mathbf{r}\right)=\mathbf{G}\left(\mathbf{r}, \mathbf{r}_{\mathbf{o}}\right) \text {, }
$$

where $G$ is the Green's function, $r_{o}$ is the source position and $r$ is the receiver position (Frisk, 1994, pg. 64).

If two animals each produce an identical call in rapid succession, each will receive signals altered in the same way by the environment. Thus, by rapidly matching, the sound produced by the matcher will reach the original signaler in the same form as 
the original sound was received by the matcher. The longer the matcher waits to respond to the original signaler, the less "reciprocal" the propagation effects on the signal, and the matcher will be less assured that the signal will be received by the original signaler. Further investigation of the implications of the reciprocity principle on matched countercalling may be warranted, especially for animals living in complex sound propagation environments such as killer whales (Mercado \& Frazer, 1999).

\subsection{Acknowledgements}

Special thanks to Ari Shapiro for helping to process the sounds from the focal follows. Thanks to Bill Watkins for various discussions on the topic of call sharing by killer whales and to Aaron Thode for pointing out to me the potential importance of the reciprocity principle on animal signaling systems. 


\subsection{References:}

Andrew, R. J. 1962. Evolution of intelligence and vocal mimicking. Science 137: 585589.

Bain, D. E. 1986. Acoustic behavior of Orcinus: sequences, periodicity, behavioral correlates and an automated technique for call classification. In: Behavioral Biology of Killer Whales. (Eds. B. C. Kirkevold \& J. S. Lockard), New York: Alan R. Liss, Inc., pp. 335-371.

Baptista, L. F. 1996. Nature and its nurturing in avian vocal development. In: Ecology and Evolution of Acoustic Communication in Birds (Eds. D. E. Kroodsma \& E. H. Miller). Ithaca, NY: Cornell University Press, pg. 39-60.

Beecher, M.D. 1989. Signaling systems for individual recognition: an information theory approach. Anim. Behav. 38: 248-261.

Beecher, M.D., Beecher, I.M., and Lunpkin, S. 1981a. Parent-offspring recognition in bank swallows: I. Natural history. Anim. Behav. 29: 86-94.

Beecher, M. D., Campbell, S. E., Burt, J. M., Hill, C. E., and Nordby, J. C. 2000. Songtype matching between neighbouring song sparrows. Anim. Behav. 59: 21-27.

Beecher, M. D., Stoddard, P. K., Campbell, S. E., and Horning, C. L. 1996. Repertoire matching between neighbouring song sparrows. Anim. Behav. 51: 917-923.

Biben, M. 1993. Recognition of order effects in squirrel monkey antiphonal call sequences. Am. J. Primat. 29: 109-124.

Biben, M., Symmes, D., and Masataka, N. 1986. Temporal and structural analysis of affiliative vocal exchanges in squirrel monkeys (Saimiri sciureus). Behaviour 98: 259-273.

Caldwell, M. C. and Caldwell, D. K. 1965. Individualized whistle contours in bottlenosed dolphins (Tursiops truncatus). Nature 207: 434-435.

Falls, J.B., Krebs, J.R., and McGregor, P.K. 1982. Song matching in the Great Tit (Parus major): the effect of similarity and familiarity. Anim. Behav. 30: 9971009.

Ford, J.K.B. 1987. A catalogue of underwater calls produced by killer whales (Orcinus orca) in British Columbia. Can. Data Rep. Fish. Aquat. Sci. No. 633. 
Ford, J.K.B. 1989. Acoustic behavior of resident killer whales (Orcinus orca) off Vancouver Island, British Columbia. Can. J. Zool. 67: 727-745.

Ford, J.K.B. 1991. Vocal traditions among resident killer whales Orcinus orca in coastal water of British Columbia. Can. J. Zool. 69: 1454-1483.

Ford, J.K.B., Ellis, G.M., and Balcomb, K.C. 1994. Killer Whales: The Natural History and Genealogy of Orcinus orca in British Columbia and Washington State. Vancouver: UBC Press, pp. 102.

Frisk, G. V. 1994. Ocean and Seabed Acoustics: a Theory of Wave Propagation. Englewood Cliffs, NJ: Prentice-Hall, ppg. 299.

Gerhardt, H. C. 1974. The significance of some spectral features in mating call recognition in the green treefrong (Hyla cinerea). J. exp. Biol. 61: 229-241.

Hughes, M., Nowicki, S., Searcy, W. A., and Peters, S. 1998. Song type sharing in song sparrows: implications for repertoire function and song learning. Behav. Ecol. Sociobiol. 42: 437-446.

Janik, V. M. and Slater, P. J. B. 1998. Context-specific use suggests that bottlenose dolphin signature whistles are cohesion calls. Anim. Behav. 56: 829-838.

McCracken, G.F. 1984. Communal nursing in Mexican free-tailed bat maternity colonies. Science 223: 1090-1091.

McGregor, P. K., Dabelsteen, T., Shepherd, M., and Pedersen, S. B. 1992. The signal value of matched singing in great tits: evidence from interactive playback experiments. Anim. Behav. 43: 987-998.

McGregor, P. K., Krebs, J. R., and Ratcliffe, L. M. 1983. The reaction of great tits (Parus major) to playback of degraded and undegraded songs: the effect of familiarity with the stimulus song type. Auk 100: 898-906.

Mercado, E. III and Frazer, L. N. 1999. Environmental constraints on sound transmission by humpback whales. J. Acoust. Soc. Am. 106: 3004-3016.

Miller, P. J. O. and Bain, D. E. in press. Within-pod variation in the sound production of a pod of killer whales, Orcinus orca. Anim. Behav.

Miller, P. J. and Tyack, P. L. 1998. A small towed beamforming array to identify vocalizing resident killer whales (Orcinus orca) concurrent with focal behavioral observations. Deep-Sea Res. II 45: 1389-1405. 
Morton, A. B., Gale, J. C., and Prince, R. C. 1986. Sound and behavioral correlations in captive Orcinus orca. In: Behavioral Biology of Killer Whales. (Eds. B. C. Kirkevold \& J. S. Lockard), . New York: Alan R. Liss, Inc. pp. 303-333.

Morton, E. S. 1982. Grading, discreteness, redundancy, and motivation-structural rules. In: Acoustic Communication in Birds, vol. 1. (Eds. D. E. Kroodsma \& E. H. Miller), New York: Academic Press, ppg. 183-212.

Naguib, M. 1997. Ranging of songs with the song type on use of different cues in Carolina wrens: effects of familiarity. Sociol. Evol. Behav. 40: 385-393.

Naguib, M. 1998. Perception of degradation in acoustic signals and its implications for ranging. Behav. Ecol. Sociobiol. 42: 139-142.

Nairns, P. M., Lewis, E. R., and McClelland, B. E. 2000. Hyperextended call note repertoire of the endemic Madagascar treefrog Boophis madagascariensis (Rhacophoridae). J. Zool., London 250: 283-298.

Payne, K. and Payne, R. 1985. Large scale changes over 19 years in the song off humpback whales in Bermuda. Z. Tierpsychol. 68: 89-114.

Rendall, D., Owren, M.J., and Rodman, P.S. 1998. The role of vocal tract filtering in identity cueing in rhesus monkey (Macaca mulatta) vocalizations. J. Acoust. Soc. Am. 103 (1): 602-614.

Rendall, D., Rodman, P.S., and Emond, R.E. 1996. Vocal recognition of individuals and kin in free-ranging rhesus monkeys. Anim. Behav. 51: 1007-1015.

Samuels, A. and Gifford, T. 1997. A quantitative assessment of dominance relations among bottlenose dolphins. Mar. Mamm. Sci. 13 (1): 70-99.

Shy, E. and Morton, E. S. 1986. The role of distance, familiarity, and time of day in Carolina wrens response to conspecific songs. Behav. Ecol. Sociobiol. 19: 393400 .

Sugiura, H. 1993. Temporal and acoustic correlates in vocal exchanges of coo calls in Japanese macaques. Behaviour 124: 207-225.

Tyack, P. 1986. Whistle repertoires of two bottlenosed dolphins, Tursiops truncatus: mimicry of signature whistles? Behav. Ecol. Sociobiol. 18: 251-257.

Wiley, R. H. 1998. Ranging reconsidered. Behav. Ecol. Sociobiol. 42: 143-146. 
Zar, J.H. 1984. Biostatistical Analysis, 2nd Edition. Englewood Cliffs, NJ: PrenticeHill, Inc. pp. 718. 


\section{CHAPTER 5: SOURCE LEVELS AND ESTIMATED ACTIVE SPACE OF THE ACOUSTIC REPERTOIRE OF RESIDENT KILLER WHALES (ORCINUS ORCA)}

\subsection{Abstract}

The goal of this study was to measure the source levels of pulsed calls and whistles produced by resident killer whales in Johnstone Strait, British Columbia, and to estimate the maximum range at which the measured sounds could be detected by a conspecific ('active space') assuming quiet noise conditions. Ranges to vocalizing animals were measured by triangulating the angles-of-arrival of sounds on two short $(2.5 \mathrm{~m}, 8$-element) beamforming arrays towed in series with a separation of $97 \mathrm{~m}$. Source levels of the loudest portion of 819 pulsed calls and 24 whistles were measured from five hours of recordings on two days in 1998 , and ranged from 131 to $168 \mathrm{~dB}$ re $1 \mu \mathrm{Pa} @ 1 \mathrm{~m}$. Whistles $(140.2 \mathrm{~dB}$; $\mathrm{sd}=4.1 \mathrm{~dB})$ were fainter than variable calls $(146.6 \mathrm{~dB}$; s.d. $=6.6$ $\mathrm{dB})$, and both were fainter than stereotyped calls $(152.6 \mathrm{~dB}$; s.d. $=5.9 \mathrm{~dB})$. Within the stereotyped calls, source levels differed across the eight most common call types with a mean of $156.5 \mathrm{~dB}$ and $145.5 \mathrm{~dB}$ for the loudest (N4) and faintest (N3) types, respectively. Active space was estimated by calculating transmission loss of each sound based upon published empirical equations, and determining the range at which energy in all $1 / 3$ octave bands from $1-20 \mathrm{kHz}$ fell below auditory threshold. Estimated active space ranged from 4.5 to $26.2 \mathrm{~km}$ with stereotyped calls $(13.1 \mathrm{~km}$; s.d. $=4.5 \mathrm{~km})$ having a larger estimated active space than either variable calls $(10.3 \mathrm{~km}$; s.d. $=3.6 \mathrm{~km})$ or whistles $(9.5 \mathrm{~km} ;$ s.d. $=2.7 \mathrm{~km})$. Estimated active space of different call types fell into two clusters; long-range types (mean of $14.5 \mathrm{~km}$ ) contained a separately modulated highfrequency component while short-range types (mean of $8.8 \mathrm{~km}$ ) did not. A short range call type (N3) and whistles were previously shown to be produced more during resting and beach-rubbing behaviors, while the louder calls are used more during foraging and pod-meeting contexts. The results of this study suggest that the various sounds produced by killer whales serve different functions in their communication system, with some sounds serving as long-distance signals and others as shorter-range signals.

\subsection{Introduction}

The amplitude at which an acoustic signal is produced, or source level (SL), is of fundamental importance in communication systems, and acoustic signals can be produced over a large range of SLs (Bradbury \& Vehrencamp, 1998). For a signaler to benefit from an information transfer, it must produce signals at a sufficient SL for an intended receiver to detect and decode the signal, which has attenuated during transmission, in the presence of competing noise (Wiley \& Richards, 1982). The level at which a signal is 
produced can be viewed as the outcome of different selection pressures. The benefits of information transfer select for louder signals because they are more likely to be detected and decoded by an intended receiver (Wiley \& Richards, 1982). Conversely, the associated energetic costs and increased risk of detection by predators, prey, or social competitors select for fainter signals (Prestwich et al., 1989; Ryan et al., 1982; Dabelsteen \& Pedersen, 1990).

Signals appear to be produced at the appropriate SL for a desired information transfer to take place over typical distances to intended receivers (Wiley \& Richards, 1982; Cynx et al., 1998). For example, the territorial song display of the red-wing blackbird (Agelaius phoeniceus) is produced at a level sufficient to be heard by other redwing blackbirds at a range of about two territories away, signaling its presence to neighboring birds (Brenowitz, 1982). Some signal types (i.e. territorial song) may be selected to cover a large area while others favor short detection ranges, reflecting the context and motivation of the signaler (Rowell and Hinde, 1962; Dittus, 1988; Marten et al., 1977). Blackbirds (Turdus merula) switch from loud song to a quieter version of song in close range threat interactions with intruders (Dabelsteen \& Pedersen, 1990).

Despite the clear evidence that descriptions of SLs can be a useful tool for elucidating the function of different signal types in a repertoire, systematic measurements of the SLs of acoustic signals are rare and have generally relied on captive studies (Loftus-Hills \& Littlejohn, 1971; Gerhardt, 1975; Prestwich et al., 1989; Cynx et al., 1998). Janik (in press) measured SLs of dolphin whistles using 2-D localization and estimated the active space of dolphin whistles based upon background noise measurements and published studies of the hearing abilities of bottlenose dolphins. He estimated that a whistle produced at the highest SL observed (169 dB re $1 \mu \mathrm{Pa})$ at typical whistle frequencies $(3.5-10 \mathrm{kHz})$ could be detected by a conspecific at 20 to $25 \mathrm{~km}$ range. These results suggest that dolphins can maintain acoustic contact over large distances, partly due to the efficiency of sound propagation in water.

Several detailed studies of marine mammal SLs have focused on echolocation signals produced by captive animals trained to remain stationary near the recording 
apparatus (reviewed in $\mathrm{Au}, 1993$ ). While this experimental design has been effective for describing the SL and directionality characteristics of echolocation signals, it cannot be used to measure SLs of communication signals produced in a natural behavioral context. Other studies of terrestrial species have related qualitative descriptions of the relative SL of different signal types to hypotheses of signal function (e.g. Marler, 1973; Dittus, 1988). Unfortunately, it is not possible to make reliable qualitative descriptions of SLs of marine mammal sounds because it is generally not possible to identify a signaler using a single hydrophone (Miller \& Tyack, 1998), and the range to a signaler can quickly change while it is out of view underwater.

A promising approach for systematic measurement of SLs of sounds produced by free-ranging marine mammals is the use of multiple hydrophones to measure the range from a signal source to a calibrated receiver (Watkins \& Schevill, 1974; Watkins et al., 1997; Cato, 1998; Mohl et al., 2000; Janik, in press). With this technique, SLs can be measured during normal behavior, although it is difficult to observe the orientation of signalers to measure or control for signal directionality as is possible in captive studies. Also, the lower range of SLs that can be measured is inherently limited because signals must be received with sufficient amplitude at multiple receivers for the range and received level to be measured. To measure SLs of faint sounds the hydrophones must be positioned near the signaler and have a small inter-hydrophone spacing (c.f. Watkins $e t$ al., 1997). Such a small array, if immobile, will have a small coverage area through which moving animals could pass quite quickly. Larger arrays will allow coverage of a larger area, but will only be useful to measure SLs of relatively loud sounds (c.f. Mohl et $a l ., 2000$ ). In this case, the mean value of SLs measured represents only a mean of relatively high SL sounds, depending on the array geometry (c.f. Janik, in press).

Killer whales produce whistles and echolocation clicks, but their sound production is dominated by burst-pulse calls (Ford, 1991). These calls are composed of multiple parts in time and frequency, and many have separately modulated low and high frequency components (Hoelzel \& Osborne, 1986; Ford, 1987; Miller \& Bain, in press). Call structure is consistent with that expected of a burst-pulse sound and calls appear to 
be high repetition rate click trains (Schevill and Watkins, 1966; Watkins, 1967; Ford, 1989). Most pulsed calls produced by resident killer whales have a stereotyped timefrequency structure, and can be reliably classified to one of several call types by eye (Bain, 1986; Hoelzel \& Osborne, 1986; Ford, 1987, 1989, 1991; Deecke et al., 1999; Miller \& Bain, in press; Deecke et al., in press). Other calls have a more variable structure, or appear to be aberrant forms of stereotyped calls (Ford, 1989). Resident pods produce a pod-specific repertoire of 7-17 of these discrete call types, which appear to form primarily as a consequence of acoustic divergence between matrilineal units which gradually separate into different pods (Ford, 1991; Miller \& Bain, in press).

Group-specific calling behavior appears to provide an indicator of pod and matrilineal-group affiliation (Ford, 1991, Miller and Bain, in press), although it has not been experimentally tested whether killer whales attend to these cues. The evidence is somewhat mixed whether call type production reflects the activities or motivations of signalers (Ford, 1989). No call type correlates exclusively with any particular activity, but relative production rates of different call types and whistles vary with behavior category (Bain, 1986; Morton et al., 1986; Ford, 1989). Aberrant calls contain variations in frequency that may reflect the emotional state of vocalizing animals (Ford, 1989). Ford (1989) concluded that the different call types produced by resident killer whales have little context-specific meaning, but that group-specific call type repertoires enhance the effectiveness of intra-pod communication and help maintain the integrity of the pod.

The primary goal of this study was to measure the SLs and estimate the active space of pulsed calls and whistles produced by resident killer whales in Johnstone Strait, BC. To measure the SLs of potentially faint sounds in the killer whale repertoire, I employed a novel towed two-beamformer array design that can be towed near animals, allowing a large 'coverage' area with a small $(97 \mathrm{~m})$ aperture array. The maximum range at which each sound could be detected by a conspecific ('active space') in quiet conditions was estimated by combining published sound propagation equations with a simple model of hearing in killer whales (Janik, in press). A secondary goal of this study was to estimate the maximum detection range of 1/3-octave bands between 1 and $20 \mathrm{kHz}$ 
to explore which frequencies are involved in long-range signaling by killer whales. If the various sound types in the killer whale repertoire all serve the same contact function of signaling group membership (Ford, 1989), then one might expect little variation in the estimated active space of different sound types in the repertoire. Conversely, if sound type production reflects the behavioral context or motivation of the signaler (Bain, 1986; Morton, 1986; Ford, 1989), one may expect to find diversity in the estimated active space of types depending on the context or behavioral state in which they tend to be produced.

\subsection{Materials and methods}

Recordings were conducted in Johnstone Strait on September 1 and 7, 1998 while killer whales from several different pods were present. All recordings were taken in low noise conditions, i.e. sea state 0 with no other vessels within a kilometer of the animals. All sound pressure levels throughout are referenced to $1 \mu \mathrm{Pa}$.

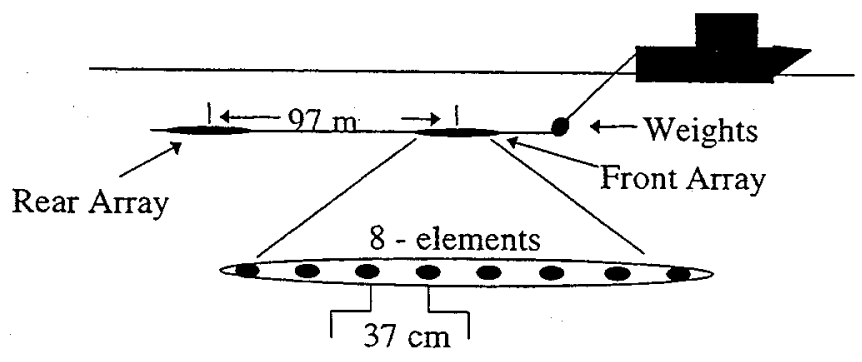

Figure 1. System design for two beamformer array.

The recording system consisted of two evenly-spaced 8-element $(2.6 \mathrm{~m})$ beamforming arrays towed in series. The array centers were separated by $97 \mathrm{~m}$ (Fig. 1). The arrays were towed parallel to the direction of movement of the whales at minimum speed $(\sim 1.5 \mathrm{~m} / \mathrm{s})$ to minimize noise generated by the ship. The signal from each hydrophone was recorded on a channel of two synchronized 16-bit Tascam 8-track digital recorders. Data from the recorders was digitally transferred into a computer as a .wavfile using a precision conversion system which maintains channel synchronization on a 
sample-by-sample basis across both recorders. Digital signal processing was carried out using custom Matlab software (see Miller \& Tyack, 1998 for other system design details).

The analog-signal to .wav-file conversion process was calibrated using tones measured on a calibrated LeCroy 9314AM oscilloscope. The hydrophone elements were Benthos AQ-2S hydrophones (sensitivity: $-195 \mathrm{dBV} / \mu \mathrm{Pa}$ ) attached to a custom WHOI preamp ( $43 \mathrm{~dB}$ gain flat from $100 \mathrm{~Hz}$ to $200 \mathrm{kHz}$ ). The sensitivity of one hydrophone in the rear array was calibrated in-situ using a Brüel \& $\mathrm{Kjær}(\mathrm{B} \& \mathrm{~K}) 8105$ hydrophone and a $\mathrm{B} \& \mathrm{~K} 2635$ preamp set at a sensitivity of $-160 \mathrm{dBV} / \mu \mathrm{Pa}$. The $\mathrm{B} \& \mathrm{~K}$ hydrophone was attached to the array next to one element, and several loud sources were used to measure the relative sensitivity of the array element to the calibrated hydrophone. The relative sensitivities of the remaining elements.were measured using a loud transient sound produced over $100 \mathrm{~m}$ from the array. The resulting measured sensitivity of -152.7 $\mathrm{dBV} / \mu \mathrm{Pa}$ was consistent across phones and closely matched the expected sensitivity based upon separate calibration of the hydrophone and pre-amp.

All sounds with a received sound pressure level (RL) at least $+3 \mathrm{~dB}$ above background noise on the rear array were extracted from the recordings and a calibrated received spectrum from 1 to $22 \mathrm{kHz}$ was calculated. The $+3 \mathrm{~dB}$ criterion was checked by measuring the noise level just prior to the onset of the signal. Calibrated spectra were calculated from the loudest subsection $(>100 \mathrm{~ms}$ in duration) of the sound. The lowfrequency cutoff of $1 \mathrm{kHz}$ was chosen for three reasons: killer whale hearing is much less sensitive at and below $1 \mathrm{kHz}$ (Hall \& Johnson, 1972; Symanski et al., 1999), there is little energy in killer whale sounds below $1 \mathrm{kHz}$ (Fig.1; Ford, 1987), and it is desirable to eliminate the low-frequency noise below $1 \mathrm{kHz}$ in calculating RL. The high-frequency cutoff of $22 \mathrm{kHz}$ was chosen to reduce the effects of filter roll-off and aliasing near the Nyquist frequency of $24 \mathrm{kHz}$. Sounds were classified as whistles or calls based upon their harmonic structure (Watkins, 1967). Calls were further classified to call type (Fig. 2; Ford, 1987; 1991; Miller \& Bain, in press). Any calls which did not clearly fall into one of the types described by Ford (1987) were classified as 'variable' calls (Ford, 1989). 

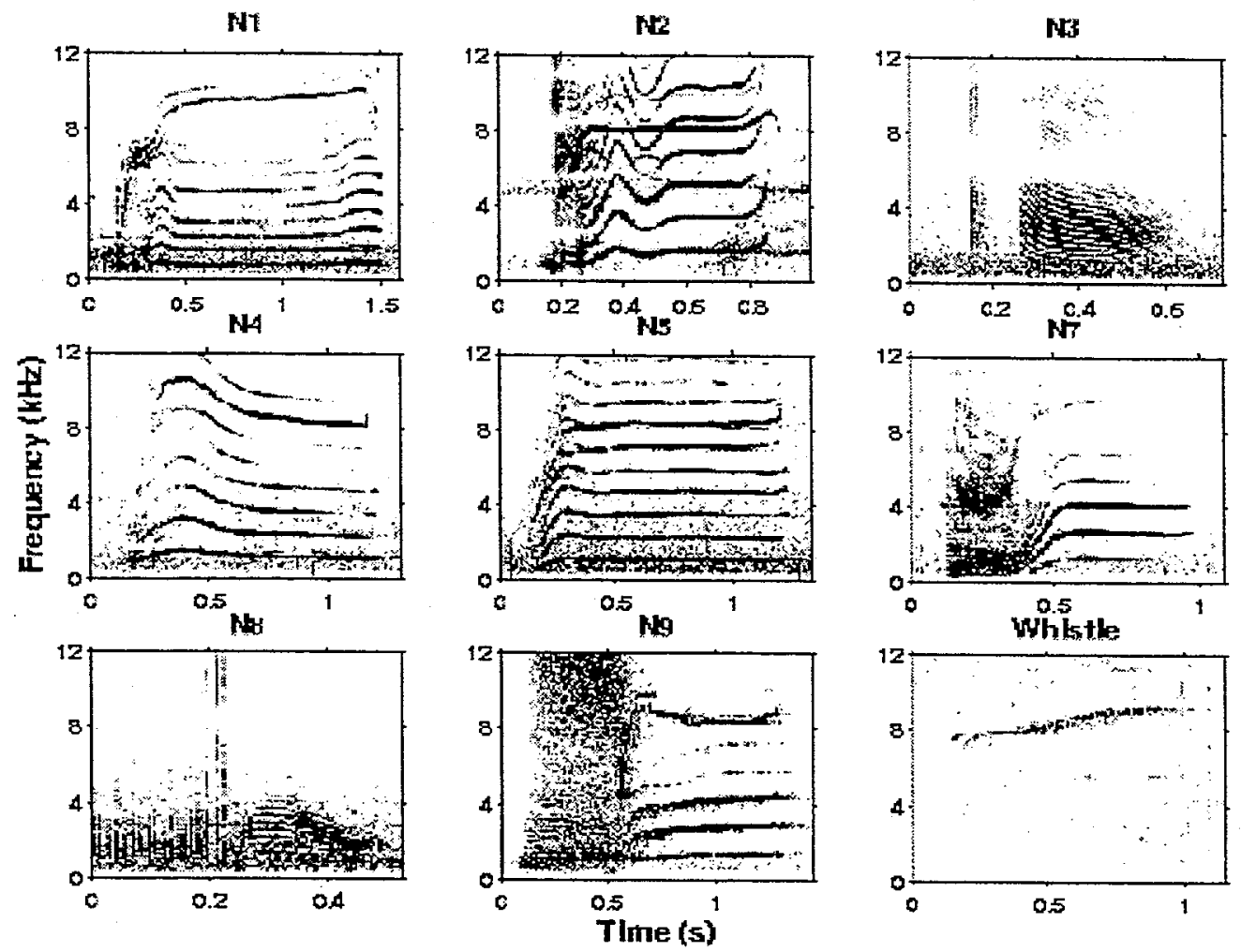

Figure 2. Spectrograms of a whistle and the eight most common call types recorded. The effective filter bandwidth was $97 \mathrm{~Hz}$.

\subsubsection{Source Level Calculation}

The source level (SL) in $\mathrm{dB} @ 1 \mathrm{~m}$ of each sound was calculated as:

$$
\mathrm{SL}=\mathrm{RL}+\mathrm{TL}
$$

where $\mathrm{RL}$ is the received level in $\mathrm{dB}$ obtained by summing the appropriate frequency regions of the calibrated spectrum, and TL is the transmission loss from the signaler to the hydrophone (Urick, 1981). A source spectrum was also calculated by adding TL to the calibrated spectrum. For calculation of SL, the RL of the loudest sub-section of the 
sound was used in order to avoid including portions of the sound that either overlapped extraneous sounds such as echolocation clicks or that were attenuated by surface diffraction. This loudest subsection was always greater than $100 \mathrm{~ms}$ in duration. TL (in dB) was calculated using a hemispherical spreading equation:

$$
\mathrm{TL}=20 \log (\mathrm{R})-3
$$

where $R$ is the measured range from the vocalizing whale to the center of the rear array. This simple spreading equation is valid when range is less than water depth and when ranges are small enough that frequency-dependent absorption can be ignored (Marsh \& Shulkin, 1962). Because the arrays were towed near the whales, the range was $<300 \mathrm{~m}$ for over $95 \%$ of the sounds analyzed; while water depth ranged between 300 and $600 \mathrm{~m}$. The $3 \mathrm{~dB}$ term subtracts energy added due to constructive interference with the surface reflection.

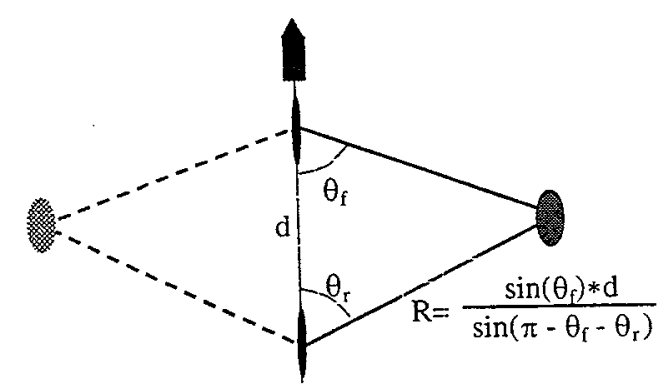

Figure 3. Range from rear array to a sound source is calculated using measured angles ( $\theta$, in radians) and the inter-array separation (d). The dashed lines illustrate the consistency of the range estimate despite the left-right (and depth) ambiguity of the linear arrays.

Range from the rear array to the vocalizing animal was calculated by intersecting the angles-of-arrival of the sound on the two in-series beamforming arrays (Fig. 3). The angle-of-arrival was calculated for each array using a broadband frequency-domain beamforming algorithm that measures the amount of energy coming from each direction at each frequency. Frequency-domain beamforming works well with killer whale sounds as previously described by Miller \& Tyack (1998). The angle-of-arrival of broadband 
killer whale calls and frequency-modulated whistles is easily resolved in the frequency domain using the frequency-dependent pattern created by the mainlobe and grating lobes (Miller \& Tyack, 1998; Thode et al., 2000b). The array hydrophones were evenly spaced at $37 \mathrm{~cm}$, which results in the appearance of grating lobes at $\sim 2 \mathrm{kHz}$ in broadband beamforming analysis (Miller \& Tyack, 1998). This technique does not obtain a 3-D localization of a sound because the linear arrays cannot resolve the left-right (and depth) ambiguity. However, the range estimate is valid for any position or depth of the signaler.

The accuracy of the range estimate was measured using a sound source deployed from a stationary boat. Several simultaneous acoustic and visual fixes were taken as the two-array system was driven past the boat. Visual fixes were taken using a laser-range finder and a hand-held compass as well as by ship's radar. At each of these points the range error was calculated and expressed as the SL error that would result from the range error. Calibration results of 8 separate passes showed that range errors contribute less than $\pm 3 \mathrm{~dB}$ error to the SL estimate over a $500 \mathrm{~m} \times 200 \mathrm{~m}$ body of water on both sides of the array (fig 4). I was careful to exclude animal sounds that came from outside the calibrated region in subsequent analyses.

Killer whale calls appear to be directional at higher frequencies (Schevill \& Watkins, 1966; Bain \& Dalheim, 1994; chapter six), so the apparent SL of a given sound will differ depending on the orientation at which it was received. Because I could not observe the orientation of signalling animals, it was not possible to calculate the dependency of SL on orientation, or 'transmit directivity index' (Urick, 1981). However, because the arrays were towed parallel to the direction of movement of the whales and sounds were localized broadside to the array (Fig. 4), signalling animals were most often oriented roughly broadside to the receiver. It is therefore reasonable to consider the SL obtained from this sample of sounds to primarily represent an off-axis SL, with a few sounds from animals randomly oriented either directly toward or away from the receiver. 


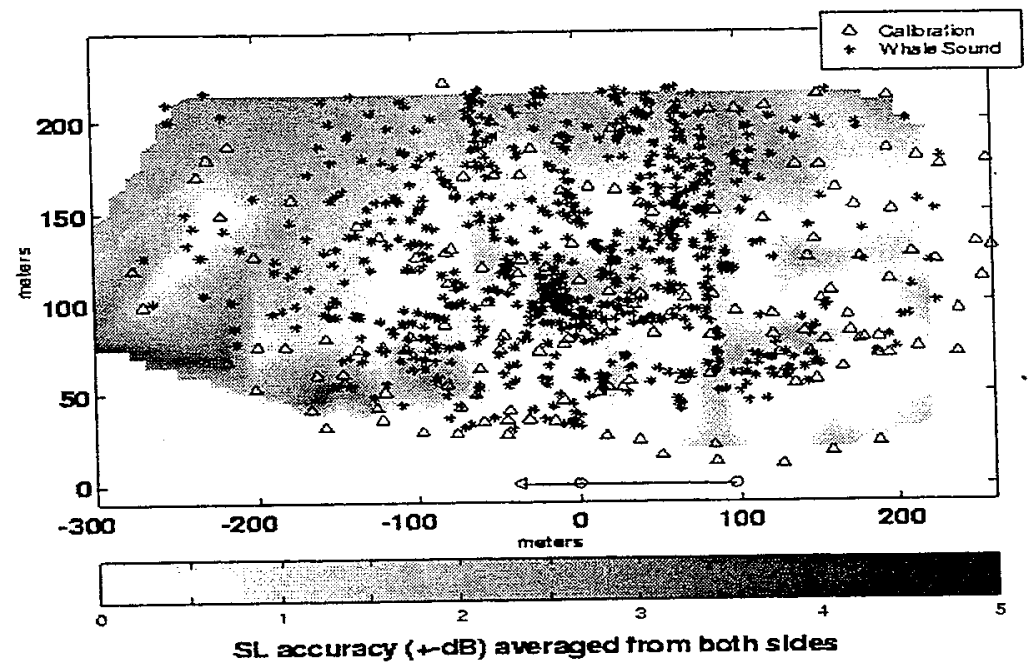

Figure 4. Calibration results of the range estimate of the 2-array system. The front array is centered on $(0,0)$ and the rear array on $(97,0)$. The $\Delta$ symbols mark where calibration measurements were taken and the $*$ symbols mark the position of all killer whale sounds for which SL was calculated. Calibration measures were taken on both sides of the array system, but are plotted together because the L-R ambiguity is not resolvable using the linear array system. The grayscale background is the interpolated range error on SL (in $\mathrm{dB}$ ) between measured points. Note that all sounds were within or near the calibrated region, and that the range error did not exceed $\pm 3 \mathrm{~dB}$ in the region from which sound SLs were calculated.

\subsubsection{Active space estimation}

The active space of each sound was estimated by calculating its frequencydependent attenuation as it propagates through seawater using empirically derived equations (Marsh \& Shulkin, 1962; Janik, in press). These equations account for spreading loss as well as frequency-dependent absorption and surface/bottom interaction. Energy in 1/3-octave bands of the attenuated signal was summed and compared to the auditory threshold of killer whales at the center frequency of each band (Hawkins \& Stevens, 1950; Hall \& Johnson, 1972; Symanski et al., 1999). The maximum detectable range, i.e. active space, was estimated as the longest range in which energy in at least one 
1/3-octave band exceeded the auditory threshold. This sensory system approach estimates the longest detectable range assuming noise levels are below the auditory threshold, which is only likely to occur in the quietest background noise conditions (Knudsen et al., 1948; ). To predict which frequencies are involved in long range signaling, the model was also used to estimate the maximum detection range of the individual 1/3-octave bands of all sounds in the sample.

The calibrated source spectrum of each signal was obtained as detailed above. To model the propagation loss of the signal, I used an empirically-derived equation for intermediate-range transmission loss in a shallow water environment:

$$
\mathrm{TL}=15 \log (\mathrm{R})+\alpha \mathrm{R}+\alpha_{\mathrm{T}}(\mathrm{R} / \mathrm{H}-1)+5 \log (\mathrm{H})+60-k_{\mathrm{L}}
$$

where TL is the transmission loss $(\mathrm{dB}), \mathrm{R}$ is the range $(\mathrm{km})$ in $0.1 \mathrm{~km}$ steps, $\alpha$ is the absorption coefficient of seawater, $\mathrm{H}$ is a function of water depth, $\alpha_{\mathrm{T}}$ is the shallow-water attenuation coefficient and $k_{\mathrm{L}}$ is a near-field anomaly (Marsh \& Shulkin, 1962). The absorption coefficient was calculated using an emprically-derived formula (Francois \& Garrison, 1982). The values for $\alpha_{\mathrm{T}}$ and $k_{\mathrm{L}}$ assuming sea state 0 and a sand bottom as well as the equation to calculate $\mathrm{H}$ based on a water depth of $100 \mathrm{~m}$ are given in Marsh \& Shulkin (1962). The empirically measured error of this formula at $2.8 \mathrm{kHz}$ and $2.7 \mathrm{~km}$ is roughly $4 \mathrm{~dB}$ (Marsh \& Shulkin, 1962).

The auditory thresholds were measured using a tonal signal (Hall \& Johnson, 1972; Symanski et al., 1999), while the "attenuated" killer whale calls in this study have energy across multiple frequencies. Models of cochlear stimulation suggest that tonal signals excite a region of hair cells commonly called the critical band centered on the frequency of the tone (Fletcher, 1940). Based upon critical bands of bottlenose dolphins (Johnson et al., 1968), I assumed 1/3-octave critical bands for killer whales, and summed the energy in each 1/3-octave band from 1 to $20 \mathrm{kHz}$ for comparison to the auditory threshold at the center frequency of the band. This approach assumes that the energy in a band of noise that is just audible is equal to the threshold energy of the pure tone that lies 
at the center of the band, as has been demonstrated in humans (Hawkins and Stevens, 1950). The auditory threshold at the center of each 1/3-octave band was obtained by fitting a third-order polynomial curve to the auditory threshold points reported (Fig. 5; Hall \& Johnson, 1972; Symanski et al., 1999). The maximum detectable range was estimated as the $0.1 \mathrm{~km}$ step shorter than the range at which energy in all $1 / 3$-octave bands fell below the threshold level.

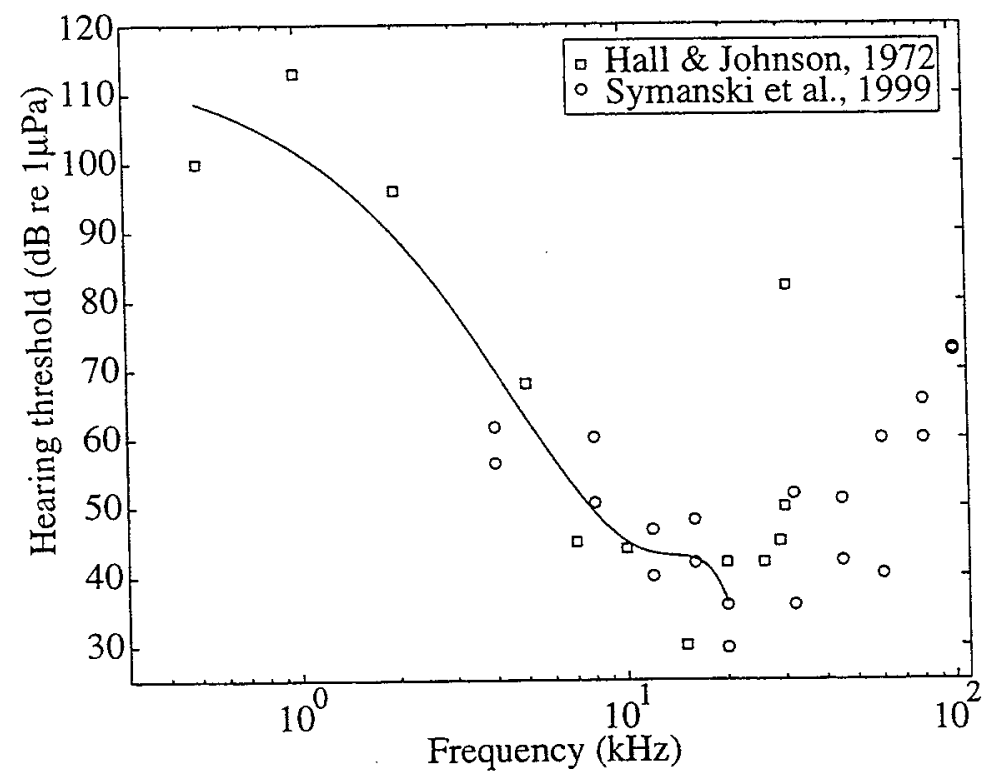

Figure 5. Auditory thresholds measured from three killer whales fit with a 3rd order polynomial least-squares curve from 0.5 to $20 \mathrm{kHz}$.

To assess the sensitivity of the active space estimate to errors in the input parameters and assumptions, I recalculated the active space of all sounds in the sample after perturbing the input parameters. SL estimates and the auditory threshold were each perturbed $\pm 6 \mathrm{~dB}$, depth was perturbed to $500 \mathrm{~m}$ and $20 \mathrm{~m}$, and the critical bandwidth was perturbed to $1 / 2$-octave and 1/6-octave bands.

\subsection{Results}

I recorded killer whale sounds for a total of five hours on two different days from a number of different killer whale pods (Table 1). I focused the sampling effort on 
animals from pods A1 and A5 to collect a broad sample of sounds from those animals. The animals were travelling tightly in various subgroups and vocally active throughout both recording sessions. In total the SLs of 819 pulsed calls and 24 whistles were calculated. Of the 819 pulsed calls, 60 did not clearly correspond to one of the call types defined by Ford (1987) and were classified as variable calls.

$\begin{array}{rrr}\text { Date: } & 9 / 1 / 98 & 9 / 8 / 98 \\ \text { Pods Present: } & \text { A1, A5 } & \text { A1, A5, B1, C1, I15 } \\ \text { \# of Animals: } & 12 & 46^{*} \\ \text { Hours Recorded: } & 2 & 3 \\ \text { Calls analyzed } & 334 & 485 \\ \text { Whistles analyzed } & 15 & 9\end{array}$

Table 1. Group composition and sample size from recording effort. The same 12 animals present on 9/1/98 were also present on $9 / 8 / 98$. $*$ The number of animals on $9 / 8 / 98$ was estimated based upon identified groups as not all individuals were seperately identified.

Overall, measured SLs ranged from 131 to $168 \mathrm{~dB} @ 1 \mathrm{~m}$ (Fig 5). With an interarray spacing of $97 \mathrm{~m}, 0$ and $+3 \mathrm{~dB}$ signal-to-noise ratio requirements for the front and rear arrays, respectively, and background noise near $90 \mathrm{~dB}$ in the $1-22 \mathrm{kHz}$ band, the lower limit of SLs measurable by the system is roughly $127 \mathrm{~dB} @ 1 \mathrm{~m}$. At the most distant point from which sounds were analyzed (see Fig. 4), sounds with a SL below $139 \mathrm{~dB}$ @1m would have insufficient SNR to be analyzed, so SLs below139 dB @1m may be underrepresented in the sample. Signals were occasionally observed only on one array when animals were quite close, suggesting that some sounds were produced below the lower SL limit of $127 \mathrm{~dB} @ 1 \mathrm{~m}$. All of these faint sounds were either whistles or variable calls - none fell into the category of stereotyped calls. 


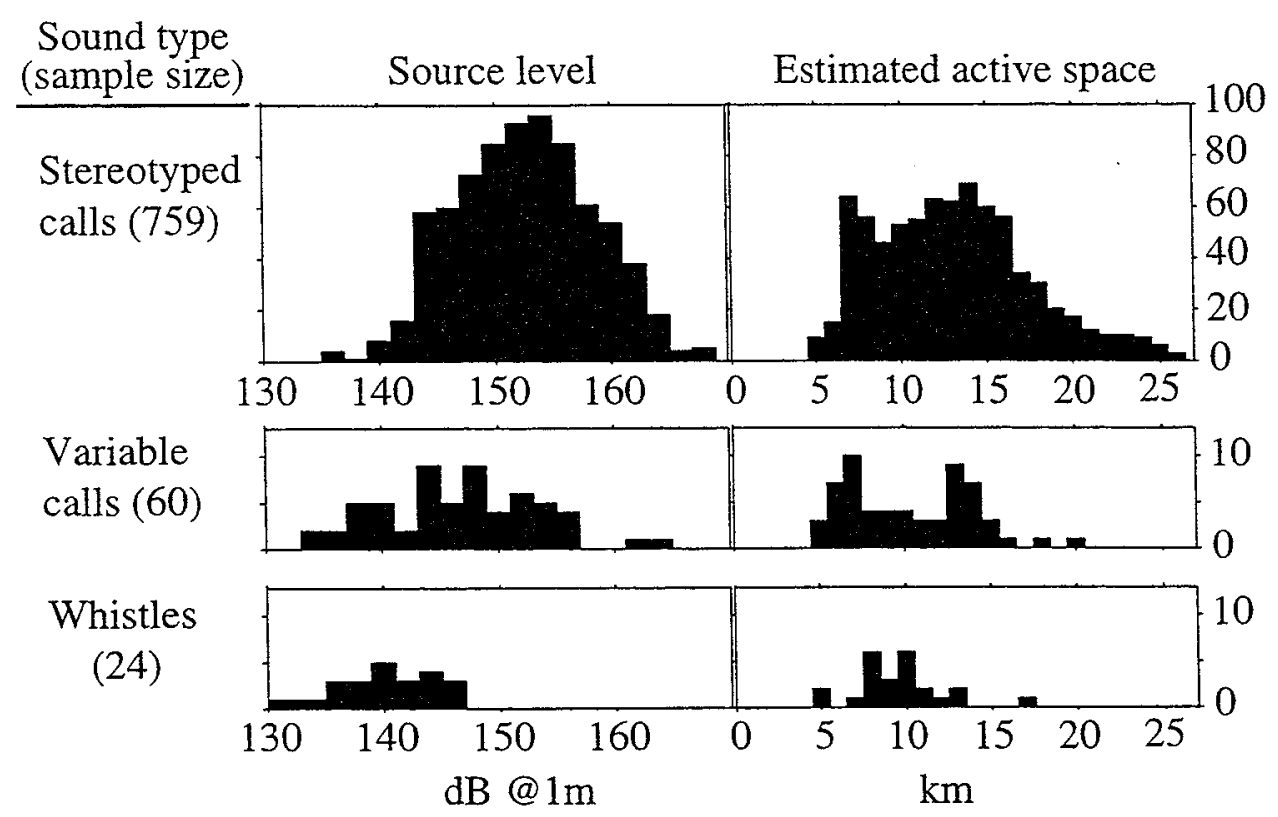

Figure 6. The source levels (left 3 panels) and estimated active space (right 3 panels) of stereotyped calls, variable calls and whistles. Note the bimodal structure of the estimated active space for both stereotyped and variable calls.

Whistles had the lowest mean SL (140.2 dB @ 1m; s.d. = 4.1 dB), followed by variable calls (146.6 dB @1m; s.d. =6.6 dB), with stereotyped calls being the loudest $(152.6 \mathrm{~dB} @ 1 \mathrm{~m}$; s.d.=5.9 dB). Using ANOVA and Tukey post-hoc analysis, the SLs of the three sound types were significantly different from each other $\left(F_{2,840}=76.1 \mathrm{p}<0.0001\right.$, Tukey post-hoc $\mathrm{p}<0.0001$ ). Estimated active space of all sounds ranged from 4.5 to 26.2 $\mathrm{km}$. Whistles had the smallest mean estimated active space $(9.5 \mathrm{~km}$, s.d. $=2.7 \mathrm{~km})$, followed by variable calls $(10.3 \mathrm{~km}$, s.d. $=3.6 \mathrm{~km})$, with stereotyped calls having the largest average estimated active space $(13.1 \mathrm{~km}$, s.d. $=4.5 \mathrm{~km})$. Using ANOVA and Tukey post-hoc analysis, the mean estimated active space of stereotyped calls was greater than that of variable calls and whistles $\left(\mathrm{F}_{2,840}=18.02, \mathrm{p}<0.001\right.$, Tukey post hoc $\mathrm{p}<0.001$ ), but the estimate for variable calls and whistles did not differ (Tukey post-hoc $\mathrm{p}=0.727)$. 
Call type

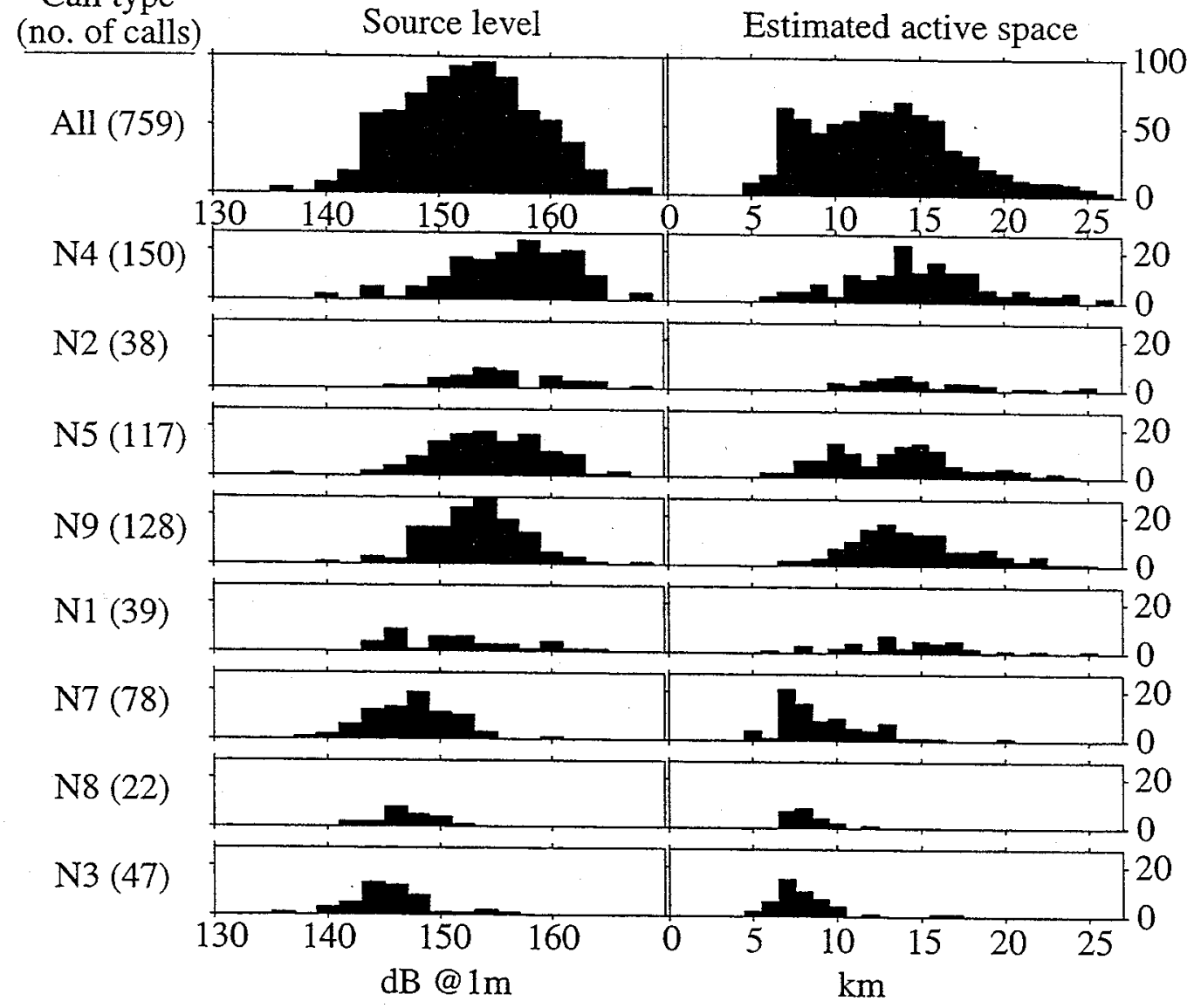

Figure 7. Source levels and estimated active space of stereotyped calls produced by pods A1 and A5. Note the diversity of source levels by call type, but a bimodal structure of estimated active space.

Within the stereotyped calls, I compared the SLs and estimated active space of the eight most common call types produced by A1 and A5 pods (Fig. 7, see Fig. 2). The same 12 animals from these pods were present on both recording days and the arrays were positioned to obtain sounds from these animals. Although I could not identify the individual producing each sound, calls were obtained from multiple locations during each follow, suggesting that the sample contains calls produced by multiple individuals in this group. The eight most common call types accounted for 618 of the 759 stereotyped calls. 
Significant differences in SL were found across types $\left(\mathrm{F}_{7,611}=54.6, \mathrm{p}<0.0001\right)$, with a mean of 156.5 and 145.4 for the loudest (N4) and faintest (N3) call types, respectively (Fig. 7). Clustering using Tukey post-hoc probability of 0.01 resulted in four clusters, suggesting diversity in the SL of different call types. Calls of the same type were produced over a wide range of SLs, with standard deviations ranging from 2.7 to 5.4 $\mathrm{dB}$ for call types $\mathrm{N} 8$ and $\mathrm{N} 4$, respectively. Significant differences across call types were also apparent in estimated active space $\left(\mathrm{F}_{7,611}=42.996 \mathrm{p}<0.0001\right)$, with a mean of 15.42 and $8.09 \mathrm{~km}$ for the longest $(\mathrm{N} 2)$ and shortest range (N3) call types. Clustering using Tukey post-hoc probability of 0.01 resulted in just two clusters of estimated active space. The long-range cluster consists of call types N2, N4, N1, N9, and N5 (overall mean 14.5 $\mathrm{km}$ ), while the short-range cluster consists of call types $\mathrm{N} 7, \mathrm{~N} 8$ and $\mathrm{N} 3$ (overall mean 8.8 km; Figs 7 \& 8).

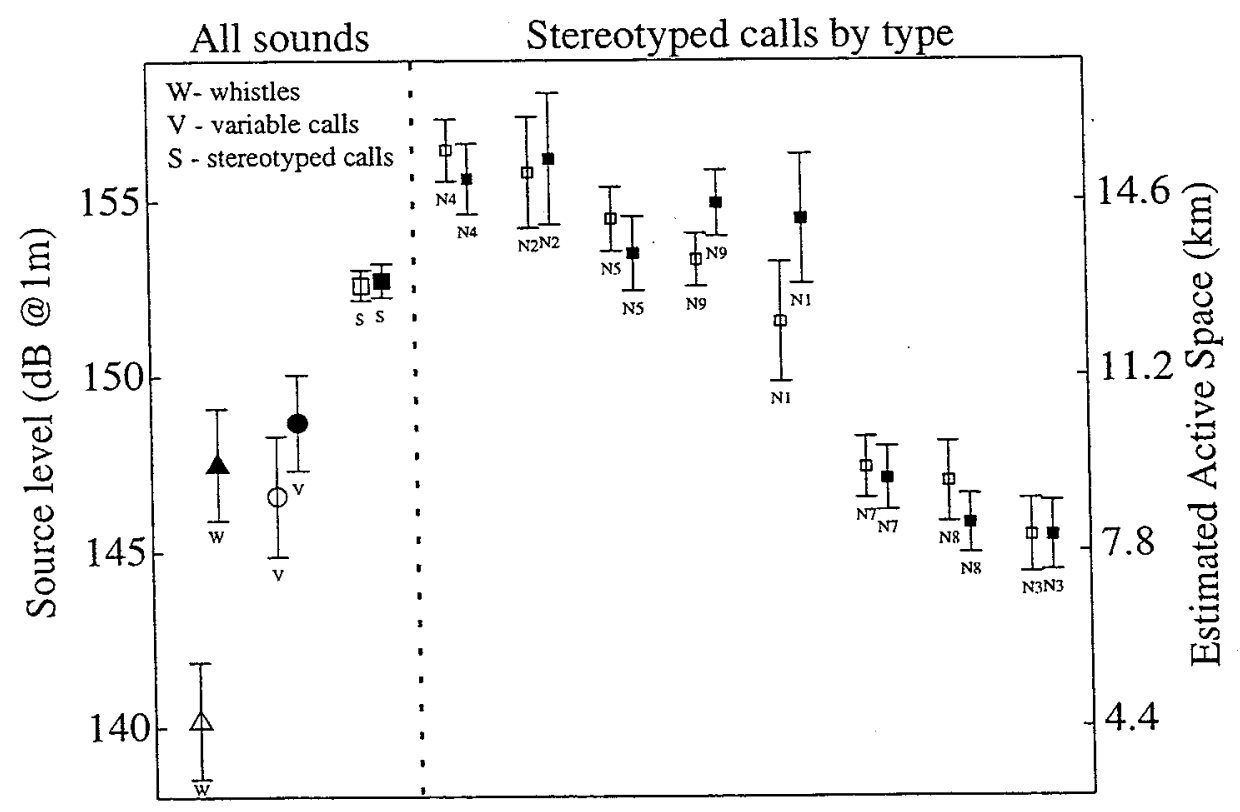

Figure 8. Mean ( \pm 1 s.e.) source level (open symbols) and estimated active space (filled symbols) of whistles, variable calls and stereotyped calls (left), and the different stereotyped call types produced by pods A1 and A5 (right). Note that the effect of the active space model was to decrease variability across sound types, especially for whistles and call types N4, N9 and N1. 
There was less diversity across sound types in estimated active space than SL (Fig. 8). This effect was most clear for whistles which had a predicted active space similar to that of variable calls even though whistles had $6.4 \mathrm{~dB}$ lower average SL. Call types N4, N9, and N1 had similar mean active space estimates despite differences in their average SL (Fig. 8). On average, the 1/3-octave band centered on $9 \mathrm{kHz}$ was the band predicted to be detectable at the longest range (Fig. 9). Relative auditory insensitivity is the key factor reducing the estimated active space of bands below $9 \mathrm{kHz}$, and decreased energy in the source spectra as well as increased absorption reduce the estimated active space of bands above $9 \mathrm{kHz}$.

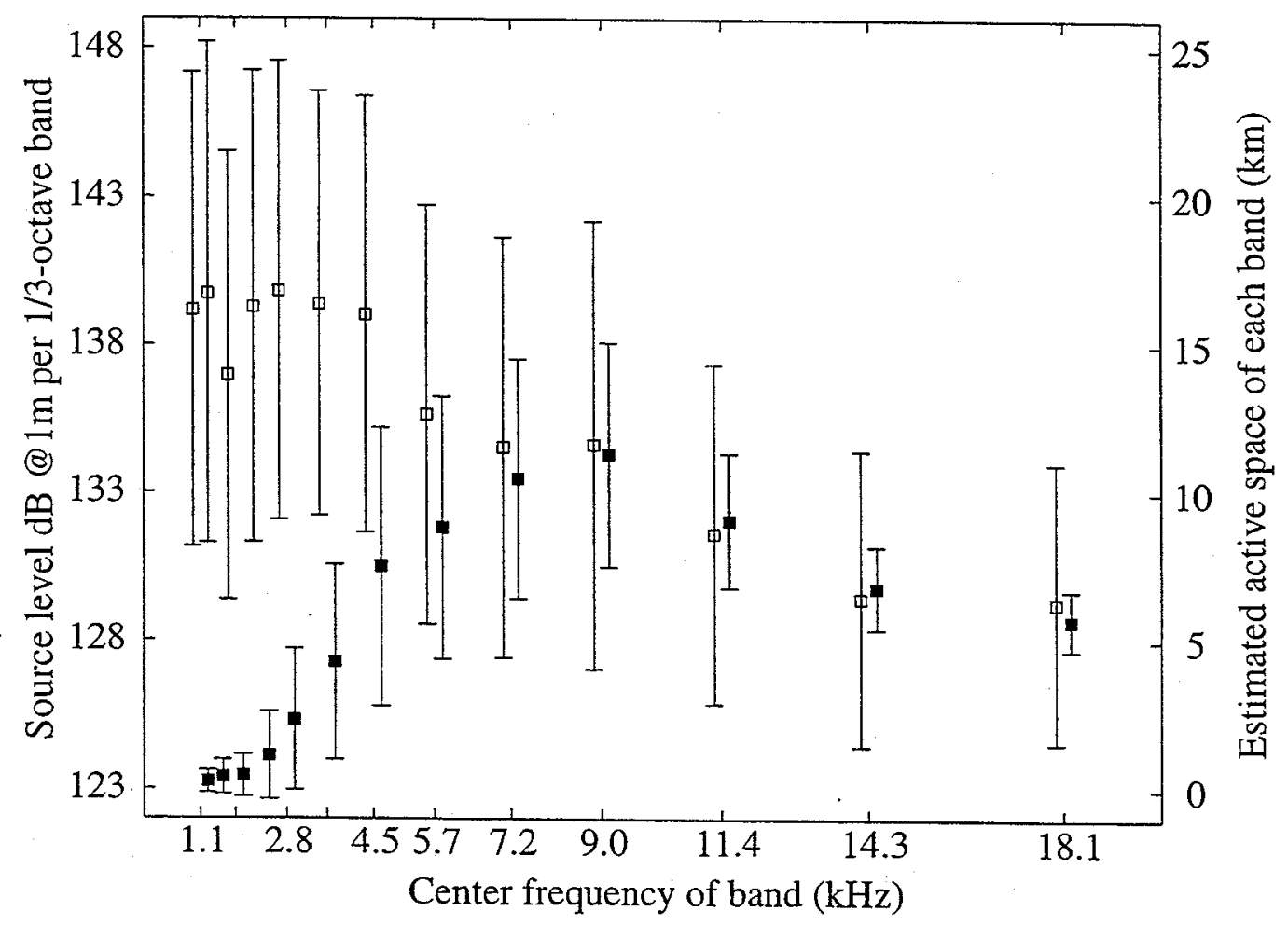

Figure 9. Mean ( \pm 1 s.d.) source level (open symbols) and estimated active space (filled symbols) of $1 / 3$-octave bands between 1 and $20 \mathrm{kHz}$. Note the band centered on $9 \mathrm{kHz}$ has the longest mean estimated active space. At low frequencies, active space is limited by the hearing threshold, while at high frequencies, decreased source energy and possibly increased frequencydependent absorption limit active space. 
The active space estimate was equally sensitive to perturbations in SL and auditory threshold. A $6 \mathrm{~dB}$ increase in SL (or decrease in threshold) resulted in an increase in estimated active space of $4.13 \mathrm{~km}(+25.5 \%)$ and $3.23(+36.7 \%) \mathrm{km}$ for longand short-range call types, while a $6 \mathrm{~dB}$ decrease in SL (or increase in threshold) resulted in a corresponding decrease of $3.53 \mathrm{~km}(-24.3 \%)$ and $2.60 \mathrm{~km}(-29.5 \%)$. Increasing water depth to $500 \mathrm{~m}$ resulted in an increase of estimated active space of $2.26 \mathrm{~km}$ $(+15.6 \%)$ and $0.76 \mathrm{~km}(+8.6 \%)$ for long- and short-range call types, while decreasing water depth to $20 \mathrm{~m}$ resulted in a corresponding decrease of $3.56 \mathrm{~km}(-24.5 \%)$ and 1.71 $\mathrm{km}(-19.4 \%)$. The model was not sensitive to changes in the bandwidth over which energy was summed. Use of 1/2-octave bands resulted in an increase in estimated active space of $0.86 \mathrm{~km}(+5.9 \%)$ and $0.79 \mathrm{~km}(+9.0 \%)$ for long- and short-range call types, while use of 1/6-octave bands resulted in a corresponding decrease of $0.86(-5.9 \%)$ and $0.99 \mathrm{~km}(-11.3 \%)$.

\subsection{Discussion}

This is the first study to systematically measure source levels and estimate the active space of sounds produced by free-ranging killer whales. SLs of the loudest portion of each sound ranged from 131-168 dB @1m with the mean of stereotyped calls (152.6 $\mathrm{dB} @ 1 \mathrm{~m})$ higher than that of variable calls $(146.6 \mathrm{~dB} @ 1 \mathrm{~m})$ and whistles $(140.2 \mathrm{~dB}$ $@ 1 \mathrm{~m})$. Within the stereotyped calls, the eight most common call types recorded from pods A1 and A5 had different mean SLs ranging from 145.4 to $156.5 \mathrm{~dB} @ 1 \mathrm{~m}$ for the faintest (N3) and loudest (N4) call types, respectively. The overall range of SLs is similar to those reported for other large odontocetes (Watkins et al., 1997; Fish \& Turl 1976; Janik, in press). Whistles were also about $10 \mathrm{~dB}$ fainter than burst-pulse sounds in a sample of sounds collected from the melon-headed whale (Watkins et al., 1997). The whistles in my sample are clearly fainter than the whistles produced by bottlenose dolphins in Moray Firth, Scotland (Janik, in press), although louder than whistles produced by spinner dolphins in Hawaii (109-125 dB @ 1m; Watkins \& Schevill, 1974). 
The results of the active space estimation suggest that killer whales can detect sounds produced by conspecifics over large distances. Overall estimated active space ranged from 4.5 to $26.2 \mathrm{~km}$, with mean values of different sound types ranging from 8.1 $\mathrm{km}$ (N3 call type) to $15.4 \mathrm{~km}$ (N2 call type). The maximum estimated active space closely matches maximum active space estimates of 20 to $25 \mathrm{~km}$ for a bottlenose dolphin whistle using the same transmission loss model in quiet conditions (Janik, in press). Based upon the results of the active space model, the acoustic repertoire of this group of resident killer whales can be divided into two primary groups: 'long-range' sounds including call types N4, N2, N5, N9 and N1 (mean estimated active space: $14.5 \mathrm{~km}$ ), and 'short-range' sounds including whistles (mean: $9.5 \mathrm{~km}$ ) and call types N7, N8 and N3 (mean: $8.8 \mathrm{~km}$ ). Interestingly, all of the long-range call types contain a stereotyped highfrequency component while the short-range call types do not (Fig. 2; Miller and Bain, in press).

Variable calls had two peaks in estimated active space, one corresponding to the mean of short-range calls and the other corresponding to the mean of long-range signals (Figs. $6 \& 7$ ), suggesting variable calls may consist of exemplars from both groups. I also found evidence for a very faint class of variable sounds and whistles. Several of these faint sounds were detected only on one array when animals were quite close, suggesting a SL less than $127 \mathrm{~dB} @ 1 \mathrm{~m}$ although it was not possible to calculate their SL. Current recording techniques may be insufficient to reliably detect this potentially important class of faint signals. Remotely attachable tags capable of recording full-bandwidth acoustic signals have recently been developed (Fletcher et al., 1996; Johnson et al., 1999), and may be an ideal tool to reliably detect these faint sounds.

Across the different sound types, estimated active space was less diverse than SL. The 'flattening' effect of the active space model was most apparent for whistles, which had a similar estimated active space as variable calls, even though the SL of whistles was an average of $6.6 \mathrm{~dB}$ lower than variable calls (Fig. 8). Concentration of acoustic power into a single frequency may increase detection ranges of tonal whistles (Wiley \& Richards, 1982). SL differences between different stereotyped call types were also 
'flattened' by the active space model, particularly for call types N4, N9 and N1 which have similar average active space estimates despite differences in mean SL (Fig. 8). This finding suggests that killer whales might pre-emphasize sounds containing energy in frequencies to which they have less sensitive hearing by producing them at a higher SL.

Sensitivity analyses suggest that the active space estimates fluctuate by roughly $\pm 30 \%$ with $\pm 6 \mathrm{~dB}$ changes in SL or auditory sensitivity, but that they are relatively insensitive to assumptions about the critical bandwidth of killer whale hearing. The actual active space of signals is profoundly affected by environmental factors including ambient noise levels, sound propagation conditions (temperature profiles, water depth, sea state, bottom type), and the presence of obstacles between signaler and receiver.

The depth of $100 \mathrm{~m}$ assumed in the model is valid over many near-shore areas that killer whales inhabit, but active space estimates increase in deeper water due to decreased surface and bottom contact loss (Marsh \& Shulkin, 1962). When water depth was increased to $500 \mathrm{~m}$ in the model, active space estimates increased by $15.6 \%$ and $8.6 \%$ for long- and short-range call types, respectively. Similarly, decreased depth $(20 \mathrm{~m})$ resulted in decreases of $24.5 \%$ and $19.4 \%$. Thus, depth has a greater influence on the active space of long-range than short-range sounds. The depth of the signaler and receiver can also profoundly influence signal propagation, with low frequencies being strongly attenuated when signalers or receivers are near the surface (Mercado \& Frazer, 1999). In relying on the Marsh \& Shulkin equations (1962), the model presented here assumes that the signaler and receiver are both in the middle of the water column which is not likely to be the case for signaling and receiving killer whales. A combined time-depth and acoustic recording tag (i.e. Fletcher et al., 1996) could be used to quantify the depth at which killer whales call. Typical signaler and receiver depths could be explicitly included in a more sophisticated model of sound propagation to more accurately predict signal transmission loss (Mercado \& Frazer, 1999).

On average, the 1/3-octave band centered on $9 \mathrm{kHz}$ had the longest detectable range (Fig. 9), with lower frequencies limited by relatively insensitive hearing and higher frequencies limited by less source energy and increased chemical absorption of sound. 
The fundamental of the high-frequency component lies near the longest-range frequency band (Fig. 2), while the most intense sidebands of the low-frequency component are in the shorter range $1-7 \mathrm{kHz}$ bands. Directionality of signal radiation will cause the active space to be larger in the forward direction at higher frequencies, so this tendency for a 9$\mathrm{kHz}$ peak is only valid for a broadside orientation as was the case in this study. Confirmation of the actual active space of these signals requires playback experiments to assess at what ranges receiving killer whales attend and respond to different features of the signals.

The difference between the loudest and faintest exemplar of the eight call types and whistles ranged from 11 to $30 \mathrm{~dB}$, with a mean range of $21.5 \mathrm{~dB}$ (Figs. $6 \&$ 7). The diversity of SLs within each sound type could result from individual differences in SL, differences in motivation and/or signal directionality. Individual differences in SL could. be a consequence of body size, which varies greatly with age and sex of killer whales (Matkin \& Leatherwood, 1986). SLs appear to increase with increasing body size across cetacean species (Patterson \& Hamilton, 1967; Cummings \& Thompson, 1971; Thode et al., 2000a; Cummings \& Holliday, 1985; Schevill \& Watkins, 1972; Cummings et al., 1968; Dawbin \& Cato, 1992). Killer whales might modulate SLs based upon perceived range to a receiver, changes in background noise levels (Cynx et al., 1998), and/or the emotional state of the signaler. Lastly, killer whale calls appear to be directional at high frequencies (Schevill \& Watkins, 1966), resulting in SLs that vary as a function of signaler orientation.

Directionality of signal transmission has an important influence on active space as both the detectable range and the frequency content of signals differ depending on orientation (see chapter six). Although I could not directly observe the orientation of signalling animals, most sounds were likely received from an off-axis orientation with some sounds produced by animals facing directly toward or away from the array. Thus, the mean estimated active space of this sample is likely to be intermediate to the extremes when an animal is facing directly toward or away from the receiver. While the transmission beam pattern of killer whale calls has not been measured, data reported in 
chapter six of this thesis showed that calls produced by animals oriented toward the receiver contained $5.7 \mathrm{~dB}$ less energy in the $5-44 \mathrm{kHz}$ frequency band than in the $1-5 \mathrm{kHz}$ band. When animals were oriented away, the $5-44 \mathrm{kHz}$ band contained $11.0 \mathrm{~dB}$ less energy. If the $1-5 \mathrm{kHz}$ band is omni-directional, then absolute directionality effects could be approximated as at least $\pm 3 \mathrm{~dB}$, corresponding to an estimated active space difference of $\sim \pm 15 \%$ depending on orientation. However, the $1-5 \mathrm{kHz}$ frequency band may not be omni-directional, so the effects of directionality on the shape of the active space around signalling killer whales will remain unclear until the beam pattern is measured. Bain and Dalheim (1994) found that the direction from which masking sounds were presented affected its effectiveness as a masker, suggesting that the orientation of the receiving animal may also be an important consideration in the shape of active space.

At this point, the function of sounds produced by killer whales is unknown. Ford (1991) proposed that discrete calls function primarily to maintain pod cohesion and coordinate activities. The maximum detection ranges estimated here are sufficiently large for matrilineal group members to maintain acoustic contact with each other over typical separation ranges, which rarely exceed a few kilometers (Miller \& Bain, in press). In the fjord-like inland waters of the coastal NE Pacific, many continuous sections of water are shorter than the average estimated active space of loud calls $(14.5 \mathrm{~km})$. In this habitat, maintaining a direct signal path may be as important as 'staying within range' for members of stable social groups to maintain acoustic contact with each other.

Call structure and use differs between pods and the highly cohesive matrilinealunits that compose pods, suggesting that the repertoire could identify multiple levels of social affiliation (Ford, 1991; Miller \& Bain, in press). In a study of call-type use in different behavior states, Ford (1989) found that no sound type is exclusively produced in association with a particular behavioral category. He proposed that calling functions to maintain contact between members of pods or highly cohesive matrilineal groups, but that different discrete call types have little context or motivation-specific meaning.

The results presented here suggest that different sound types in the killer whale repertoire do not all function in the same manner, but that some serve as long-range 
contact sounds and others as short-range signals. The long-range call types all contain a stereotyped high-frequency component while the short-range call types do not. The active space estimates correlate with the behavioral context in which those signal types are more likely to be produced. In his study comparing behavior and sound production of pods A1, A4, and A5, Ford (1989) found significant increases in the production of whistles, variable calls, and the faint N3 call type during group-resting, beach-rubbing, and socializing behaviors. In these behavioral states, animals tend to be closely spaced and interactions between group members appear to be primarily affiliative. Loud call types N2, N4, N5, and N9 were used more during behaviors where group members are dispersed, including travelling, foraging, when different pods were meeting, or in large aggregations of animals (Ford, 1989, pg 737). Similarly, Bain (1986) identified clusters of call types produced by two captive killer whales captured from A5 pod in 1969. The cluster associated with high activity levels (assessed by respiration rate) included call types N4, N2, and N9, while lower-activity clusters contained call types N7, N8, N3 and whistles (Bain, 1986).

Ford's (1989) finding that no sound type is exclusively produced in a particular behavioral state was corroborated by Bain's (1986) captive study, and also by the diversity of types in the data set reported here. However, the context or motivation of different individuals living in a stable group may not always be the same (Trivers, 1974). Production of a certain call type may be a means for an individual whale to signal its motivational state and manipulate the behavior of other group members, no matter what the current dominant behavior. For example, a whale producing a set of N3 calls while the group appears to be foraging may be signaling its motivation to rest, or conversely an individual producing loud call types while the group appears to be resting may be signaling its desire to begin foraging or travel. Once sufficient individuals are in the same behavioral state, the group will produce more calls of the appropriate type. Clearly, more detailed observations of the behavior and sound production of individual killer whales (Miller \& Tyack, 1998) are needed to explore the extent to which different sound types might encode motivational or context-specific information. 
In this study, active space was estimated assuming that signal detection was threshold-limited rather than noise-limited, so the estimates presented here are only valid for quiet conditions in which background noise levels are below threshold. Such low noise conditions are likely to occur only rarely (Knudsen et al. 1948) and masking due to noise generated by wave action, rain, sounds of other animals, or anthropogenic sources will reduce active space (Payne \& Webb, 1971). The model presented here could be expanded to adjust the detection threshold based upon the noise level in each 1/3-octave band. Payne \& Webb (1971) assumed a detection threshold of $0 \mathrm{~dB}$ signal-to-noise ratio to estimate the active space of fin whale calls. A more detailed prediction of the effects of noise on detection ranges is difficult given scant information on masked hearing thresholds in killer whales (see Bain \& Dalheim, 1994), and the lack of studies addressing how communication signals are masked by noise sources which actually exist in nature (Bain \& Dalheim, 1994; Erbe \& Farmer, 1998). Signalers may also adjust their source level in different noise conditions, which may reduce the impact noise has on active space (Cynx et al., 1998; Lengagne et al., 1999).

\subsection{Acknowledgements}

Many thanks to Mark Johnson and WHOI's acoustic systems group for assistance with equipment development and data analysis. Field assistance was provided by Erin Gentry, Miranda Buck, Leandra de Sousa, Dennis Schmidt, Nicoletta Biassoni, Morgan Heim, Michael Richlen, Mariya Sweetwyne, and Jodi Udd. Thanks also to David Bain, David Tyre, and Bill \& Donna MacKay for help in the field. Darlene Ketten provided invaluable advice on the hearing model. Helpful comments on the manuscript were provided by Peter Tyack, Peter Slater, David Bain, Nicoletta Biassoni, Rebecca Thomas, Vincent Janik. Funding was provided by WHOI's Ocean Ventures Fund and Rinehart Coastal Research Center. 


\subsection{References}

Au, W. W. L. 1993. The Sonar of Dolphins. New York: Springer-Verlag, pp. 277.

Bain, D. E. 1986. Acoustic behavior of Orcinus: sequences, periodicity, behavioral correlates and an automated technique for call classification. In: Behavioral Biology of Killer Whales. (Eds. B. C. Kirkevold \& J. S. Lockard), New York: Alan R. Liss, Inc., pp. 335-371.

Bain, D. E. and Dalheim, M. E. 1994. Effects of masking noise on detection thresholds of killer whales. In: Marine Mammals and the Exxon Valdez. (Ed. T. R. Loughlin) San Diego: Academic Press, pp. 243-256.

Bradbury, J. W., and Vehrencamp, S. L. 1998. Principles of Animal Communication. New. York: Sinauer Press, ppg. 882.

Brenowitz, E. A. 1982. The active space of red-winged blackbird song. J. Comp. Physiol. 147: 511-522.

Cato, D. H. 1998. Simple methods of estimating source levels and locations of marine animal sounds. J. Acoust. Soc. Am. 104 (3): 1667-1678.

Cummings, W. C. and Holliday, D. V. 1985. Passive acoustic location of bowhead whales in a population census off Point Barrow, Alaska. J. Acoust. Soc. Am. 78 (4): $1163-1169$.

Cummings, W. C., Thompson, P. O. 1971. Underwater sounds from the blue whale, Balaenoptera musculus. J. Acoust. Soc. Am. 50 (4): 1193-1198.

Cummings, W. C., Thompson, P. O., and Cook, R. 1968. Underwater sounds of migrating gray whales, Eschrichtius glaucus (Cope). J. Acoust. Soc. Am. 44 (5): $1278-1281$.

Cynx, J., Lewis, R., Tavel, B., and Tse, H. 1998. Amplitude regulation of vocalizations in noise by a songbird, Taeniopygia guttata. Anim. Behav. 56: 107-113.

Dabelsteen, T. and Pedersen, S. B. 1990. Song and information about aggressive responses of blackbirds, Turdus merula: evidence from interactive playback experiments with territory owners. Anim. Behav. 40: 1158-1168.

Dawbin, W. H. and Cato, D. H. 1992. Sounds of a pygmy right whale (Caperea marginata). Mar. Mamm. Sci. 8 (3): 213-219. 
Deecke, V. B., Ford, J. K. B., and Spong, P. 1999. Quantifying complex patterns of bioacoustic variation: use of a neural network to compare killer whale (Orcinus orca) dialects. J. Acoust. Soc. Am. 105 (4): 2499-2507.

Deecke, V. B., Ford, J. K. B., and Spong, P. in press. Dialect change in resident killer whales (Orcinus orca): implications for vocal learning and cultural transmission. Anim. Behav.

Dittus, W. 1988. An analysis of Toque macaque cohesion calls from an ecological perspective. In: Primate Vocal Communication (D. Todt, P. Goedeking, \& D. Symmes, eds.) New York: Springer-Verlag, ppg. 31-50.

Erbe, C. and Farmer, D. M. 1998. Masked hearing thresholds of a beluga whale (Delphinapterus leucas) in icebreaker noise. Deep-Sea Res. II 45: 1373-1388.

Fish, J. F. and Turl, C. W. 1976. Acoustic Source Levels of Four Species of Small Whales. Naval Undersea Center Report, NUC-TP 547.

Fletcher, H. 1940. Auditory patterns. Rev. Mod. Phys. 12: 47-65.

Fletcher, S., LeBoeuf, B. J., Costa, D. P., Tyack, P. L., and Blackwell, S. B. 1996. Onboard acoustic recording from diving northern elephant seals. J. Acoust. Soc. Am. 100 (4): 2531-2539.

Ford, J. K. B. 1987. A catalogue of underwater calls produced by killer whales (Orcinus orca) in British Columbia. Canadian Data Report of Fisheries and Aquatic Sciences No. 633.

Ford, J. K. B. 1989. Acoustic behavior of resident killer whales (Orcinus orca) in British Columbia. Canadian Journal of Zoology, 67, 727-745.

Ford, J. K. B. 1991. Vocal traditions among resident killer whales (Orcinus orca) in coastal waters of British Columbia. Canadian Journal of Zoology, 69, 14541483 .

Francois, R. E. and Garrison, G. R. 1982. Sound absorption based upon ocean measurements. Part II: boric acid contribution and equation for total absorption. J. Acoust. Soc. Am. 72 (6): 1879-1890.

Gerhardt, H. G. 1975. Sound pressure levels and radiation patterns of the vocalizations of some north American frogs and toads. J. Comp. Physiol. 102: 1-12.

Hall, J. and Johnson, C. S. 1972. Auditory thresholds of a killer whale Orcinus orca Linnaeus. J. Acoust. Soc. Am. 51: 515-517. 
Hawkins, J. E. and Stevens, S. S. 1950. The masking of pure tones and of speech by white noise. J. Acoust. Soc. Am. 22: 6-13.

Hoelzel, A. R. and Osborne, R. W. 1986. Killer whale call characteristics: implications for cooperative foraging strategies. In: Behavioral Biology of Killer Whales. (Eds. B. C. Kirkevold \& J. S. Lockard), New York: Alan R. Liss, Inc. pp. 373403.

Janik, V. in press. Source levels and the estimated active space of bottlenose dolphin (Tursiops truncatus) whistles in the Moray Firth, Scotland. J. Comp. Physiol. A.

Johnson, C. S. 1968. Masked tonal thresholds in the bottlenosed porpoise. J. Acoust. Soc. Am. 44: 965-967.

Johnson, M. A., Tyack, P. L., and Nowacek, D. P. 1999. A digital acoustic recording tag for measuring the response of marine mammals to sound. In: Abstracts of the International Council for the Exploration of the Seas (ICES), Stockholm, Sweden.

Lengagne, T., Aubin, T., Lauga, J., and Jouventin, P. 1999. How do king penguins (Aptenodytes patagonicus) apply the mathematical theory of information to communicate in windy conditions? Proc. Roy. Soc. Lond. B 26: 1623-1628.

Loftus-Hills, J. J. and Littlejohn, M. J. 1971. Mating-call sound intensities of anuran amphibians. J. Acoust. Soc. Am. 49: 1327-1329.

Knudsen, V. O., Alford, R. S., and Emling, J. W. 1948. Underwater ambient noise. J. Mar. Research 7 (3): 410-429.

Marler, P. 1973. A comparison of vocalizations of red-tailed monkeys and blue monkeys, Cercopithecus ascanius and C.mitis, in Uganda. Z. Tierpsychol. 33: 223-247.

Marsh, H. W. and Schulkin, M. 1962. Shallow water transmission. J. Acoust. Soc. Am. 34: $863-864$.

Marten, K., Quine, D., and Marler, P. 1977. Sound transmission and its significance for animal vocalization II. tropical forest habitats. Behav. Ecol. Sociobiol. 2: 291302.

Matkin, C. O. and Leatherwood, S. 1986. General biology of the killer whale, Orcinus orca: a synopsis of knowledge. In: Behavioral Biology of Killer Whales. (Eds. B. C. Kirkevold \& J. S. Lockard), New York: Alan R. Liss, Inc. pp. 35-95. 
Mercado, E. III and Frazer, L. N. 1999. Environmental constraints on sound transmission by humpback whales. J. Acoust. Soc. Am. 106: 3004-3016.

Miller, P. J. O. and Bain, D. E. in press. Within-pod variation in the sound production of a pod of killer whales (Orcinus orca). Anim. Behav.

Miller, P. J. and Tyack, P. L. 1998. A small towed beamforming array to identify vocalizing resident killer whales (Orcinus orca) concurrent with focal behavioral observations. Deep-Sea Res. II 45: 1389-1405.

Mohl, B., Wahlberg, M., Madsen, P. T. 2000. Sperm whale clicks: directionality and source level revisited. J. Acoust. Soc. Am. 107 (1): 638-648.

Morton, A. B., Gale, J. C., and Prince, R. C. 1986. Sound and behavioral correlations in captive Orcinus orca. In: Behavioral Biology of Killer Whales. (Eds. B. C. Kirkevold \& J. S. Lockard), New York: Alan R. Liss, Inc. pp. 303-333.

Patterson, B. and Hamilton, G.R. 1967. Repetitive 20 cycle per second biological hydroacoustic signals at Bermuda. In: Marine Bioacoustics, vol. 1 (W. N. Tavolga, ed.) New York: Pergamon Press, pgs. 125-145.

Payne, R. and Webb, D. 1971. Orientation by means of long range acoustic signaling in baleen whales. Ann. (N.Y.) Acad. Sci. 188: 110-141.

Prestwich, K. N., Brugger, K. E., and Topping, M. 1989. Energy and communication in three species of hylid frogs: power input, power output and efficiency. J. Exp. Biol. 144: 53-80.

Rowell, T. E. and Hinde, R. A. 1962. Vocal communication by the rhesus monkey (Macaca mulatta). Proc. Zool. Soc. Lon. 138: 279-294.

Ryan, M. J., Tuttle, M. D., and Rand, A. S. 1982. Bat predation and sexual advertisement in a netropical frog. Am. Nat. 119: 136-139.

Schevill, W. E. and Watkins, W. A. 1966. Sound structure and directionality in Orcinus (killer whale). Zoologica 51: 71-76.

Schevill, W. E. and Watkins, W. A. 1972. Intense low-frequency sounds from an Antarctic minke whale, Balaenoptera acutorostata. Brevoria 388: 1-8.

Symanski, M. D., Bain, D. E., Kiehl, K., Pennington, W., Wong, S., and Henry, K. R. 1999. Killer whale (Orcinus orca) hearing: auditory brainstem response and behavioral audiograms. J. Acoust. Soc. Am. 106 (2): 1134-1141. 
Thode, A. M., D'Spain, G. L., and Kuperman, W. A. 2000a. Matched-field processing, geoacoustic inversion, and source signature recovery of blue whale vocalizations. J. Acoust. Soc. Am. 107 (3): 1286-1300.

Thode, A., Norris, T., and Barlow, J. 2000b. Frequency beamforming of dolphin whistles using a sparse three-element towed array. J. Acoust. Soc. Am. 107 (6): 3581-3484.

Trivers, R. L. 1974. Parent-offspring conflict. Amer. Zool. 14: 249-264.

Urick, R. J. 1981. Principles of underwater sound. New York: McGraw-Hill.

Watkins, W. A. 1967. Harmonic interval: fact or artifact in spectral analysis of pulse trains. In: Marine Bio-acoustics, Vol. 2 (Ed. W. N. Tavolga), Oxford: Pergamon Press, pp. 15-42.

Watkins, W. A., Daher, M. A., Samuels, A., and Gannon, D. P. 1997. Observations of Peponocephala electra, the melon-headed whale, in the Southeastern Caribbean. Car. J. Sci. 33: 34-40.

Watkins, W. A. and Schevill, W. E. 1974. Listening to Hawaiian spinner porpoises, Stenella $c f$. longirostris, with a three-dimensional hydrophone array. Mammology 55 (2): 319-328.

Wiley, R. H. and Richards, D. G. 1982. Adaptations for acoustic communication in birds: sound transmission and signal detection. In: Acoustic Communication in Birds, Vol. 2. (Ed. by D.E. Kroodsma \& E.H. Miller) New York: Academic Press, pg. 131-181. 


\section{CHAPTER 6: DIRECTION-OF-MOVEMENT CUEING VIA DIFFERENTIAL DIRECTIONALITY IN ACOUSTIC SIGNALS PRODUCED BY FREE- RANGING KILLER WHALES, ORCINUS ORCA}

\subsection{Introduction}

Many studies have shown that animals are capable of localizing sound sources by determining the source's azimuth, elevation, and distance (rev. in Klump \& Shalter, 1984; Nelson \& Stoddard, 1998). In group-living animals, sound source localization provides a means for receivers to approach or maintain distance from signalers (Marler, 1965 ) or to stay within acoustic range of other group members (Caine \& Stevens, 1990). Here I present data demonstrating that the frequency structure of intense, broadband calls produced by killer whales in the wild shows a clear dependence on the orientation of the signaler, with high-frequency components attenuated when signalers are oriented away from the hydrophone. In my sample, the directionality pattern of calls correlated both with the surfacing orientation and overall direction-of-movement of signalers. Combined with sound source localization, direction-of-movement cueing via differential directionality in acoustic signals may be a reliable and efficient means for mobile animals to regulate their spacing relative to other group members.

Acoustic signals produced by animals commonly radiate in a non-uniform fashion from the signaler (anurans: Gerhardt, 1975; Prestwich et al., 1989, fish: Barimo \& Fine, 1998, birds: Archibald, 1974; Witkin, 1977; Hunter et al., 1986; Larsen \& Dabelsteen, 1990; bats: Schnitzler \& Grinnell, 1977, seals: Schevill \& Watkins, 1971, odontocetes: Schevill \& Watkins, 1966; Au et al., 1986, 1987, 1995; Mohl et al., 2000, primates: Dunn \& Farnsworth, 1939). The directional pattern of sound transmission is thought to arise from directional sound source resonators (Hunter et al., 1986; Au et al., 1987), shadowing by tissues (Schnitzler \& Grinnell, 1977), and/or gradations in sound speed in fatty structures in the head of delphinids (Aroyan, 1990; Au, 1993).

Studies of the directional structure of sounds produced by birds show increased directionality in higher frequency portions of the signal (Witkin, 1974; Larsen \& Dabelsteen, 1990). Directionality is typically more pronounced in higher frequencies 
because sound source resonators and tissue structures are more effective at absorbing, reflecting, and/or focusing small-wavelengths. The term "differential directionality" is proposed here to refer to compound signals containing multiple frequency bands that radiate from the signaler with differing degrees of directionality. The echolocation clicks of bats and odontocetes are highly directional, and detailed studies have confirmed narrower beamwidths for higher frequency portions of the echolocation signals ( $\mathrm{Au}$, 1993; Au et al., 1995). Directionality of sounds used primarily for echolocation results in higher signal-to-noise ratio of returning echoes, a fact which has been exploited by human-designed sonar systems (Urick, 1983).

Little is known about the consequences of signal directionality on communication systems, partly due to difficulties entailed with measuring directionality of natural signals (Larsen \& Dabelsteen, 1990). In birds, directionality of relatively faint signals used in close-range signaling is thought to decrease the risk of signal reception by non-intended receivers such as predators (Witkin, 1974; Klump \& Shalter, 1984). Hunter et al. (1986) transmitted sounds from within starling carcasses to confirm Witkin's (1974) finding that high-frequency sounds are more directional than low-frequency sounds. Hunter et al. (1986) speculated that broad-band signals might cue signaler orientation, possibly to communicate the location of a predator to flockmates or to direct sounds at a particular receiver such as territory intruders. Territorial blackbirds switch from a loud omnidirectional version of their territorial display to a more faint directional display when they approach a conspecific intruder, presumably to reduce detection risk and direct signals at the intruder (Dabelsteen \& Pedersen, 1988; Larsen \& Dabelsteen, 1990).

A transmission beampattern has never been measured for killer whales, although Schevill \& Watkins (1966) and Bain \& Dalheim (1994) noted that high frequency components of both clicks and calls of killer whales appeared to be directional. Some killer whale calls recorded in the field lack high-frequency components, suggesting they were received from animals oriented away from the hydrophone (chapter two; Miller and Bain, in press). The goal of this study was to measure the influence of signaler orientation on the frequency structure of calls in free-ranging killer whales. To assess whether signal 
structure could be a reliable indicator of the direction-of-movement, sounds were recorded while animals were moving in a directional fashion (i.e. not milling; see Hoelzel, 1993). Based upon measured source levels and estimated active space, the common call types produced by pods A1 and A5 can be classified as "long-range" or "short-range" call types (chapter five). The long-range call types contain an independently modulated high-frequency component (Miller \& Bain, in press), so a second goal was to assess whether the long-range call types have a stronger directionality cue than the short range call types.

\subsection{Methods}

To measure the effect of signaler orientation and direction-of-movement on the frequency content of received signals, I approached isolated groups of killer whales which were consistently moving in one direction and vocally active. Using a small research vessel, I positioned a towed 16-element linear hydrophone array (see Miller \& Tyack, 1998 for details of the array system) roughly $200 \mathrm{~m}$ in front of the killer whale group, and towed the array parallel to the direction of movement of the animals at deadslow speed $(\sim 1.5 \mathrm{~m} / \mathrm{s})$. At this speed, whales typically passed the array and research vessel over a 15-25 minute time period. To confirm that animals were consistently oriented in the direction-of-movement, two teams of observers on the research vessel visually scored the orientations of surfacing whales relative to the array. One team recorded surfacing orientations of animals within $30^{\circ}$ of directly behind the array, while the other recorded orientations of animals within $30^{\circ}$ of directly in front of the array. Orientations were scored in $30^{\circ}$ bins as "o'clocks", with " 12 " being the value for orientations directly toward the array and " 6 " for orientations directly away from the array. Orientation scores were subsequently converted to off-axis values (i.e. $12=0,3 \&$ $9=90,6=180$, etc.).

The angle-of-arrival of sounds recorded during the "pass-by" sessions were calculated using beamforming techniques (Miller \& Tyack, 1998). Sounds arriving 
toward the array, while sounds arriving within $30^{\circ}$ of directly in front of the array were considered to be from animals oriented away from the array. In addition to the multichannel array recording system (see Miller \& Tyack, 1998 for system details), sounds from one hydrophone were recorded on a Pioneer D-9601 recorder (flat $\pm 0.5 \mathrm{~dB} 20 \mathrm{~Hz}$ to $44 \mathrm{kHz}$ ), and redigitized at $100 \mathrm{kHz}$ sampling rate using a custom digital processor board. I used Matlab software to calculate the power spectral density of each call and a portion of noise immediately prior to the onset of the call. The noise power spectral density was subtracted from that of the call to reduce frequency-dependent effects of external noise sources. All calls were classified to type using the naming system devised by Ford (1987, 1991). Call types N2, N4, N9, N1, and N5 were grouped as long-range types, while N7, $\mathrm{N} 8$, and N3 were grouped as short range types (chapter five).

The spectral structure of the calls was then measured by comparing noisesubtracted signal intensity in different frequency bands. Previous observations suggested that the $1-5 \mathrm{kHz}$ band was considerably less directional than higher frequencies (chapter two; Miller \& Bain, in press), so the intensity of this band was compared to the energy in higher frequency bands. Energy in the noise-subtracted spectra was summed across the $1-5 \mathrm{kHz}$ band and the $5-44 \mathrm{kHz}$ band, and converted to decibels. The ratio of energy in the two bands was obtained by subtracting the energy in the $5-44 \mathrm{kHz}$ band from that in the $1-5 \mathrm{kHz}$ band. The effect of orientation on the relative energy in the two bands was assessed using a two-sample t-test, and differences between long- and short- range call types were assessed by the interaction term in a 2-way ANOVA. For a more detailed frequency analysis of the directionality pattern, energy in the $5-44 \mathrm{kHz}$ band was divided into two frequency bands, $5-16 \mathrm{kHz}$ and $16-44 \mathrm{kHz}$, which were each compared to the energy in the $1-5 \mathrm{kHz}$ reference band. Differential directionality of these bands was assessed by the interaction term of a two-way ANOVA.

\subsection{Results}

I analyzed sounds from a total of six "pass-by" sessions totaling 124.6 minutes of recordings on five different days in 1999. All sessions were carried out in Johnstone 
Strait, BC, with animals from pods $\mathrm{A} 5$ and $\mathrm{W} 3$ present in five sessions and animals from pod A1 present in one session. Animals surfacing behind the array had a mean orientation of $40.4^{\circ}$ off-axis (s.d. $=13.8^{\circ}$ ), while animals surfacing forward of the array had a mean orientation of $158.6^{\circ}$ off-axis $\left(\right.$ s.d. $=14.9^{\circ}$ ). As expected, the whales' direction-ofmovement was consistent with surfacing orientations and paralleled the direction of movement of the research vessel. A total of 666 calls were recorded on the array, with 174 calls arriving from within $30^{\circ}$ of directly behind the array (mean $=-73.4^{\circ}$, s.d. $=$ $5.3^{\circ}$ ) and 89 calls arriving from within $30^{\circ}$ of directly in front of the array (mean $=73.4^{\circ}$, s.d. $=7.2^{\circ}$ ).

The frequency structure of calls was strongly dependent on the orientation and direction-of-movement of the group of killer whales (Fig. 1 \& Table 1). Figure 1 shows the average geometry of whales relative to the array during the pass-by sessions, and hypothetical beampatterns of the $1-5 \mathrm{kHz}$ and $5-44 \mathrm{kHz}$ bands consistent with the average difference of these bands from animals behind and ahead of the boat. Across all calls, energy in the $5-44 \mathrm{kHz}$ band was an average of $5.7 \mathrm{~dB}$ below that in the $1-5 \mathrm{kHz}$ band when animals were oriented toward the array, but was $11.0 \mathrm{~dB}$ less when animals were

\begin{tabular}{rrrrr} 
& & \multicolumn{3}{c}{ Energy compared to 1-5 kHz reference band (dB) } \\
\cline { 3 - 5 } Call group & $\begin{array}{r}\text { Orientation } \\
\text { (\# of calls) }\end{array}$ & $\begin{array}{r}5-44 \text { band } \\
\text { mean (s. e.) }\end{array}$ & $\begin{array}{r}5-16 \text { band } \\
\text { mean (s. e.) }\end{array}$ & $\begin{array}{r}16-44 \text { band } \\
\text { mean (s. e.) }\end{array}$ \\
\hline All calls & $\mathrm{T}(174)$ & $-5.7(0.43)$ & $-7.6(0.39)$ & $-12.7(0.63)$ \\
& $\mathrm{A}(89)$ & $-11.0(0.55)$ & $-12.0(0.52)$ & $-19.7(0.83)$ \\
& $\Delta(\mathrm{T}-\mathrm{A})$ & +5.3 & +4.4 & +7.0
\end{tabular}

$\begin{array}{rrr}\text { Long-range } & \mathrm{T}(132) & -4.8(0.50) \\ \mathrm{A}(72) & -11.0(0.62) \\ \Delta(\mathrm{T}-\mathrm{A}) & +6.2\end{array}$

$\begin{array}{rrr}\text { Short-range } & \mathrm{T}(17) & -10.8(1.20) \\ & \mathrm{A}(7) & -11.2(1.26) \\ \Delta(\mathrm{T}-\mathrm{A}) & +0.4\end{array}$

Table 1. Mean (s. e.) difference in energy in the $1-5 \mathrm{kHz}$ band versus energy in various higher-frequency bands for all calls, long-range, and short-range calls. $\mathrm{T}=$ toward condition, $\mathrm{A}=$ away condition. 

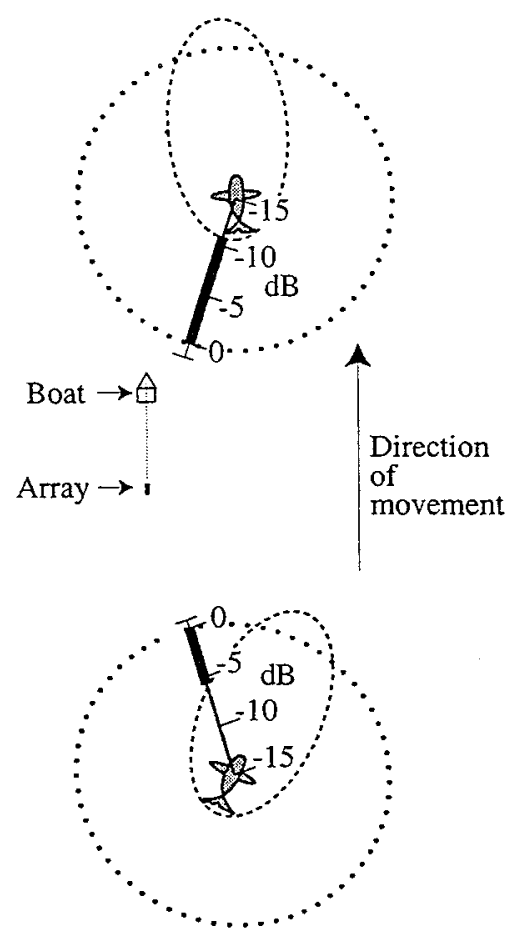

Figure 1. Direction-of movement cueing in an acoustic signal with differential directionality in low and high frequency bands. The dashed lines represent hypothetical beampatterns of the $1-5 \mathrm{kHz}$ band (circles) and $5-44 \mathrm{kHz}$ band (ellipses) consistent with the observed relative level of those bands. The position of the whale figures were based upon the average angle-of-arrival of sounds from within $30^{\circ}$ of directly in front and behind the array. The orientation of the whale figures is based upon the average surfacing orientation of whales within $30^{\circ}$ of directly in front and behind the array.

oriented away from the array (mean difference of $5.3 \mathrm{~dB}, \mathrm{t}_{261}=7.28, P<0.001$; Fig. $1 \&$ Table 1). Differential directionality was greater in the high-frequency $16-44 \mathrm{kHz}$ band $(7.0 \mathrm{~dB})$ than in the mid-frequency $5-16 \mathrm{kHz}$ band $\left(4.4 \mathrm{~dB}\right.$; interaction $\mathrm{F}_{1,515}=4.44, P=$ 0.036). The effect of orientation on relative energy in the $1-5$ and $5-44 \mathrm{kHz}$ bands was greater for long-range (mean difference $=6.2 \mathrm{~dB}$ ) than short-range $($ mean difference $=$ $0.4 \mathrm{~dB}$ ) call types (interaction $\mathrm{F}_{1,224}=5.07, P=0.025$; Table 1). The two most common call types (N4 and N9) accounted for 65\% of all calls produced, and had striking differences in frequency content depending on signaler orientation (Fig. 2). 


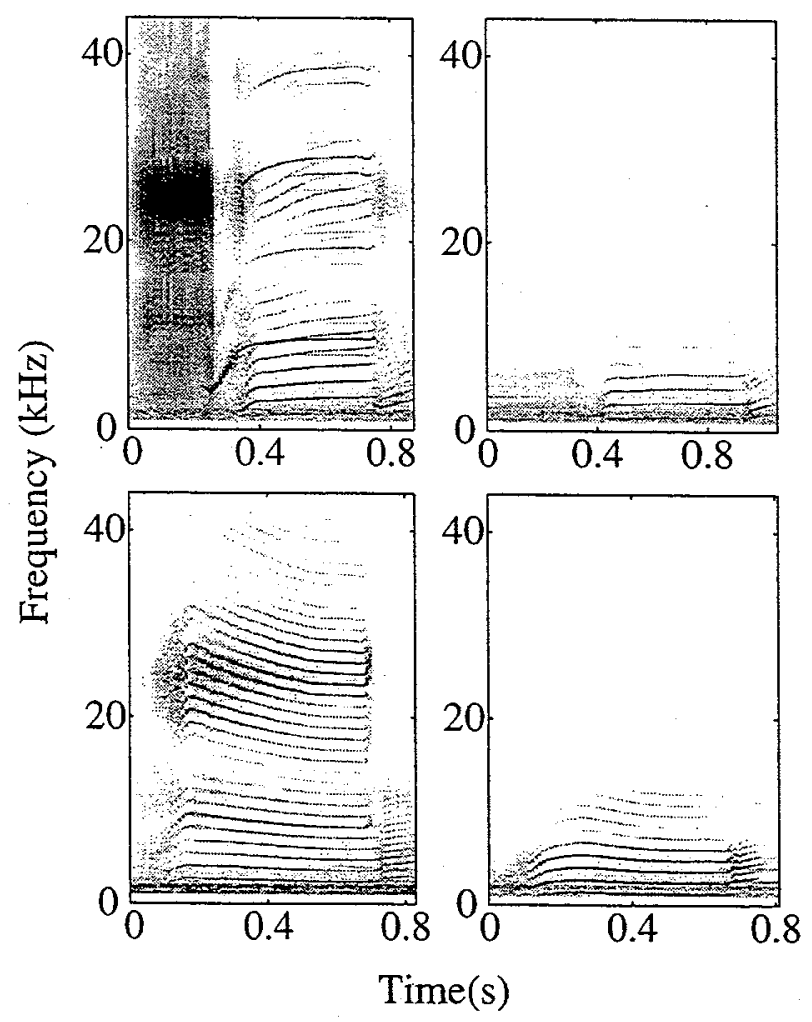

Figure 2. Example spectrograms of call types N9 (top two panels) and N4 (bottom two panels) from animals moving toward (left two panels) and away (right two panels) from the array. Spectrograms have a effective filter bandwidth of $48.8 \mathrm{~Hz}$ and dynamic range of $55-85 \mathrm{~dB}$ re $1 \mu \mathrm{Pa}^{2} / \mathrm{Hz}$. Note the clear differences in frequency content of calls depending on the orientation of the caller.

\subsection{Discussion}

The results of this study confirm previous suggestions that killer whale calls produced in the wild are directional at high frequencies and suggest that differing levels of directionality in various frequency bands provide a cue of signaler orientation and direction-of-movement. Whales behind and ahead of the array were clearly not always oriented directly toward or away from the array when calling (Fig. 1), so the data reported here were biased against finding a difference depending on orientation. Clear differences were still found, suggesting that the orientation cue is quite strong and the 
results reported here should be considered a minimum estimate. While figure 1 shows a hypothetical beampattern consistent with the data collected in this study, a complete and accurate transmission beampattern can only be effectively measured using captive animals trained to vocalize in a fixed position (e.g. Au, 1993).

I propose that the direction-of-movement cue may be an important structural feature of calls that helps individual killer whales regulate their spacing relative to each other. Observations of killer whales in the field suggest that travel direction is highly synchronized, even when individuals are out of visual range with each other, and that calling often occurs immediate to a change in swim-direction (Jacobsen, 1986; personal observation). Direction-of-movement cueing in calls may be particularly helpful for these mobile animals to maintain contact while spread out over large areas, and out of visual range with each other. In other behavioral contexts, i.e. socializing (Osborne, 1986; Ford, 1989), direction-of-movement may not be as closely correlated with orientation as in my sample. In these non-travel contexts, the orientation-cue provided by the directionality structure of calls could serve other functions such as cueing the intended receiver (Hunter et al., 1986).

The effect of orientation on the relative intensity of different bands increased with band frequency (Table 1). While I found significant differences by arbitrarily splitting the signal at $5 \mathrm{kHz}$ and again at $16 \mathrm{kHz}$, it is likely that broadband killer whale calls actually radiate with a continuum of directionality across frequencies. The lowest frequencies appear to be fairly omni-directional (Fig. 2), allowing signal detection independent of signaler orientation. The middle frequency bands provide a broad directionality cue that is most appropriate for cueing direction-of-movement as a receiver somewhat off-axis would still receive the mid-frequency cue. The highest frequency bands appear to have sharp directionality, and may be more useful for directing vocalizations at a particular receiver.

The manner in which killer whales use this feature of their signal depends on how animals orient when signaling. If the cue functions to signal direction-of-movement, one would expect animals to call while oriented in their direction-of-movement (as was found 
in this study). Alternatively, if animals use the cue to direct vocalizations at an intended receiver, one would expect animals to orient towards a receiver when they call, regardless of their direction-of-movement. A cetacean tag capable of recording full bandwidth audio as well as animal orientation has recently been developed (Johnson et al., 1999) and may be an ideal tool to explore how free-ranging killer whales orient when calling.

The directionality cue was stronger for long-range call types than short-range call types (Table 1). This finding stands in contrast to Witkin's (1977) conclusion that directionality features of calls should be most pronounced in relatively faint sounds used in close interactions. A long-range acoustic direction-of-movement cue may not be particularly useful for most terrestrial animals because visual inspection is likely to be a more effect means of discerning orientation or travel direction of other individuals. The long-range call types all have independently modulated high-frequency components (chapter two; Miller \& Bain, in press). This independently modulated high-frequency component may be an adaptation to accentuate the directionality cues in killer whale calls.

Direction-of-movement cueing may be especially useful for widely separated animals, as large changes in relative position may be difficult to track over successive calls. However, Hunter et al. (1986) pointed out that the effects of frequency-dependent absorption potentially confound orientation cues from directional signals because both processes result in less high frequency energy at the receiver. Frequency dependent absorption is roughly $1 \mathrm{~dB} / \mathrm{km}$ at $12 \mathrm{kHz}$ (the center of the $5-16 \mathrm{kHz}$ band; Francois \& Garrison, 1982), so absorption will have a similar magnitude of frequency shaping as the directionality cue at roughly $4.4 \mathrm{~km}$. It is possible that killer whales could estimate range from a signaler using non-frequency dependent amplitude and reverberation cues (Richards, 1981) to compensate for absorption effects. Because range estimation is likely to be poor at long ranges, the directionality cue may not function at maximum call detection ranges. Ultimately, controlled playback experiments (i.e. Miller et al., 2000) are needed to assess how receiving killer whales respond to the directionality cue at various ranges. 


\subsection{References}

Archibald, H. L. 1974. Directional differences in the sound intensity of ruffed grouse drumming. Auk 91: 517-521.

Aroyan, J. L. 1990. Supercomputer modeling of delphinid sonar beam formation. J. Acoust. Soc. Am. 88: S4.

Au, W. W. L. 1993. The Sonar of Dolphins. New York: Springer-Verlag, ppg. 277.

Au, W. W. L. , Moore, P. W. B., and Pawloski, D. 1986. Echolocation transmitting beam of the Atlantic bottlenose dolphin. J. Acoust. Soc. Am. 80: 688-691.

Au, W. W. L. , Pawloski, J. L., Nachtigall, P. E., Blonz, M., and Gisiner, R. C. 1995. Echolocation signals and transmission beam pattern of a false killer whale (Pseudorca crassidens). J. Acoust. Soc. Am. 98 (1): 51-59.

Au, W. W. L., Penner, R. H., and Turl, C. W. 1987. Propogation of beluga echolocation signals. J. Acoust. Soc. Am. 82: 807-813.

Bain, D. E. and Dalheim, M. E. 1994. Effects of masking noise on detection thresholds of killer whales. In: Marine Mammals and the Exxon Valdez. (Ed. T. R. Loughlin) San Diego: Academic Press, pp. 243-256.

Barimo, J. F. and Fine, M. L. 1998. Relationship of swim-bladder shape to the directionality pattern of underwater sound in the oyster toadfish. Can. J. Zool. 76: 134-143.

Caine, N. G. and Stevens, C. 1990. Evidence for a "monitoring call" in red-bellied tamarins. Am. J. Primatol. 22: 251-262.

Dabelsteen, T. and Pedersen, S. B. 1988. Song parts adapted to function both at long and short ranges may communicate information about the species to female blackbirds Turdus merula. Ornis Scand. 19: 195-198.

Dunn, H. K. and Farnsworth, D. W. 1939. Exploration of pressure field around the human head during speech. J. Acoust. Soc. Am. 10: 184-199.

Ford, J. K. B. 1987. A catlogue of underwater calls produced by killer whales (Orcinus orca) in British Columbia. Can. Data Rep. Fish. Aquat. Sci. No. 633, ppg. 165. 
Ford, J. K. B. 1989. Acoustic behavior of resident killer whales (Orcinus orca) off Vancouver Island, British Columbia. Can. J. Zool. 67: 727-745.

Ford, J. K. B. 1991. Vocal traditions among resident killer whales Orcinus orca in coastal waters of British Columbia. Can. J. Zool. 69: 1454-1483.

Francois, R. E. and Garrison, G. R. 1982. Sound absorption based on ocean measurements. Part II: boric acid contribution and equation for total absorption. J. Acoust. Soc. Am./ 72: 1879-1890.

Gerhardt, H. C. 1975. Sound pressure levels and radiation patterns of the vocalizations of some north American frogs and toads. J. Comp. Physiol. 102: 1-12.

Hoelzel, A. R. 1993. Foraging behaviour and social group dynamics in Puget Sound killer whales. Anim. Behav. 45: 581-591.

Hunter, M. L. Jr., Kacelnik, A., Roberts, J., and Vuillermoz, M. 1986. Directionality of avian vocalizations: a laboratory study. Condor 88: 371-375.

Jacobsen, J. K. 1986. The behavior of Orcinus orca in the Johnstone Strait, British Columbia. In: Behavioral Biology of Killer Whales (Ed by B. C. Kirkevold \& J. S. Lockard) New York: Alan R. Liss, Inc. ppg. 135-185.

Johnson, M. A., Tyack, P. L., and Nowacek, D. P. 1999. A digital acoustic recording tag for measuring the response of marine mammals to sound. In: Abstracts of the International Council for the Exploration of the Seas (ICES), Stockholm, Sweden.

Klump, G. M. and Shalter, M. D. 1984. Acoustic behavior of birds and mammals in the predator context I. Factors affecting the structure of alarm signals. $\mathrm{Z}$. Tierpsychol. 66: 189-226.

Larsen, O. N. and Dabelsteen, T. 1990. Directionality of blackbird vocalization. Implications for vocal communication and its further study. Ornis Scand. 21: 3745.

Marler, P. 1965. Aggregation and dispersal: two functions in primate communication. In: Primates: Studies in Adaptation and Variability (Ed. by P. C. Jay). New York: Holt, Rinehart, and Winston, ppg. 420-438.

Miller, P. J. O. and Bain, D. E. in press. Within-pod variation in the sound production of a pod of killer whales (Orcinus orca). Anim. Behav.

Miller, P. J. O., Biassoni, N., Samuels, A., and Tyack, P. L. 2000. Whale songs lengthen in response to sonar. Nature 405: 903. 
Miller, P. J. and Tyack, P. L. 1998. A small towed beamforming array to identify vocalizing resident killer whales (Orcinus orca) concurrent with focal behavioral observations. Deep-Sea Res. II 45: 1389-1405.

Mohl, B., Wahlberg, M., Madsen, P. T., Miller, L. A., and Surlykke, A. 2000. Sperm whale clicks: directionality and source level revisited. J. Acoust. Soc. Am. 107: 638-648.

Nelson, B. S. and Stoddard, P. K. 1998. Accuracy of auditory distance and azimuth perception by a passerine bird in natural habitat. Anim. Behav. 56: 467-477.

Osborne, R. W. 1986. A behavioral budget of Puget Sound killer whales. In: Behavioral Biology of Killer Whales (Ed by B. C. Kirkevold \& J. S. Lockard) New York: Alan R. Liss, Inc. ppg. 211-249.

Prestwich, K., Brugger, K. E. , and Topping, M. 1989. Energy and communication in three species of hylid frogs: power input, power output and efficiency. J. exp. Biol. 144: 53-80.

Richards, D. G. 1981. Estimation of distance of singing conspecifics by the Carolina wren. Auk 98: 127-133.

Schevill, W. E. and Watkins, W. A. 1966. Sound structure and directionality in Orcinus (killer whale) Zoologica 51: 71-76:

Schevill, W. E. and Watkins, W. A. 1971. Directionality of the sound beam in Leptonychotes weddelli (Mammalia: Pinnipedia). Antarctic Res. Series 18: 163168.

Schnitzler, H.-U. and Grinnell, A. D. 1977. Directional sensitivity of echolocation in the horseshoe bat, Rhinolophus ferrumequinum. J. Comp. Physiol. 116: 51-61.

Urick, R. J. 1983. Principles of Underwater Sound, $3^{\text {rd }}$ edition. New York: McGrawHill, ppg. 423.

Witkin, S. R. 1977. The importance of directional sound radiation in avian vocalization. Condor 79: 490-493. 


\section{CHAPTER 7: SUMMARY AND CONCLUSIONS}

\subsection{Thesis Summary}

The aim of this thesis was to describe aspects of the structure and use of calls produced by free-ranging resident killer whales. Because these animals have natural individually-distinctive markings, it has been possible for researchers to undertake a unique long-term study of the association patterns of individual killer whales (Bigg et al., 1987, 1990; Olesiuk et al., 1990; Ford et al., 1994). Their long-term study has shown that resident killer whales have a nested hierarchy of stable social interactions based upon mother-offspring associations in "matrilineal groups" (Bigg et al., 1990). These motheroffspring groups are remarkably stable, with no observed cases of dispersal by either sex over 20 years of intensive observation (Ford et al., 1994). Matrilineal groups associate preferentially with each other to form "pods", and pods interact on a broader scale as part of the same community (Bigg et al., 1990).

The pod-specific repertoire of calls produced by these animals was first identified by Ford and Fisher in 1982, and was then extensively documented by Ford using recordings from identified pods $(1987,1989,1991)$. Other studies, both in the wild and in captivity, have confirmed the group-specific repertoires of killer whales (Bain, 1986; Strager, 1995; Miller \& Bain, in press). While the rate of call-type production varies in different broad behavioral states, no call type is exclusively linked to one particular behavioral state (Bain, 1986; Morton et al., 1986; Ford, 1989). Given the stability of killer whale matrilineal groups (despite common separations beyond visual range), calling is thought to help maintain contact between group members and coordinate their activities (Ford, 1989). The pod-specific repertoire is thought to enhance the efficiency of the contact system by providing a group-distinctive marker, allowing individuals to maintain contact and coordinate activities with their group (Ford, 1991).

These important studies have relied upon the use of a single hydrophone to record sounds produced by identified pods of animals while isolated from other pods (Ford, 1991). In this thesis, I extended this technique of recording and comparing sounds from isolated groups of animals to the matrilineal subgroups which compose pods (Chapter two). However, with the use of a single hydrophone it is not possible to identify an 
individual caller or to determine the range from the hydrophone to the caller (Miller \& Tyack, 1998). This obstacle explains why no studies to date have described the calling behavior of individual killer whales or explored fundamental structural features of calls as source levels or directionality.

In chapters three through six, I reported the development and demonstration of an engineering solution to overcome some of the difficulties inherent in studying underwater sound. I developed and deployed a towed array of hydrophones that allowed spatial resolution of underwater sounds that could subsequently be linked to visual observations of surfacing animals (chapter three; Miller \& Tyack, 1998). Beamforming the signal recorded on the towed array makes it possible to identify a signaler while following it from a boat, allowing focal observations (Altmann, 1974) of both the sound-production and surface behavior of individual animals (chapter four). I utilized the spatial resolution of the towed array to measure the range to signalers and calculate signal source levels (chapter five). The spatial resolution provided by the array also made it possible to record sounds ahead of and behind killer whale groups consistently moving in one direction, in order to characterize directionality features of killer whale sounds (chapter six). The main results of each chapter are summarized below.

\subsubsection{Summary by chapter}

\subsubsection{Chapter two}

Ford (1991) suggested that pod-specific call repertoires form as a consequence of the accumulation of small vocal changes from generation to generation. To test this idea, I compared the structure and use of different call types recorded from the three matrilineal groups which form pod A1. If pod-specific calling develops from smallerscale changes, fine-scale differences should exist between the matrilineal groups in the same pod (Bigg et al., 1990). Alternatively, finding no differences in call structure or use between matrilineal groups would have cast doubt on Ford's (1991) hypothesis and alternatively suggest that pod-specific calling arises from rare but large changes in the vocal behavior of entire pods. The results strongly supported Ford's (1991) suggestion, 
as both call use and structure differed across the matrilineal units within pod A1. The three matrilineal groups produced shared call types at different rates, and one type was used almost exclusively by one matrilineal group. Cross-validated discriminant function analyses revealed matrilineal-unit distinctive structure in five of the six call types examined. The differences in calling behavior between matrilineal groups were similar in form to the previously described differences between pods, although more subtle. In this study, I also carefully measured and described the variability in the high frequency component of killer whale calls, and showed that the low- and high-frequency components have roughly equal overall variability, each containing independent matrilineal-group distinctive information.

\subsubsection{Chapter three}

All studies of sound production by free-ranging killer whales to date have relied upon recordings of sounds from identified groups of animals (Ford, 1991; Strager et al., 1995; Deecke et al., 1999; Miller \& Bain, in press). Even though killer whales are individually identifiable by natural markings and sampling methods for visually observable behaviors have received attention in recent years (Samuels \& Gifford, 1997), the use of a single, omni-directional hydrophone has limited the ability of observers to identify a vocalizing animal or to continually observe its behavior. In this chapter I described the design and use of a towable beamforming system to identify signaling killer whales. Frequency-domain beamforming of signals recorded on a linear array of hydrophones is used to calculate a precise angle-of-arrival of a sound. The acoustic angle-of-arrival is compared with a visual track of a focal whale to determine whether it produced the sound. This system allows identification of callers separated from other animals by $20 \mathrm{~m}$ or more, a common separation distance in killer whales. While this chapter only demonstrates use of the system with resident killer whales, it should be possible to apply this method to other free-ranging species, such as bottlenose dolphins. This localization technique has promise for advancing the abilities of researchers to conduct unbiased behavioral and acoustic sampling of individual free-ranging cetaceans. 


\subsubsection{Chapter four}

The goal of this chapter was to test whether the call types in a matrilineal group's repertoire are produced by different individuals composing the group. Vocal sharing by individuals in a social group has important implications for how sounds are used in a contact function. Vocal sharing allows for matched counter-calling which may be a simple means for animals to direct sounds at a particular receiver (McGregor et al., 1992). Vocal sharing also affects how individual identity is encoded in acoustic signals (detailed structure versus different types). In this chapter I used the newly developed array system to record sounds from each of the three individual whales within W-pod, and then classified the sounds to call type based upon the naming system developed by Ford $(1987,1991)$. The results clearly confirmed that different individuals within a matrilineal group share a repertoire of calls, as four call types were produced by more than one individual in the group. A few call types were observed only from a single animal, but these types were produced at a very low overall rate by the group. It is therefore possible that these rare types are shared but that the sample was too small to detect them from more than one individual. The frequency of call-type production did not differ across the three individuals, suggesting that each member of stable killer whale matrilineal groups uses different call types in a similar manner.

\subsubsection{Chapter five}

While killer whale sounds appear to be used to maintain contact and coordinate activities among group members, there are no published reports of the source level of killer whale sounds or estimates of their 'active-space', the range over which one killer whale might detect the call of another (Brenowitz, 1982; Bain \& Dalheim, 1994). If the various sound types in the killer whale repertoire all serve the same contact function of signaling group membership, then one might expect little variation in the source levels and estimated active space of different sound types in the repertoire (Ford, 1989). In this chapter I measured source levels of calls and whistles by triangulating the angle-ofarrival of sounds on two short beamforming arrays towed in series. Measured source 
levels were used in a propagation-perception model to estimate the 'active-space' in quiet, hearing-threshold limited, conditions.

The estimated maximum range of detectability (active space) of the calls in my sample ranged from 4.5 to $26.2 \mathrm{~km}$, suggesting that killer whales are able to maintain acoustic contact over large distances. Stereotyped calls had a larger estimated active space than variable calls and whistles, but there was no significant difference between variable calls and whistles. Active space of different stereotyped call types fell into two clusters, with long-range call types having a mean estimated active space of $14.5 \mathrm{~km}$ and short-range call types having a mean of $8.8 \mathrm{~km}$. A short-range call type (N3) and whistles were previously shown to be produced more during resting and beach-rubbing activities, while the long-range call types were used more during foraging and podmeeting contexts (Ford, 1989). These results suggest that the various sounds produced by killer whales serve different functions in their communication system, with some sounds serving as long-distance signals and others as shorter-range signals. Interestingly, all of the long-range call types include a separately modulated high-frequency component while the short-range call types do not (see chapter two).

\subsubsection{Chapter six}

Biological studies have shown that animals are better able to estimate the range to, and azimuth of, signals with a high time-bandwidth structure, so broadband killer whale calls appear to be well-designed for localization (Brown et al., 1979; Klump \& Shalter, 1984; Nelson \& Stoddard, 1998). In this chapter I investigated whether the pattern of directionality of killer whale calls has the potential to communicate directionof-movement of the signaler to other killer whales. Specifically, I compared the frequency structure of calls depending on the orientation and direction-of-movement of the signaler. The direction-of-movement of signalers was determined by recording sounds from a group of animals as they passed the towed array; animal orientation was confirmed by visually scoring the orientation of surfacing animals. The results demonstrated that the frequency structure of calls is strongly dependent upon the orientation of the signaler, with high-frequency portions of calls strongly attenuated when 
the signaler is oriented away from the receiver. The directionality pattern of calls in my sample was correlated with the direction-of-movement of animals. Combined with sound source localization, the direction-of-movement cue may help animals efficiently regulate their spacing relative to each other. The direction-of-movement cue was stronger in long-range than short range call types (see chapter five), suggesting the cue may be particularly useful for animals to synchronize their travel direction when they are spread out over large areas.

\subsubsection{Conclusions}

The design and use of acoustic signals in resident killer whales, Orcinus orca, appear to be well suited to help maintain the integrity of their unusually stable social structure (Bigg et al., 1990). The word "design" refers to structural features of signals that affect the efficiency by which signals serve their function (Klump \& Shalter, 1984). Natural selection favors genes encoding structural features that benefit the signaler, so signal "design" is shaped and adapted by the forces of natural selection (Bradbury \& Vehrencamp, 1998). The primary design features explored in this thesis were distinctiveness by group or individual, amplitude, and location-cueing.

Ford (1991) convincingly demonstrated pod-specific calling behavior in resident killer whales. Chapter two extended the analysis of group distinctiveness in killer whale calling to the matrilineal group, the most stable unit of killer whale social structure. Podspecific calling likely arises as a consequence of accumulated drift or divergence between the highly cohesive matrilineal groups as they gradually separate into different pods (Ford, 1991; Miller \& Bain, in press). While the mechanism by which offspring acquire their acoustic repertoire remains somewhat controversial (Janik \& Slater, 1997), multiple lines of evidence support the idea that vocal learning occurs in this species and that offspring learn the calls produced by their mother (Bain, 1986, 1989; Bowles et al., 1988; Ford, 1991; Deecke et al., 1999; Deecke et al., in press; Miller \& Bain, in press). Group distinctiveness is a design feature that has possibly been selected by evolution because it improves the function of the signaling system in maintaining the cohesion of the group. 
However, playback experiments are required to confirm that receiving killer whales attend and respond to the group-distinctive cues.

While group-distinctiveness might support the stability of resident killer whale matrilineal groups (Tyack, 1986), individual distinctiveness may be helpful for coordinating the activities of group members (Heimlich-Boran, 1986; Waite, 1988; Rose, 1992; Hoelzel, 1993). An investigation of individual distinctiveness requires sounds to be recorded from identified animals - a long-standing difficulty in the study of underwater communication (Tyack, 1985; Sayigh, 1992). I developed an engineering solution to this problem, and was able to record a number of sounds from free-ranging killer whales to confirm that individuals within a matrilineal group share the calls in their repertoire. While a detailed analysis of individual signature information in shared calls was beyond the scope of this thesis, the primary requirement for this investigation (recording sounds from identified individuals) has been achieved.

Killer whale calls appear to have some other basic features that should be useful for members of stable killer whale groups to stay in contact with each other and coordinate their direction-of-movement. Using measured source levels as input to a sound propagation and perception model, I calculated that calls are likely to be audible to conspecifics over large ranges in quiet conditions (chapter five). I was also able to confirm that killer whale calls are directional at high frequencies, and show that this directionality structure provides a potentially useful cue of the direction-of-movement of the signaler (chapter six). Call-type sharing by members of the same group may help receivers more accurately identify orientation and range-dependent effects on the signal (Morton, 1982).

The development of spatial processing tools to identify which animal was signaling increased my awareness of the spatial processing problems the animals themselves need to solve. Locating oneself relative to food, conspecifics, and other features of the environment is a general problem for organisms (von Frisch, 1967), and organisms must combine inputs from multiple sensory modalities at a higher cognitive level to locate themselves in space. Because light is so rapidly attenuated (and sound travels well) in the marine environment, features of marine mammal acoustic signals may be adapted to fulfill functions served by vision in terrestrial organisms (e.g. echolocation, 
$\mathrm{Au}, 1993)$. Direction-of-movement cueing via the directionality structure of calls may be particularly important for marine organisms, but less so for terrestrial organisms capable of visually inspecting the direction-of-movement of other animals. Further comparative studies of signaling by terrestrial and marine organisms may help us understand not only how ecological factors influence signals, but also how organisms integrate various sensory modalities into a cohesive internal representation of their environment.

\subsection{Suggestions for future research}

Partly due to the difficulties of localizing underwater sound and identifying signalers, our current understanding of the vocal behavior of marine mammals is quite primitive. Although the research conducted in this thesis addressed some basic questions regarding the structure and use of calls by free-ranging killer whales, it has also highlighted many areas that would be worthy of further investigation both in the wild and in captivity. Several of these are outlined below.

1.) This thesis contains statistical analyses of signal structure (group distinctiveness, source level, directionality cues) which may be salient to killer whales, but ultimately carefully controlled playback experiments are required to test whether and how killer whales attend and respond to these cues (i.e. Cheney \& Seyfarth, 1980). Methods should be developed to conduct realistic playback experiments to free-ranging cetaceans, killer whales and other species (e.g. Miller et al., 2000; Appendix). A particular challenge is the development of a valid and measurable bioassay to score the response of playback subjects in a meaningful way. An attachable tag capable of recording both the sounds received by the subject and detailed behavior responses of the tagged animal has recently been developed (Fletcher et al., 1996; Johnson et al., 1999). This device has enormous potential to improve our ability to measure the responses of free-ranging animals to controlled sound exposures.

2.) The results of chapter four confirmed the findings of previous studies (Bain, 1986; Morton et al., 1986; Ford, 1991), demonstrating conclusively that members of 
stable killer whale social groups share a vocal repertoire. These results naturally lead to two important questions that should be addressed in the future.

A.) Do killer whales exchange calls with other group members either using matched counter-calling or repertoire-matching? Analyses of call sequences from killer whale pods show a strong tendency for calls of the same type to follow each other (Ford, 1989). The focal follow technique described in chapter three and demonstrated in chapter four should allow investigators to determine whether those call sequences represent counter-calling of the same type by different individuals, or sequential correlation in the calling of a single animal.

B.) Do killer whale calls contain individual signature information? Unlike bottlenose dolphins that appear to produce an individually distinctive whistle contour ("signature whistle", Caldwell \& Caldwell, 1965; Smolker et al., 1993; Janik \& Slater, 1998), killer whales primarily produce calls that are shared by other individuals (chapter four). If killer whales are able to identify a particular signaler based upon vocal cues, individual signature must be encoded in more subtle structural or spectral cues of the shared calls (Beecher et al., 1981; Rendall et al., 1996). Chapter three detailed a method by which one can obtain sounds from identified killer whales in the wild (Miller \& Tyack, 1998). Features of calls produced by different killer whales can be compared to measure the degree of signature information in shared calls (Beecher, 1989). Given the structural similarity of killer whale calls to human speech, analysis tools developed for human speech may be fruitfully applied to the analysis of killer whale calls (see Rendall et al., 1996, 1998).

3.) To explore the function of calling in wild killer whales, further studies simultaneously recording vocal and non-vocal behavior of individual killer whales using focal animal sampling should be carried out (Altmann, 1974; Boinski, 1993; Miller \& Tyack, 1998). Because of the directional nature of killer whale calls (chapter six), a particular area of interest is how killer whales orient when calling. If killer whales use the directional structure of calls to cue their direction-of-movement to other whales, one would predict that signalers would orient in the direction they are moving when they call. Alternatively, if signaling killer whales use the directional cue to direct signals at a 
particular receiver, one would predict signalers to orient toward a particular receiver when calling. As discussed in chapter six, killer whales' use of this structural feature of calls may vary depending on their motivation and the behavioral context in which the signal is produced.

4.) Further work assessing sound perception in killer whales would be useful. Given the number of killer whales living in captivity in the world's aquaria, suprisingly few psychophysical studies of the hearing abilities of killer whales have been reported. A total of three animals have had their absolute hearing thresholds measured (Hall \& Johnson, 1972; Symanski et al., 2000), and one of those may have had a hearing disorder (Symanski et al., 2000). Studies of masked thresholds are particularly needed to assess how noise reduces the range over which killer whales can maintain acoustic contact. Bain \& Dalheim (1994) reported masked hearing thresholds at two frequencies, and assessed masking of tones and calls by vessel noise. More of these types of studies are urgently needed to improve our ability to estimate the active space of killer whale calls, and assess the impact human-generated noise may have on active space.

5.) In chapter six, I reported data confirming that killer whale calls are directional at high frequencies (Schevill \& Watkins, 1966; Bain \& Dalheim, 1994). Further work should be carried out with both captive and free-ranging animals to accurately measure the sound transmission beam pattern of killer whales and other marine mammal species. In captivity, beam patterns can be measured from animals trained to vocalize from a fixed position using the same techniques previously used to assess directionality of echolocation clicks ( $\mathrm{Au}, 1993$ ). In the wild, animals can be tagged with a device that records their orientation. Sound levels on multiple hydrophones positioned around the tagged animal could be measured to compute a rough beam pattern. Ideally, both captive and wild studies should be carried out: captive studies can obtain detailed and accurate measurements, that wild studies can potentially confirm in an ecologically valid setting.

6.) A convincing set of observations and/or experiments need to be carried out to test whether killer whales acquire their call repertoire through vocal learning (Janik \& Slater, 
1997; Miller \& Bain, in press). Although significant evidence exists for vocal learning in killer whales (see chapter two; Bain, 1988; Deecke et al., 1999, in press), the high degree of matrilineal relatedness between pod and matrilineal subgroup members makes it difficult to convincingly rule out a genetic mechanism (Janik \& Slater, 1997). If killer whales do learn their calls, they could become a model species (along with the bottlenose dolphin) to explore processes of cultural transmission in marine mammals.

\subsection{References}

Au, W. W. L. 1993. The Sonar of Dolphins. New York: Springer-Verlag, ppg. 277.

Altmann, J. 1974. Observational study of behavior: sampling methods. Behaviour 49: 227-267.

Bain, D. E. 1986. Acoustic behavior of Orcinus: sequences, periodicity, behavioral correlates and an automated technique for call classification. In: Behavioral Biology of Killer Whales. (Eds. B. C. Kirkevold \& J. S. Lockard), New York: Alan R. Liss, Inc., pp. 335-371.

Bain, D.E. 1988. An evaluation of evolutionary processes: studies of natural selection, dispersal, and cultural evolution in killer whales (Orcinus orca). Ph.D. dissertation, University of California, Santa Cruz.

Bain, D. E. and Dalheim, M. E. 1994. Effects of masking noise on detection thresholds of killer whales. In: Marine Mammals and the Exxon Valdez. (Ed. T. R. Loughlin) San Diego: Academic Press, pp. 243-256.

Beecher, M.D. 1989. Signaling systems for individual recognition: an information theory approach. Anim. Behav. 38: 248-261.

Beecher, M.D., Beecher, I.M., and Lunpkin, S. 1981. Parent-offspring recognition in bank swallows: I. Natural history. Anim. Behav. 29: 86-94.

Bigg, M.A., Ellis, G.M., Ford, J.K.B., and Balcomb, K.C. III. 1987. Killer Whales: Genealogy and Natural History in British Columbia and Washington State. Nanaimo: Phantom Press.

Bigg, M.A., Olesiuk, P.F., Ellis, G.M., Ford, J.K.B., and Balcomb, K.C. 1990. Social organization and genealogy of resident killer whales (Orcinus orca) in the coastal waters of British Columbia and Washington State. Rep. Int. Whal. Commn. Special Issue 12: 383-405. 
Boinski, S. 1993. Vocal coordination of troop movement among white-faced capuchin monkeys, Cebus capucinus. Am. J. Primatol. 30: 85-100.

Bowles, A. E., Young, W. G. \& Asper, E. D. 1988. Ontogeny of stereotyped calling of a killer whale calf, Orcinus orca, during her first year. Rit Fiskideildar, 11, 251-275.

Bradbury, J.W. and Vehrencamp, S.L. 1998. Principles of Animal Communication. Sunderland, MA: Sinauer Ass., Inc. pp. 882.

Brenowitz, E.A. 1982a. The active space of red-winged blackbird song. J. Comp. Physiol. 147: 511-522.

Brown, C.H., Beecher, M.D., Moody, D.B., and Stebbins, W.C. 1979. Locatability of vocal signals in old old monkeys: design features for the communication fo position. J. comp. Physiol. Psych. 93 (5): 806-819.

Caldwell, M. C. and Caldwell, D. K. 1965. Individualized whistle contours in bottlenosed dolphins (Tursiops truncatus). Nature 207: 434-435.

Cheney, D. L. and Seyfarth, R. M. 1980. Vocal recognition in free-ranging vervet monkeys. Anim. Behav. 28: 362-367.

Deecke, V. B., Ford, J. K. B., and Spong, P. 1999. Quantifying complex patterns of bioacoustic variation: use of a neural network to compare killer whale (Orcinus orca) dialects. J. Acoust. Soc. Am. 105 (4): 2499-2507.

Deecke, V. B., Ford, J. K. B., and Spong, P. in press. Dialect change in resident killer whales (Orcinus orca): implications for vocal learning and cultural transmission. Anim. Behav.

Fletcher, S., LeBoeuf, B. J., Costa, D. P., Tyack, P. L., and Blackwell, S. B. 1996. Onboard acoustic recording from diving northern elephant seals. J. Acoust. Soc. Am. 100 (4): 2531-2539.

Ford, J.K.B. 1987. A catalogue of underwater calls produced by killer whales (Orcinus orca) in British Columbia. Can. Data Rep. Fish. Aquat. Sci. No. 633.

Ford, J.K.B. 1989. Acoustic behavior of resident killer whales (Orcinus orca) off Vancouver Island, British Columbia. Can. J. Zool. 67: 727-745.

Ford, J.K.B. 1991. Vocal traditions among resident killer whales Orcinus orca in coastal water of British Columbia. Can. J. Zool. 69: 1454-1483.

Ford, J.K.B., Ellis, G.M., and Balcomb, K.C. 1994. Killer Whales: The Natural History and Genealogy of Orcinus orca in British Columbia and Washington State. Vancouver: UBC Press, pp. 102. 
Ford, J.K.B. and Fisher, H.D. 1982. Killer whale (Orcinus orca) dialects as an indicator of stocks in British Columbia. Report of the International Whaling Commission, 32, 671-679.

Hall, J. and Johnson, C. S. 1972. Auditory thresholds of a killer whale Orcinus orca Linnaeus. J. Acoust. Soc. Am. 51: 515-517.

Heimlich-Boran, S.L. 1986. Cohesive relationships among Puget Sound killer whales. In: Behavioral Biology of Killer Whales (B.C. Kirkevold \& J.S. Lockard, eds.) New York: Alan R. Liss, Inc. pp. 251-284.

Hoelzel, A.R. 1993. Foraging behavior and social group dynamics in Puget Sound killer whales. Anim. Behav. 45: 581-591.

Janik, V. M. and Slater, P. J. B. 1997. Vocal learning in mammals. Advances in the Study of Behaviour, 26, 59-99.

Janik, V.M and Slater, P.J.B. 1998. Context-specific use suggests that bottlenose dolphin signature whistles are cohesion calls. Anim. Behav. 56: 829-838.

Johnson, M. A., Tyack, P. L., and Nowacek, D. P. 1999. A digital acoustic recording tag for measuring the response of marine mammals to sound. In: Abstracts of the International Council for the Exploration of the Seas (ICES), Stockholm, Sweden.

Klump, G. M. and Shalter, M. D. 1984. Acoustic behavior of birds and mammals in the predator context I. Factors affecting the structure of alarm signals. Z. Tierpsychol. 66: 189-226.

McGregor, P. K., Dabelsteen, T., Shepherd, M., and Pedersen, S. B. 1992. The signal value of matched singing in great tits: evidence from interactive playback experiments. Anim. Behav. 43: 987-998.

Miller, P. J. O. and Bain, D. E. in press. Within-pod variation in the sound production of a pod of killer whales (Orcinus orca). Anim. Behav.

Miller, P. J. O., Biassoni, N., Samuels, A., and Tyack, P. L. 2000. Whale songs lengthen in response to sonar. Nature 405: 903.

Miller, P. J. and Tyack, P. L. 1998. A small towed beamforming array to identify vocalizing resident killer whales (Orcinus orca) concurrent with focal behavioral observations. Deep-Sea Res. II 45: 1389-1405.

Morton, A. B., Gale, J. C., and Prince, R. C. 1986. Sound and behavioral correlations in captive Orcinus orca. In: Behavioral Biology of Killer Whales. (Eds. B. C. Kirkevold \& J. S. Lockard), New York: Alan R. Liss, Inc. pp. 303-333. 
Nelson, B. S. and Stoddard, P. K. 1998. Accuracy of auditory distance and azimuth perception by a passerine bird in natural habitat. Anim. Behav. 56: 467-477.

Olesiuk, P.F., Bigg, M.A., and Ellis, G.M. 1990. Life history and population dynamics of resident killer whales (Orcinus orca) in the coastal waters of British Columbia and Washington State. Rep. Int. Whal. Commn. Special Issue 12: 209-243.

Rendall, D., Owren, M. J., and Rodman, P. S. 1998. The role of vocal tract filtering in identity cueing in rhesus monkey (Macaca mulatta) vocalizations. J. Acoust. Soc. Am. 103: 602-614.

Rendall, D., Rodman, P.S., and Emond, R.E. 1996. Vocal recognition of individuals and kin in free-ranging rhesus monkeys. Anim. Behav. 51: 1007-1015.

Rose, N.A. 1992. The social dynamics of male killer whales (Orcinus orca) in Johnstone Strait, British Columbia. Ph.D. thesis. University of California, Santa Cruz.

Samuels, A. and Gifford, T. 1997. A quantitative assessment of dominance relations among bottlenose dolphins. Mar. Mamm. Sci. 13 (1): 70-99.

Sayigh, L.S. 1992. Development and function of signature whistles of free-ranging bottlenose dolphins, Tursiops truncatus. Ph.D. Disseration, MIT/WHOI Joint Program.

Schevill, W. E. and Watkins, W. A. 1966. Sound structure and directionality in Orcinus (killer whale). Zoologica 51: 71-76.

Smolker, R.A., Mann, J., and Smuts, B.B. 1993. Use of signature whistles during separations and reunions by wild bottlenose dolphin mothers and infants. Behav. Ecol. Sociobiol. 33: 393-402.

Strager, H. 1995. Pod-specific call repertoires and compound calls of killer whales, Orcinus orca Linnaeus, 1758, in the waters of northern Norway. Can. J. Zool. 73: 1037-1047.

Symanski, M. D., Bain, D. E., Kiehl, K., Pennington, W., Wong, S., and Henry, K. R. 1999. Killer whale (Orcinus orca) hearing: auditory brainstem response and behavioral audiograms. J. Acoust. Soc. Am. 106 (2): 1134-1141.

Tyack, P. L. 1985. An optical telemetry device to identify which dolphin produces a sound. J. Acoust. Soc. Am. 78: 1892-1895.

Tyack, P. L. 1986. Population biology, social behavior, and communication in whales and dolphins. Trends Ecol. Evol. 1: 144-150. 
von Frisch, K. 1967. The Dance Language and Orientation of Bees. Cambridge, MA: Harvard University Press.

Waite, J.M. 1988. Alloparental care in killer whale (Orcinus orca). Master's Thesis, University of California, Santa Cruz. 


\section{APPENDIX.}

\section{WHALE SONGS LENGTHEN IN RESPONSE TO SONAR}

Patrick J. O. Miller ${ }^{1}$, Nicoletta Biassoni ${ }^{1}$, Amy Samuels ${ }^{1,2}$, and Peter L. Tyack ${ }^{1}$

${ }^{1}$ Biology Department, Woods Hole Oceanographic Institution, Woods Hole, MA 02543, USA

${ }^{2}$ Daniel F. and Ada L. Rice Conservation Biology and Research Center, Chicago Zoological Society, Brookfield, Illinois, 60513, USA

Nature 405: 903

Reprinted by permission from Nature 405: 903 @ 2000.

MacMillan Magazines Ltd. 


\section{Whale songs lengthen in response to sonar}

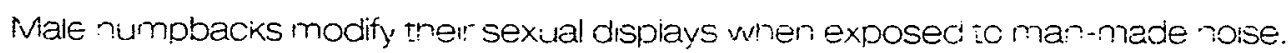

5 There is growing concern about the effects of man-made noise on marine life. In particular, marine mammals that use sound to communicate, navigate, and detect predators and prey may try to avoid loud sound sources up to tens of kilometres away'. Here, in a study conducted in cooperation with the US Navy', we show that the singing behaviour of male humpback whales was altered when they were exposed to LFA (low-frequency active) sonar. As the song of these whales is associated with reproduction ${ }^{3}$, widespread alteration of their singing behaviour might affect demographic parämeters, or it could represent a strategy to compensate for interference from the sonar.

During the breeding season male humpback whales sing long, complex songs that are thought to be sexual displays ${ }^{3}$. Songs consist of a series of themes, progressing in

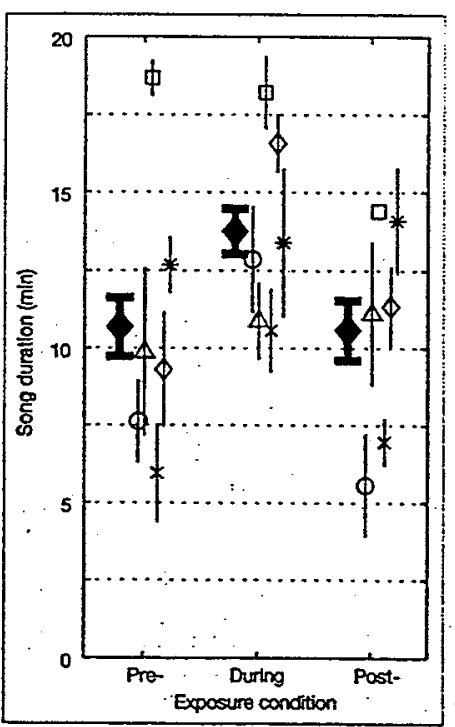

Figure $i$ biration of songs ( \pm se.n. produced by humplecks betore, ouring and after exposure to IFA sonar iansmissions

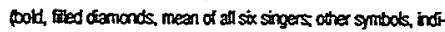
vitual singers. The macinum receives level of the sonar at the whale ranged trom 130 v 150 ob re 1 pPa Songs were grouped Ii the exposure conction $f$ a soner tansmission ocoumed at aty point during the song. The average number of songs per singer in the preeposure, expesure and postexposure conditions wes 32. 4.7 and 3.8, respectively. Dafierencos were assessed using a mixes-moded anaysis of varance treating eposure confition as a fwed tator, whate bentity as a random facor, and each song - duration as an indeperident obsenation. The effect of exposure conction on song duration was statistically stgiticant at $P=0.047\left(F_{2 x}=4.200\right.$, power $=0.50, n=0$ a predictable order, that may repeat for several hours". We used a small observation vessel to find singing humpbacks and conduct focal sampling, recording behaviour before, during and after playback. (Strictly speaking, we have evaluated the additional impact that LFA sounds have on a singing whale that is already being followed.)

We recorded the vocal behaviour of each focal singer continuously for sevetal hours using a towed, calibrated hydrophone arrays. When the whale was at the surface, observers sampled visible behaviour. Photographs of fluke and dorsal fin features confirmed the whale's identity throughout each follow. At least two songs were recorded before the observation vessel requested the US Navy RN Cory Chouest to transmit ten (in one case four) 42-s LFA signals at 6-min intervals. The sonar was broadcast at less than full strength, and no focal singer was exposed to a signal louder than $150 \mathrm{~dB}$ (with respect to $1 \mu \mathrm{Pa}$ ).

Sixteen singers were followed during 18 playbacks. In nine follows, the whale sang continuously throughout the playback; in four the singer stopped when he joined other whales (typical of normal social interaction); and in five the singer stopped, presumably in response to the playback. We recorded at least one complete song in all conditions from six individuals, and pooled the songs of each of the two individuals that were subjects in two experiments. For these six whales, we measured the duration and theme structure of song spectrograms, comparing song duration in the three conditions using analysis of variance ${ }^{8}$.

On average, humpback whales' songs were $29 \%$ longer during LFA playbacks

\section{Nutrition \\ Antioxidant activity of fresh apples}

V itamin $C$ is used as a dietary supplement because of its antioxidant activity, although a high dose $(500 \mathrm{mg})$ may act as a pro-oxidant in the body ${ }^{12}$. Here we show that $100 \mathrm{~g}$ of fresh apples has an antioxidant activity equivalent to $1,500 \mathrm{mg}$ of vitamin $C$, and that whole-apple extracts inhibit the growth of colon- and livercancer cells in vitro in a dose-dependent manner. Our results indicate that natural antioxidants from fresh fruit could be more effective than a dietary supplement.

Apples of the Red Delicious variety were
(Fig. 1) - a particularly strong result, given the low power of the test and small sample size?. Song duration returned to normal after exposure, suggesting that this response has a limited duration. There was little difference in the likelihood of an aberrant theme transition across exposure conditions $\left(\chi^{2}=3.273, P=0.195\right)$, indicating that long songs resulted from longer themes within a normal song structure. Across the six singers, maximum received level of the sonar at the whale did not correlate positively with either the increase in mean song duration from pre-exposure to exposure condition $(r=-0.90)$ or with the subsequent decrease from exposure to post-exposure condition $(r=-0.63$ )

We suggest that humpbacks sang longer songs during IFA sonar transmissions to compensate for acoustic interference. Our study shows that it is possible to measure the behavioural responses of individual whales in controlled experiments at sea. Patrick J. O. Miller ${ }^{*}$, Nicoletta Biassoni*, Amy Samuels*t, Peter L Tyack*

- Biology Department, Woods Hole Oceanographic Institution, Woads Hole, Massachusers 02543, USA tDariel F. and Ada L Rice Conservation Biology and Research Center, Chicago Zoological Society, Brookfield, IIIinois 60513, USA

I. Richandoon, W. L Grene CR It Malmac C. L \& Thomson, D. H. Merine Memmenels and Noise (Nodemic Son Dicga, 1995)

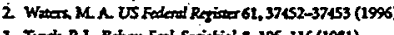
3. That, R I Bdior Eol Sociotial \&, $105-116$ (1981)

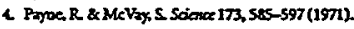

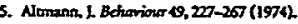
6. Malle R. L \& Tyad, P. L Dequ Ser Rea 1145, 1369-1405 (1958). 7. Ketome S. et al in The Bechevior of Marize Manmmals (eds Wian,

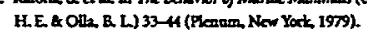

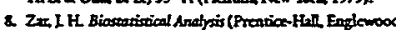
Ciff Nh, 1984)

9. Latumane, E. L Avor Mart Scot 29,1167-1176 (1958).

extracted using $80 \%$ acetone and their content of phenolics and flavonoids determined ${ }^{\mathrm{M}}$ : the extracts contained $290.2 \pm 4.2$ and $219.8 \pm 1.8 \mathrm{mg}$ phenolies, and $142.7 \pm 3.7$ and $97.6 \pm 3.9 \mathrm{mg}$ flavonoids per $100 \mathrm{~g}$ apples with and without skin, respectively. There are known to be more phenolics in the skins of apples than in the flesh, and quercetin glycosides are found only in the skins.

We measured the total antioxidant activity of apples by using the total oxyradicalscavenging capacity (TOSC) assay and found that apples with skin had a higher TOSC value than apples without skin (Fig. 1a). The total antioxidant activity of $1 \mathrm{~g}$ apples with skin was $83.3 \pm 8.9$ TOSC ( $\mu$ mol vitamin C equivalents) - that is, the 


\section{BIOGRAPHICAL NOTE}

The author attended Georgetown University from 1983-1988 earning a B.S. in Foreign Service, and later attended the University of Washington from 1991-1994 earning a B.S. in Zoology with distinction. He entered the MIT/WHOI joint program in Biological Oceanography in June of 1994.

\section{Research experience}

1998-1999: Collected sounds from identified killer whales (Orcinus orca) in Johnstone Strait.

1998: Participated in a study assessing possible effects of the Navy's Low-Frequency Active (LFA) sonar on singing humpback whales off the Kona coast of Hawaii.

1997: Assisted in project off California to assess Navy's LFA on blue and fin whales.

1997: Collected sounds from killer whales in Haro Strait using new array system, conducted Dall's porpoise follow-up study.

1996: WHOI: Conducted the marine mammal monitoring component to the Haro Strait Frontal Dynamics Experiment.

1995: WHOI: Conducted pilot studies of towable beamformer system in Haro Strait. Participated in the Bioacoustics Workshop at the University of Santa Cruz.

1991-1993: University of Washington: Independent study of killer whale dialect development. Advisors: Dr. John K.B. Ford, Vancouver Aquarium and Dr. D.E. Bain, University of Washington.

1992: University of Washington: Assisted field project studying song learning in song sparrows, (Melospiza melodia). Advisor: Dr. Michael Beecher, Chairman Phychology Dept., University of Washington.

\section{Previous work experience}

1989-1991: Assistant Vice-President, Chuo Trust \& Banking, New York Branch. Originated and managed $\$ 350$ million loan portfolio to US companies.

\section{Grants, fellowships, and research permits}

1995-1999: National Marine Fisheries Service (NMFS) General Authorization \#12, permit to observe and record killer whales in US waters.

1998-1999: Canadian Department of Fisheries and Oceans Authorization, permit to observe and record killer whales in Canadian waters.

1999: WHOI's Rinehart Coastal Research Center grant co-PI to describe individual signature information, source levels and directionality of killer whale calls, $\$ 10,000$.

1998: $\quad$ WHOI's Ocean Ventures Fund grant PI to record individual killer whales, $\$ 9,970$.

1997-1998: NMFS permit co-holder to assess effects of US Navy's LFA sonar on whales.

1997: ONR grant co-PI to conduct follow-up study on Dall's porpoise in Haro Strait, $\$ 4,860$. 
1996: NMFS permit holder to conduct marine mammal component to the Haro Strait Frontal Dynamics Experiment.

1996: ONR grant co-PI to conduct the marine mammal monitoring component to the Haro Strait Frontal Dynamics Experiment, $\$ 44,800$.

1995: Coastal Research Center grant PI to build and test towable array, $\$ 3,000.00$.

1994-1997: National Science Foundation Graduate Fellow.

\section{Publications / reports}

2000 Miller, P.J.O., Biassoni, N., Samuels, A., and Tyack, P.L. 2000. Humpback whales sing longer songs when exposed to LFA sonar. Nature 405: 903.

2000: $\quad$ Miller, P.J.O. and Bain, D.E. Within-pod variation in the sound production of a pod of killer whales, Orcinus orca. Animal Behaviour, in press.

2000: Miller, P.J.O. Source levels and estimated active space of the acoustic repertoire of resident killer whales (Orcinus orca). J. Comp. Physiol. A, in prep.

2000: Miller, P.J.O. Direction-of-travel cueing via differential directionality in broadband calls produced by free-ranging killer whales, Orcinus orca, Science, in prep.

1999: Miller, P.J.O. and Tyack, P.L. Source levels of killer whale sounds measured with two beamforming arrays towed in series. Abstracts of the $13^{\text {th }}$ Biennial Conference of the Society for Marine Mammalogy, Wailea, HI, pg. 126.

1998: $\quad$ Miller, P.J. and Tyack, P.L. 1998. A small towed beamforming array to identify vocalizing resident killer whales (Orcinus orca) concurrent with focal behavioral observations. Deep-Sea Research II, 45: 1389-1405.

1998: Miller, P.J. and Tyack, P.L. A small towed beamforming array to identify vocalizing resident killer whales (Orcinus orca) concurrent with focal behavioral observations. Abstracts of the 12th Biennial Conference of the Society for Marine Mammology, Monaco, pg. 92.

1998: Miller, P.J. and Willis, P.M. Should I stay or should I go now?? The biological relevance of avoidance reactions. In: Disturbance Effects Workshop Abstracts, 12th Biennial Conference of the Society for Marine Mammalogy.

1997: Miller, P.J., Willis, P.M., and Tyack, P.L. Marine mammals and underwater sound: monitoring the Haro Strait experiment. Abstracts of the $\mathrm{XI}$ annual meeting of the Society for Conservation Biology, Victoria, BC, Canada, pg. 150..

1997: Miller, P. J. and Willis, P.M. Preliminary Report Monitoring the Effects of the Haro Strait Frontal Dynamics Experiment on Marine Mammals Abundance, Distribution, and Behavior. unpub. rep. National Marine Fisheries Service, Silver Spring, MD

1996: Miller, P. J. Request for a Letter of Authorization to Allow Activities that may result in the Incidental Harassment of a Small Number of Marine Mammals, including the Draft Plan for Monitoring and Mitigation. Unpub. Doc. NMFS ID\# 032296A Silver Spring, MD 